\title{
Highly Sterically Encumbered Gold Acyclic Diaminocarbene Complexes: Overriding Electronic Control in Regiodivergent Gold Catalysis
}

Aaron A. Ruch, ${ }^{\dagger}$ Matthew C. Ellison, ${ }^{\dagger}$ John K. Nguyen, ${ }^{\dagger}$ Fanji Kong, ${ }^{\dagger}$ Sachin Handa ${ }^{\dagger}$ Vladimir N. Nesterov, ${ }^{\dagger}$ and LeGrande M. Slaughter*, ${ }^{\dagger}$

'Department of Chemistry, University of North Texas, Denton, Texas 76203, United States

tDepartment of Chemistry, Oklahoma State University, Stillwater, Oklahoma 74078, United States

*legrande@unt.edu

\section{SUPPORTING INFORMATION}

Evidence of multiple conformational isomers

in Au-ADC complexes p. S2

Supplemental Figures $\quad$ p. S9

Detailed Discussion of Out-of-Plane Distortions $\begin{array}{ll}\text { of ADC Ligands } & \text { p. S12 }\end{array}$

Additional Details of Catalytic Studies p. S17

X-ray Crystallographic Data and Procedures p. S21

$\begin{array}{ll}\text { Details of Computational Studies } & \text { p. S36 }\end{array}$

$\begin{array}{ll}\text { References } & \text { P. S44 }\end{array}$

${ }^{1} \mathrm{H}$ and ${ }^{13} \mathrm{C}$ NMR spectra p. S46 


\section{EVIDENCE OF MULTIPLE CONFORMATIONAL ISOMERS IN AU-ADC COMPLEXES}

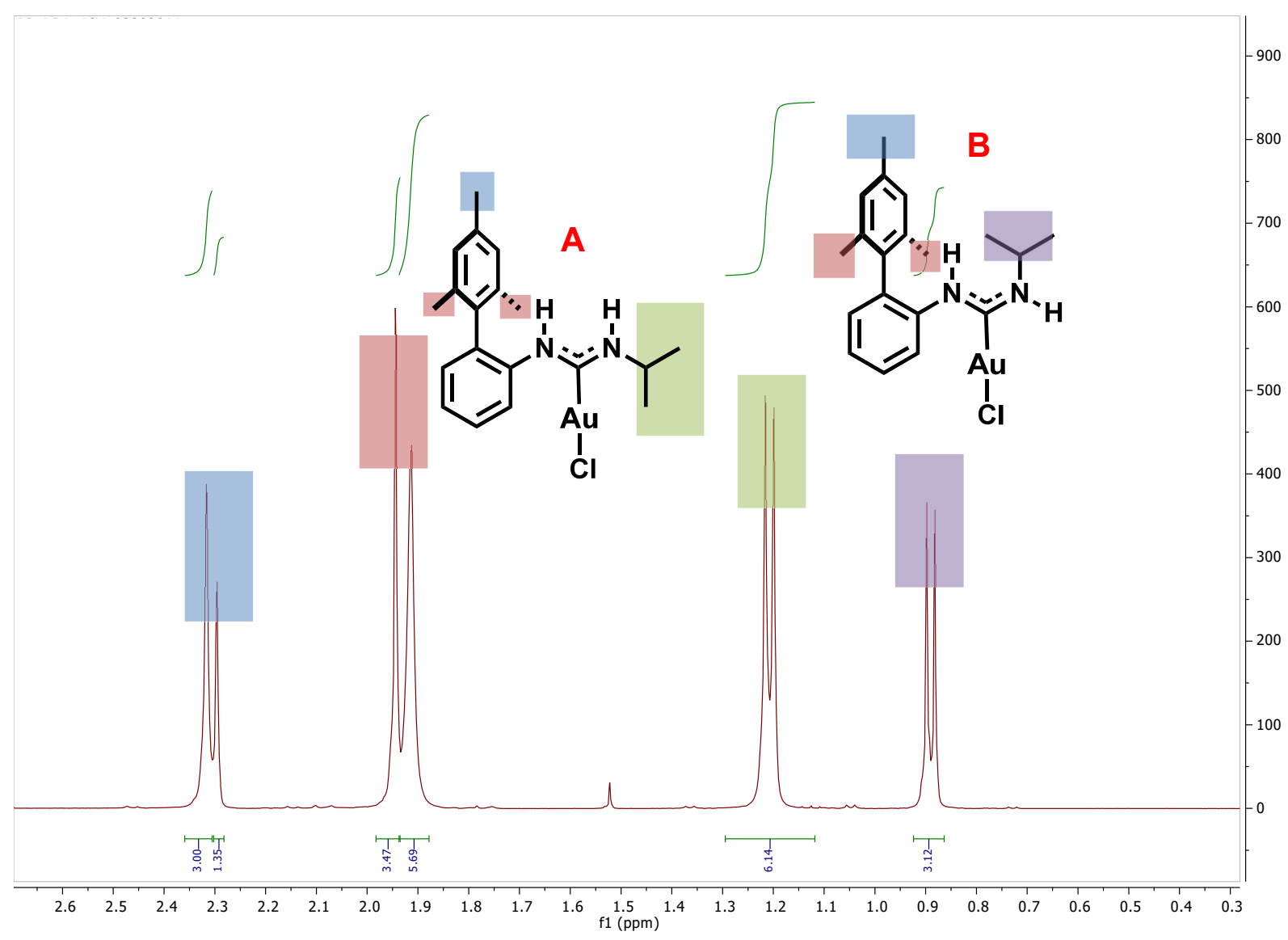

Figure S1. Methyl region of ${ }^{1} \mathrm{H}$ NMR spectrum of 5a in $\mathrm{CD}_{2} \mathrm{Cl}_{2}$, showing separate peaks for conformers $\mathbf{A}$ and $\mathbf{B}$. 

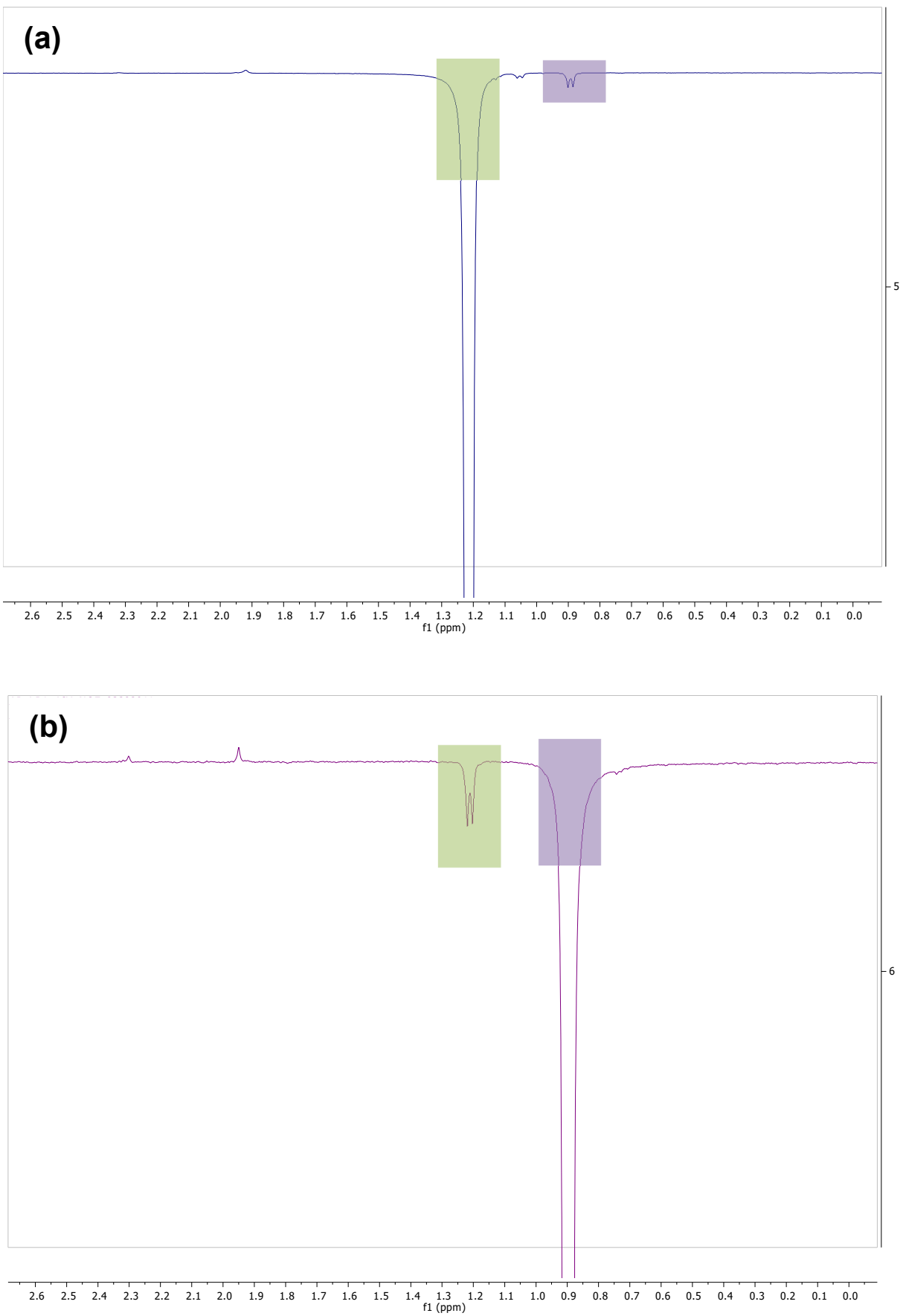

Figure S2. 1D-EXSY ${ }^{1} \mathrm{H}$ NMR experiments with the same sample of 5a, indicating dynamic interconversion of the two conformers. In (a), the $i$ Pr methyl signal for conformer $\mathbf{A}$ at $1.22 \mathrm{ppm}$ was irradiated, and the $1 \mathrm{D}$ gradient $\mathrm{NOE}$ spectrum was acquired $\left({ }^{1} \mathrm{H}, 400 \mathrm{MHz}, \mathrm{CD}_{2} \mathrm{Cl}_{2}\right.$ solvent, acquisition time $2.0 \mathrm{~s}$, mixing time $500 \mathrm{~ms}$ ). In (b), the signal for conformer $\mathbf{B}$ at $0.90 \mathrm{ppm}$ was irradiated. 


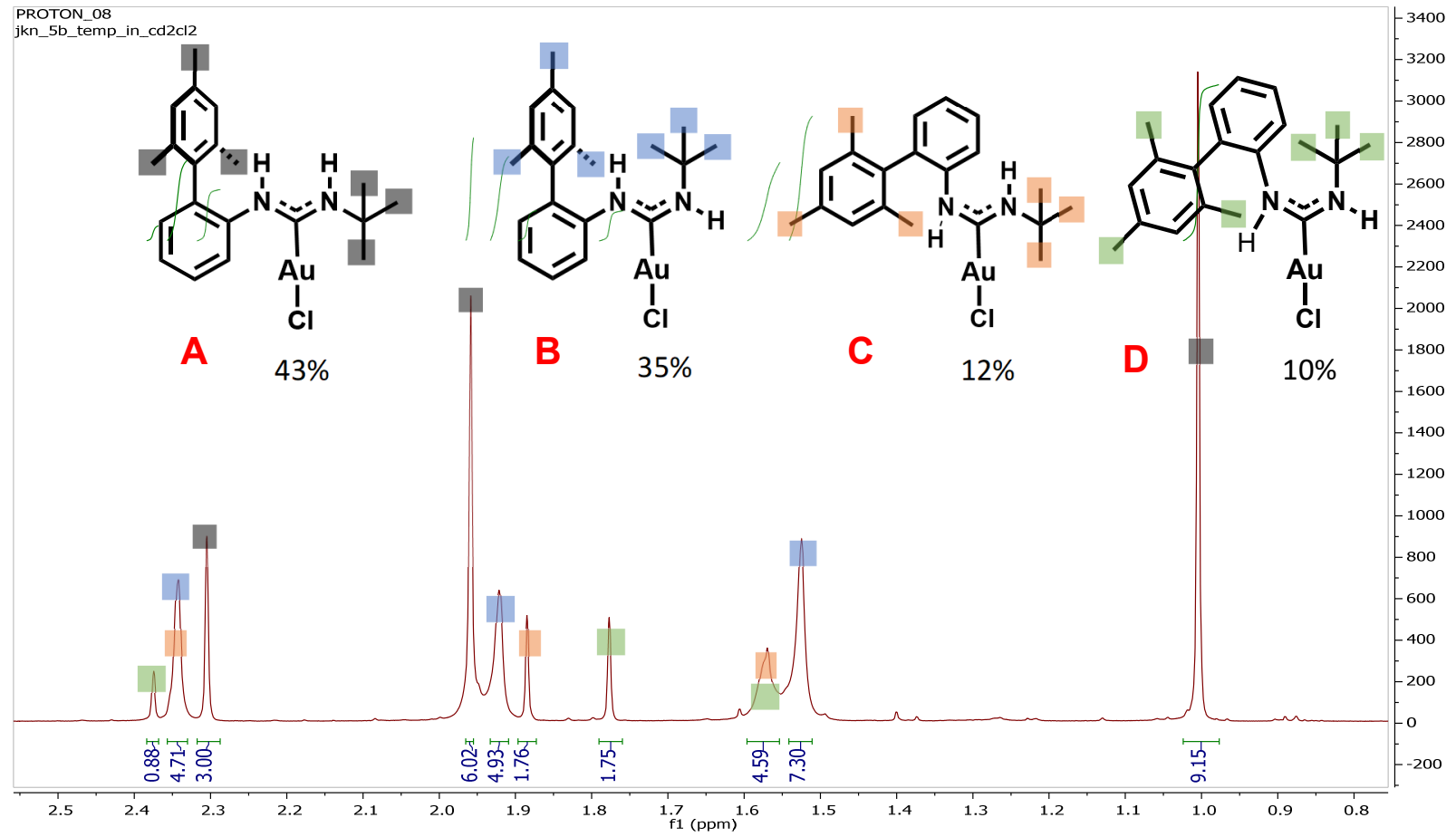

Figure S3. Methyl region of ${ }^{1} \mathrm{H}$ NMR spectrum of $\mathbf{5 b}$ at $-2{ }^{\circ} \mathrm{C}$ in $\mathrm{CD}_{2} \mathrm{Cl}_{2}$, showing peaks for four distinct conformers.

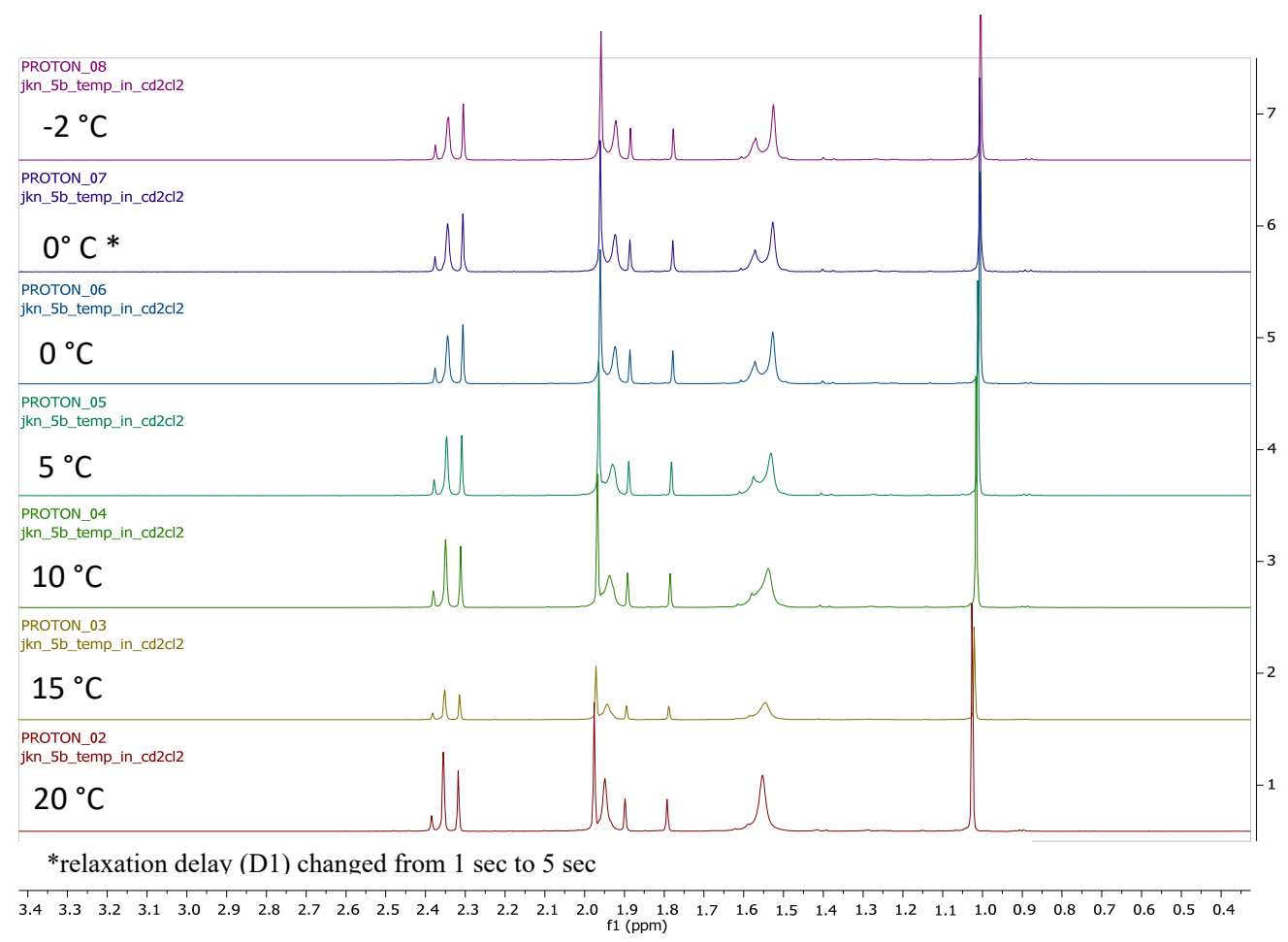

Figure S4. Variable temperature ${ }^{1} \mathrm{H}$ NMR spectra of $\mathbf{5 b}$ in $\mathrm{CD}_{2} \mathrm{Cl}_{2}$, showing decoalescence of the overlapped tert-butyl signals of conformers $\mathbf{C} / \mathbf{D}$ from that of conformer $\mathbf{B}$. 


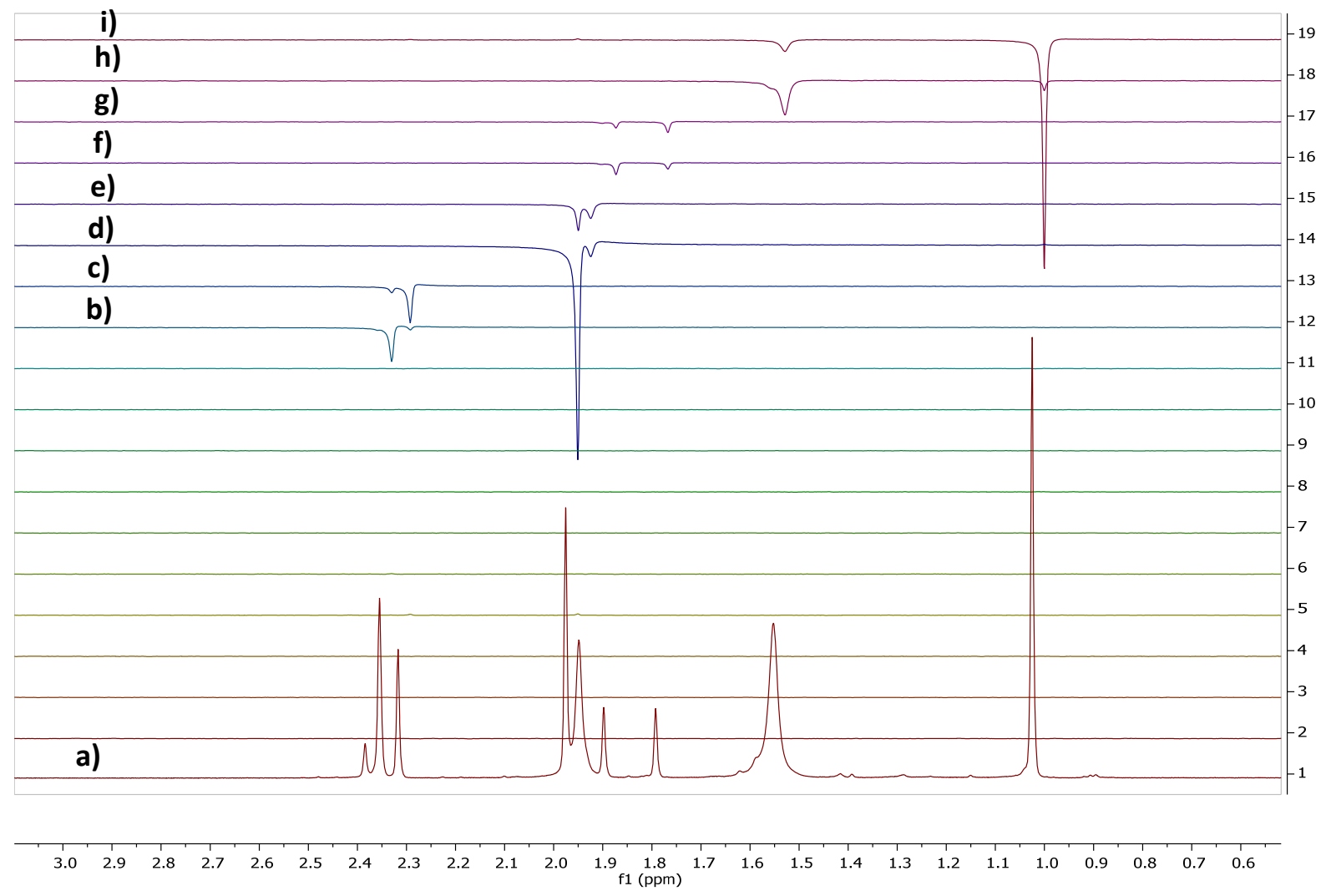

Figure S5. Stacked series of ${ }^{1} \mathrm{H}$ NMR spectra of $\mathbf{5 b}$ including 1D-EXSY experiments supporting dynamic interconversion of the distinct conformers $\left(400 \mathrm{MHz}, \mathrm{CD}_{2} \mathrm{Cl}_{2}\right.$ solvent, 20

${ }^{\circ} \mathrm{C}$, acquisition time $2.0 \mathrm{~s}$, mixing time $500 \mathrm{~ms}$ ). (a) regular 1D NMR spectrum of the methyl/tert-butyl region of $\mathbf{5 b}$. Remaining spectra are 1D gradient NOE (1D EXSY) spectra after selective irradiation of ${ }^{1} \mathrm{H}$ NMR signals at: (b) $2.35 \mathrm{ppm}$ ( $p$-mesityl, conformers $\left.\mathbf{B} \& \mathbf{C}\right)$; (c) 2.32 ppm ( $p$-mesityl, A); (d) 1.98 ppm (o-mesityl, A); (e) 1.95 ppm (o-mesityl, B); (f) 1.90 ppm (o-mesityl, A); (g) 1.78 ppm (o-mesityl, D); (h) 1.55 ppm (tert-butyl, B, C, \& D); (i) 1.01 ppm (tert-butyl, A). 


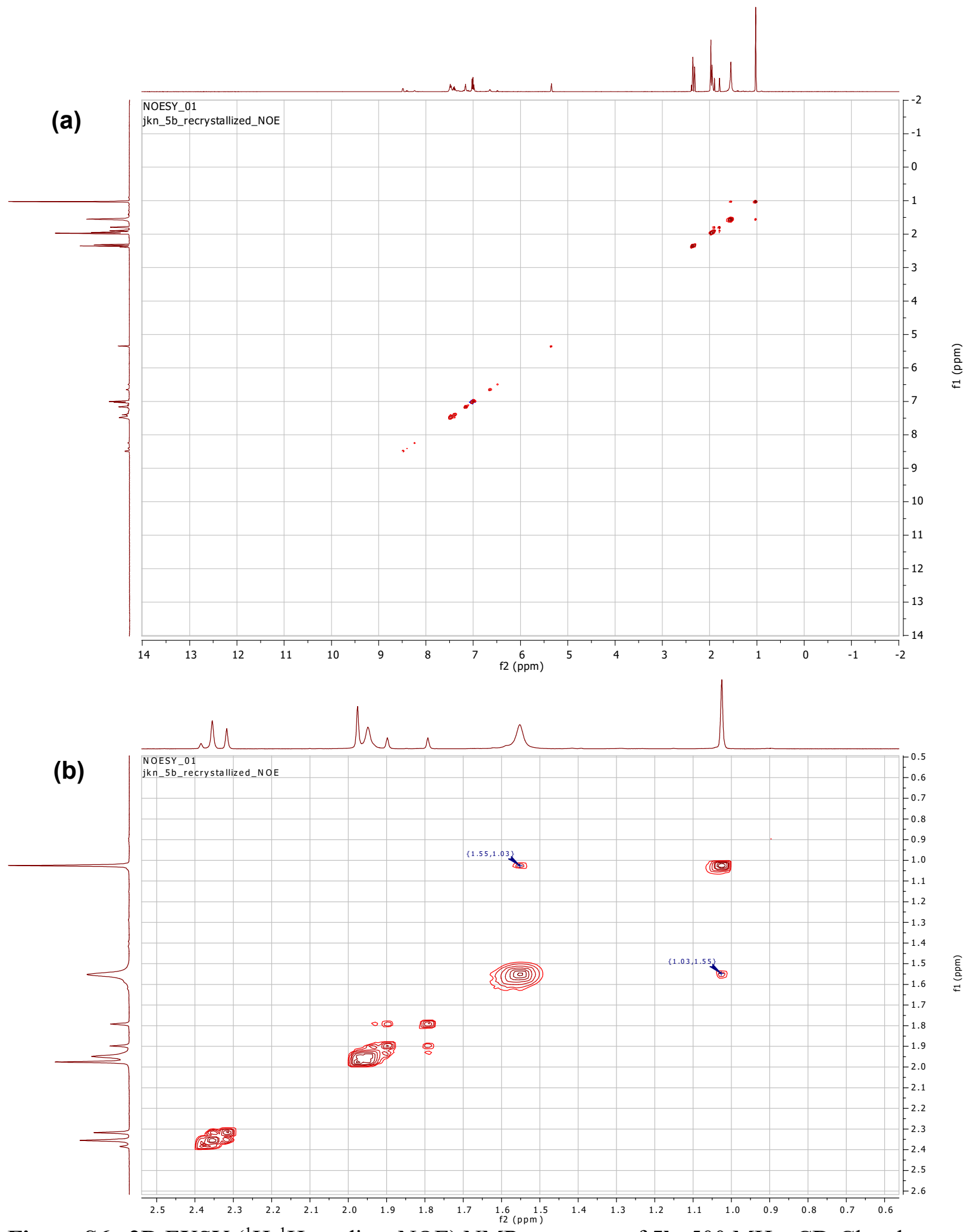

Figure S6. 2D EXSY $\left({ }^{1} \mathrm{H}-{ }^{1} \mathrm{H}\right.$ gradient NOE) NMR spectrum of $\mathbf{5 b} .500 \mathrm{MHz}, \mathrm{CD}_{2} \mathrm{Cl}_{2}$ solvent, $20{ }^{\circ} \mathrm{C}$, acquisition time $0.15 \mathrm{~s}$, mixing time $600 \mathrm{~ms}$. (a) Full spectral window. (b) Methyl and tert-butyl region, with cross-peaks indicating dynamic interconversion of conformers. 
(a)

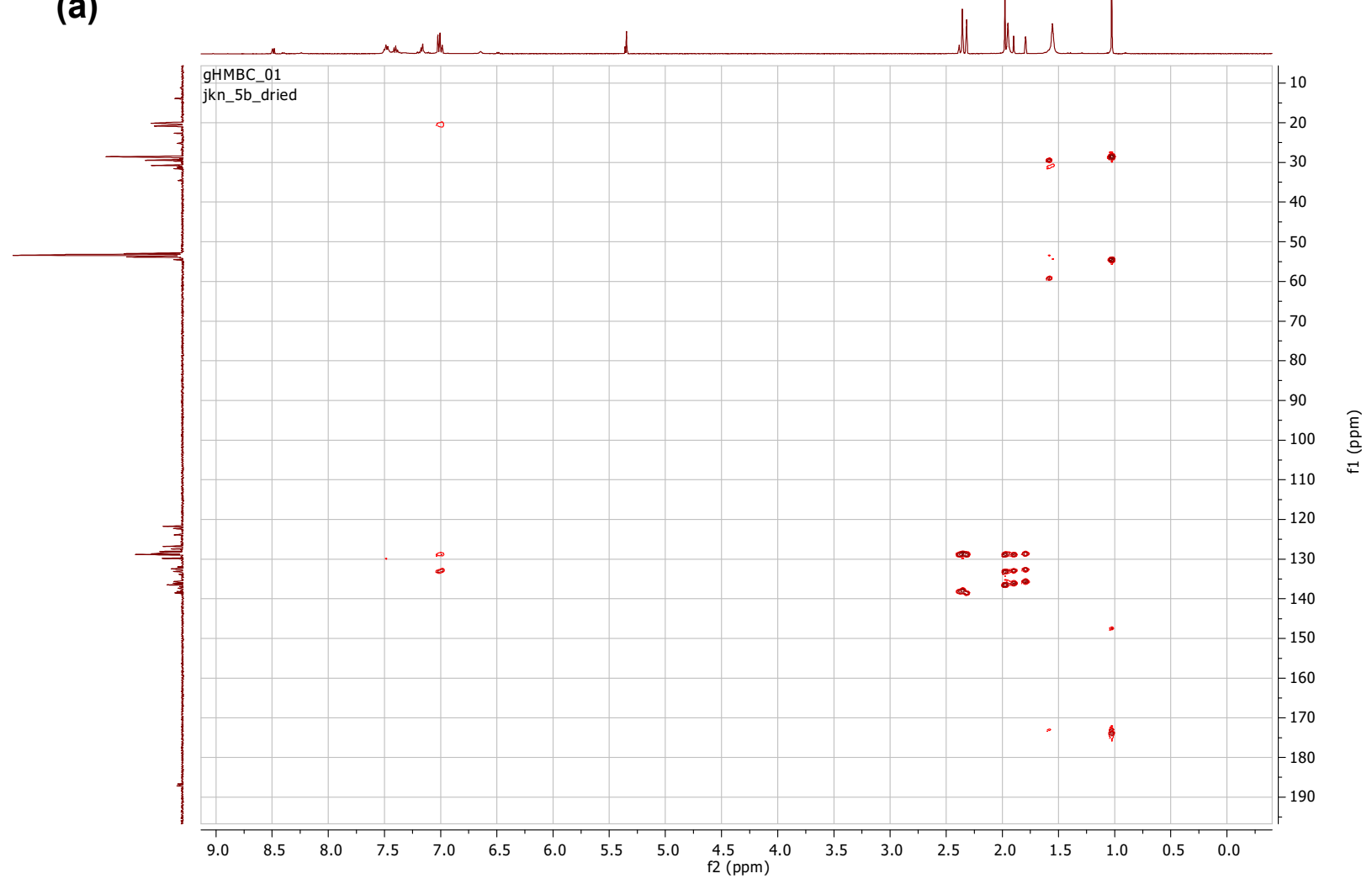

(b)

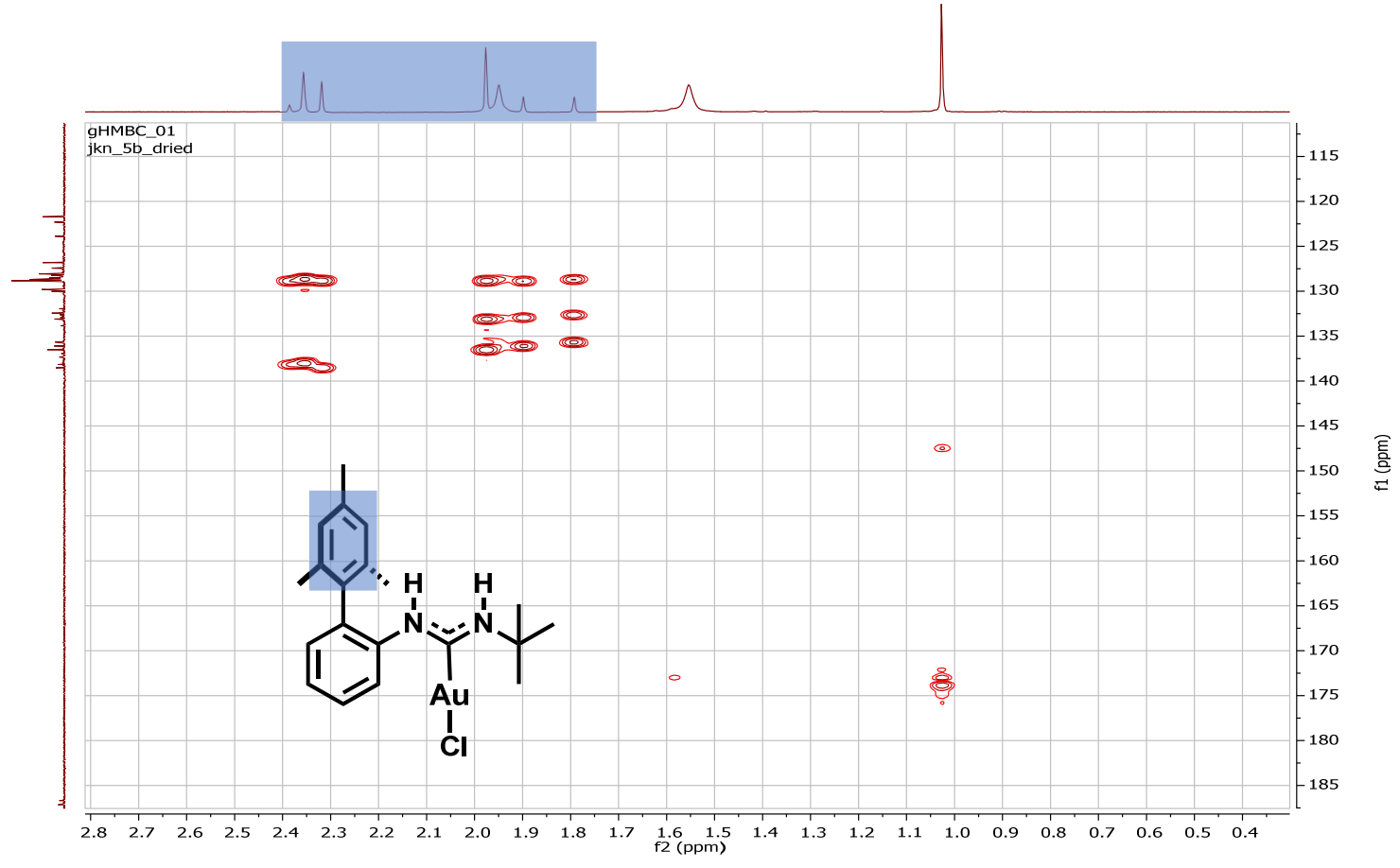




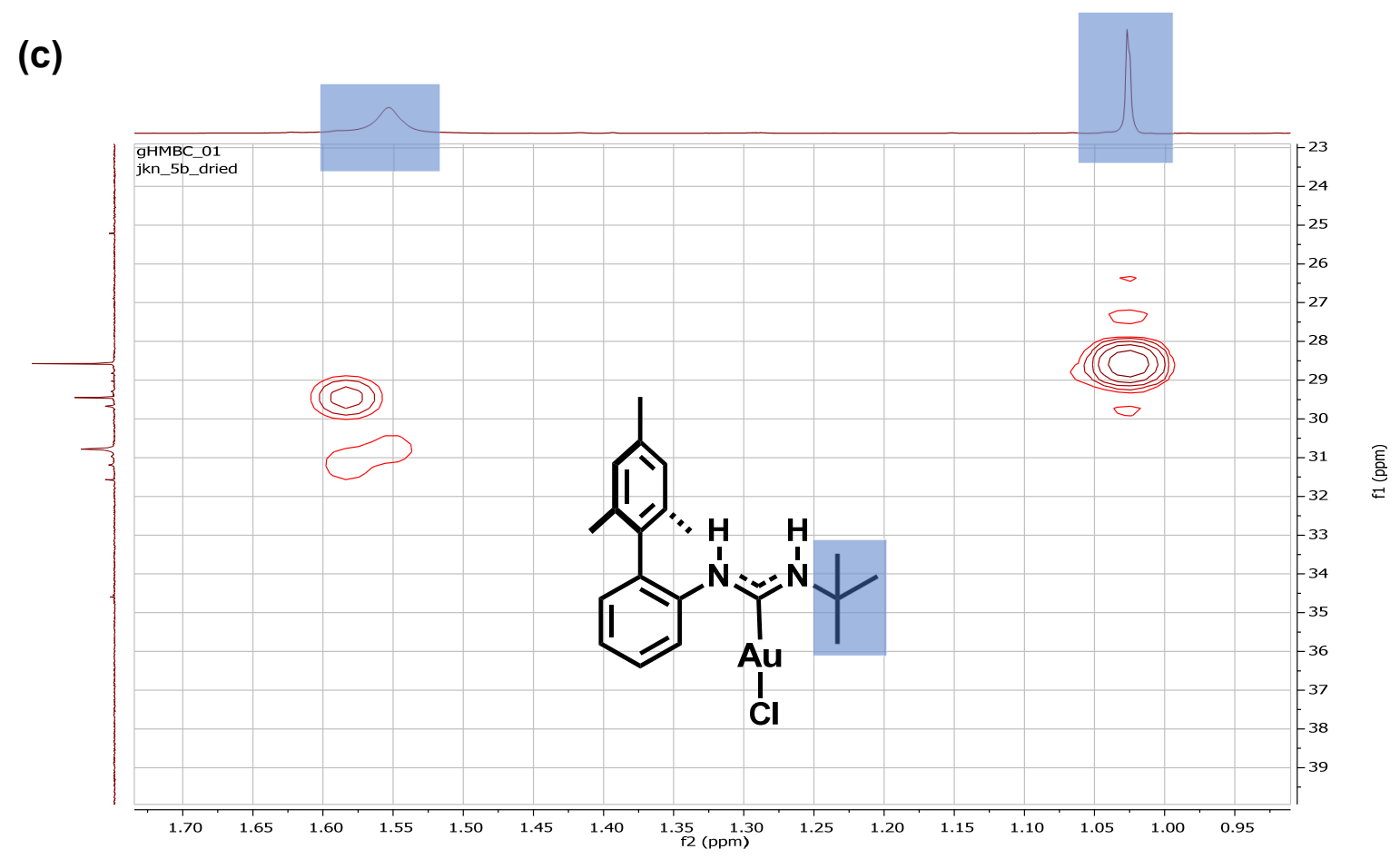

Figure S7. ${ }^{1} \mathrm{H}_{-}{ }^{13} \mathrm{C}$ HMBC (Heteronuclear Multiple Bond Correlation) NMR spectrum of 5b, supporting the existence of four distinct conformers. $500 \mathrm{MHz}\left({ }^{1} \mathrm{H}\right) / 125 \mathrm{MHz}\left({ }^{13} \mathrm{C}\right), 20{ }^{\circ} \mathrm{C}$, $\mathrm{CD}_{2} \mathrm{Cl}_{2}$, acquisition time $0.15 \mathrm{~s}$, relaxation delay $1 \mathrm{~s}$. (a) Full range of observed ${ }^{1} \mathrm{H}$ and ${ }^{13} \mathrm{C}$ chemical shifts. (b) Zoomed spectrum to show correlations between aromatic ${ }^{13} \mathrm{C}$ peaks and mesityl methyl ${ }^{1} \mathrm{H}$ peaks. (c) Zoomed spectrum to show correlations between aliphatic ${ }^{13} \mathrm{C}$ peaks and tert-butyl ${ }^{1} \mathrm{H}$ peaks. 


\section{SUPPLEMENTAL FIGURES}
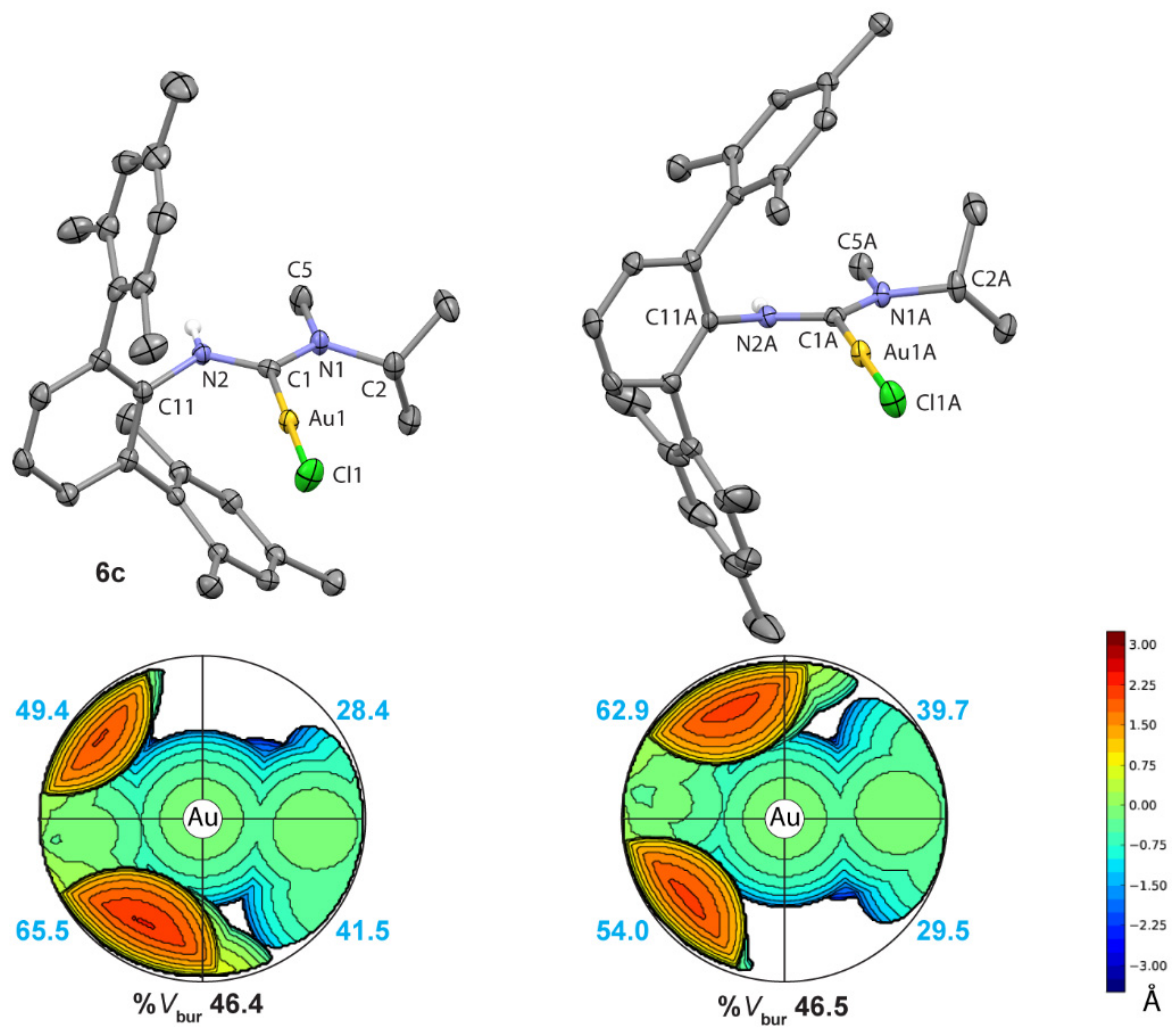

Figure S8. Ellipsoid plots (50\% probability) and steric contour maps of the two crystallographically independent molecules of complex $\mathbf{6 c}$ found in its X-ray crystal structure.

The two complexes are near mirror images in terms of their ligand conformations and steric profiles. Steric maps are drawn with $\mathrm{Au}, \mathrm{Cl}$ and $\mathrm{H}$ atoms removed, and show only the portion of the ligand within the $3.5 \AA$ radius sphere used to calculate $\% V_{\text {bur values. }}$

Table S1. Geometric parameters for the two crystallographically independent molecules of $\mathbf{6 c}$.

\begin{tabular}{|c|c|c|}
\hline & 6c (Au1) & 6c $(\mathrm{Au} 1 \mathrm{~A})$ \\
\hline \multicolumn{3}{|l|}{ Distances $(\AA)$} \\
\hline $\mathrm{Au}-\mathrm{C}_{\text {carbene }}$ & $1.992(3)$ & $1.991(3)$ \\
\hline $\mathrm{Au}-\mathrm{Cl}$ & $2.2822(8)$ & $2.2869(8)$ \\
\hline $\mathrm{C}_{\text {carbene-N1 }}$ & $1.332(4)$ & $1.331(4)$ \\
\hline $\mathrm{C}_{\text {carbene-N2 }}$ & $1.340(4)$ & $1.345(4)$ \\
\hline \multicolumn{3}{|l|}{ Angles $\left({ }^{\circ}\right)$} \\
\hline $\mathrm{N} 1-\mathrm{C} 1-\mathrm{N} 2$ & $117.8(3)$ & $117.1(3)$ \\
\hline $\mathrm{Au}-\mathrm{C} 1-\mathrm{N} 1$ & $123.6(2)$ & $122.9(2)$ \\
\hline $\mathrm{Au}-\mathrm{C} 1-\mathrm{N} 2$ & $118.4(2)$ & $119.9(2)$ \\
\hline yaw angle & $2.6(1)$ & $1.5(1)$ \\
\hline \multicolumn{3}{|l|}{$\begin{array}{l}\text { ADC substituent } \\
\text { torsion angles }\left({ }^{\circ}\right)\end{array}$} \\
\hline $\mathrm{N} 1-\mathrm{C} 1-\mathrm{N} 2-\mathrm{C} 11$ & $165.0(3)$ & $-163.2(3)^{\mathrm{c}}$ \\
\hline N2-C1-N1-C2 & $-169.8(3)$ & $174.2(3)^{\mathrm{c}}$ \\
\hline \multicolumn{3}{|l|}{ Other } \\
\hline $\begin{array}{l}\text { Aryl dihedral from } \\
\text { NCN plane }\left(^{\circ}\right)\end{array}$ & 96.5 & 85 \\
\hline $\begin{array}{l}\text { C11 deviation from } \\
\text { NCN plane }(\AA)\end{array}$ & $0.312(6)$ & $0.348(6)$ \\
\hline
\end{tabular}




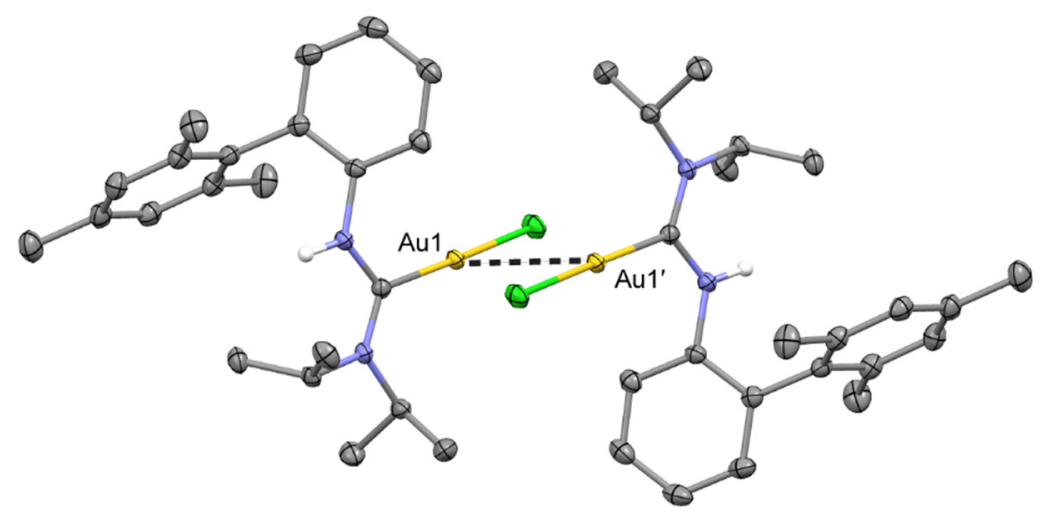

Figure S9. Centrosymmetric aurophilic dimer present in the X-ray structure of complex 5d. The Au1-Au1' distance is $3.59 \AA$. 


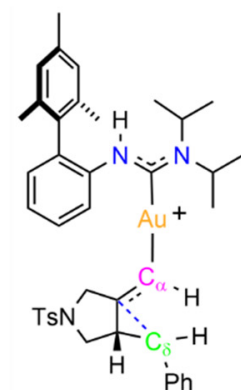

10-5d

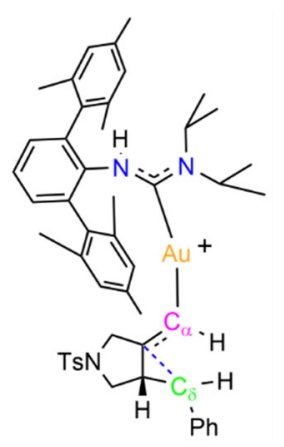

10-6d

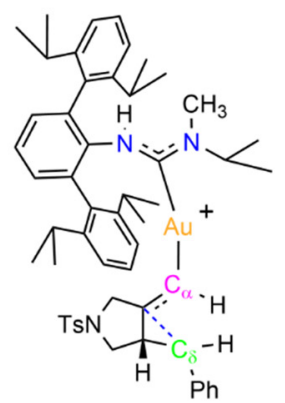

$10-13 c$

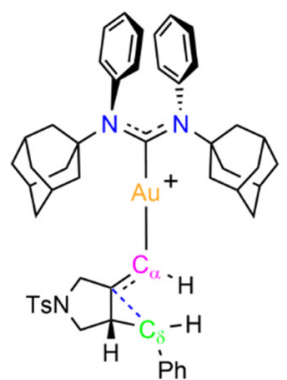

$10-\mathrm{Ad}_{2} \mathrm{Ph}_{2} \mathrm{ADC}$

\section{"Front" view}
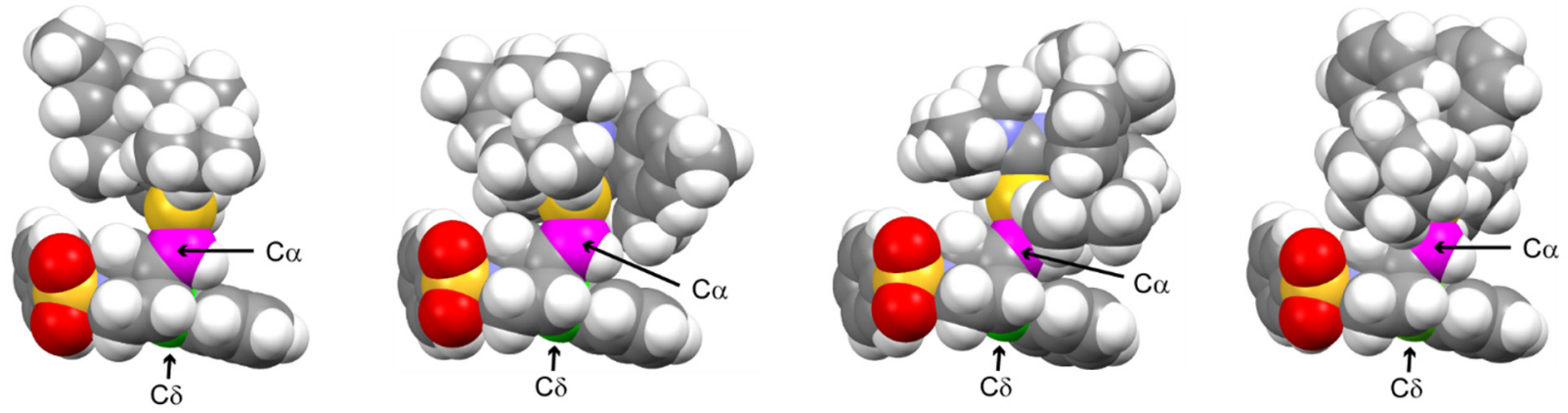

"Back" view
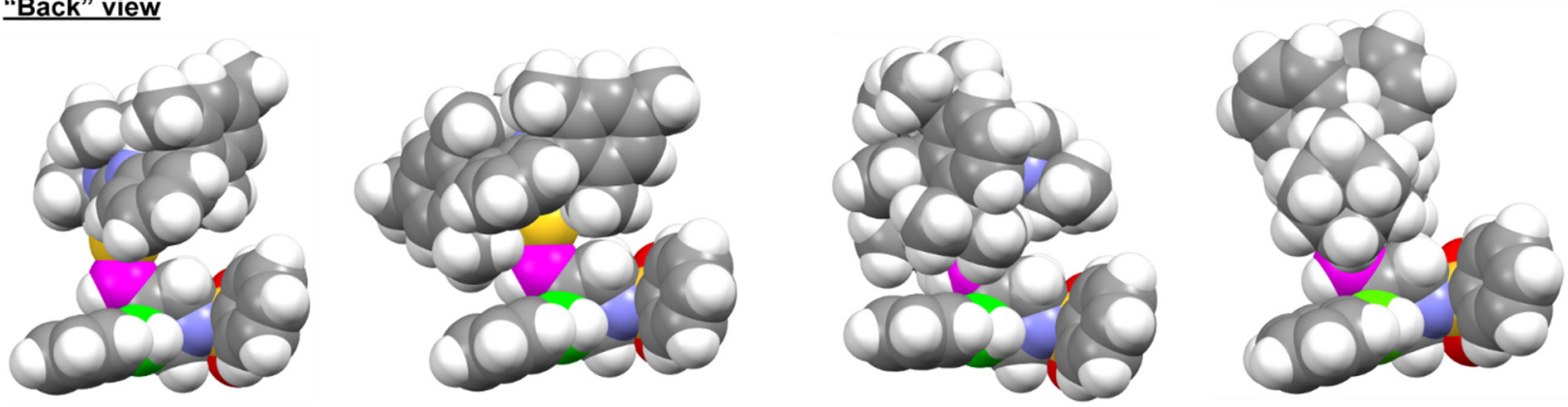

"Bottom" view
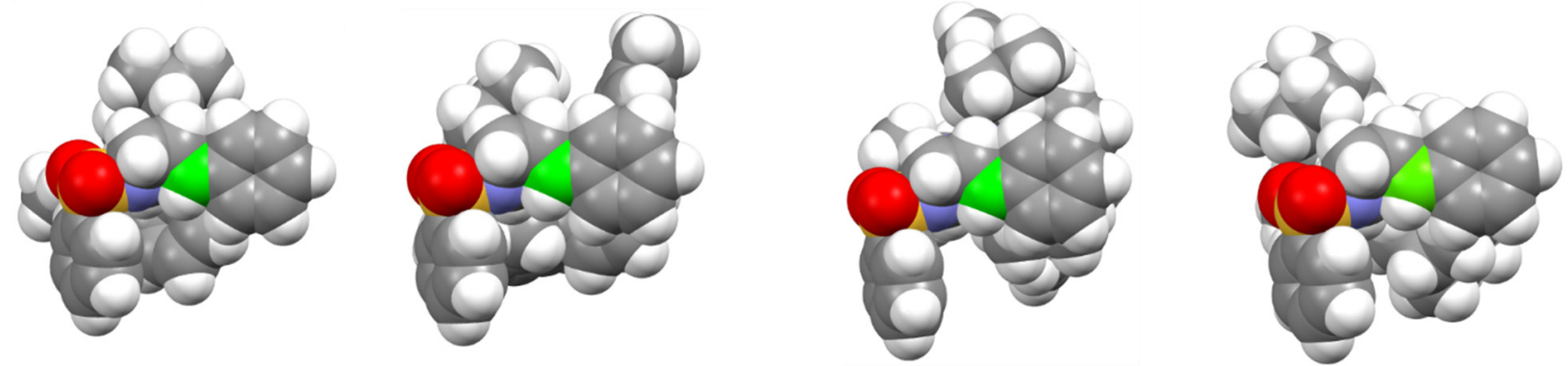

Figure S10. Spacefilling plots of the DFT-optimized geometries of putative intermediate $\mathbf{1 0}$ in the cyclization/hydroarylation of enyne 7 , showing three different orientations of the intermediate for four different sterically encumbered ADC ligands. The tetrasubstituted $\mathrm{Ad}_{2} \mathrm{Ph}_{2} \mathrm{ADC}$ ligand was reported by Hong. ${ }^{1}$ DFT method: BP86/6-31+G* (main group), CEP$31 \mathrm{G}(\mathrm{Au})$. 


\section{DETAILED DISCUSSION OF OUT-OF-PLANE DISTORTIONS OF ADC LIGANDS}

The significant out-of-plane distortions observed in the ADC ligands of complexes $6 \mathbf{b}-\mathbf{d}$ (see "ADC substituent torsion angles", Table 1, main text) may serve to slightly relieve steric crowding of the mesityl $o-\mathrm{CH}_{3}$ groups with the ADC NH groups (avg shortest $\mathrm{CH}^{\cdots} \cdot \mathrm{HN}$ distance $2.44 \AA$ ). This crowding is slightly greater in the less distorted ADC ligand of $6 \mathbf{a}$ (avg shortest $\mathrm{CH} \cdots \mathrm{HN}$ distance $2.26 \AA$ ) and significantly less in the monomesityl analogues $\mathbf{5 c}$ and $\mathbf{5 d}$ (avg shortest $\mathrm{CH} \cdots \mathrm{HN}$ distance $3.29 \AA$ ). However, the ADC ligand distortions also appear to facilitate potentially attractive $\mathrm{CH}^{\cdots} \pi$ interactions ${ }^{2}$ involving $\mathrm{N}$-alkyl groups and one of the two mesityl rings, as illustrated by a $\mathrm{C}-\mathrm{H} \cdots \mathrm{C}_{\text {Ar }}$ contact of $2.86 \AA$ involving the "upper" isopropyl group in the crystal structure of $\mathbf{6} \mathbf{d}$ (Figure 6a, main text, magenta structure). The absence of an isopropyl group in this position in 6a precludes this type of interaction, and no corresponding distortion of the ADC substituents is evident in 6a (Figure 6a, blue structure).

To gain insights into the possible role of attractive noncovalent interactions in the observed ligand distortions, we utilized density functional theory (DFT) to calculate optimized gas-phase geometries of all of the Au-ADC complexes, both with and without Grimme's empirical dispersion correction (D3). ${ }^{3}$ This correction has been shown to improve modeling of noncovalent interactions derived from London dispersion forces. ${ }^{4}$ A benchmarking study showed that the BP86 functional, in combination with the $6-31 \mathrm{G}^{*}$ basis set for main group elements and the CEP-31G pseudopotential basis set for $\mathrm{Au}$, reliably modeled important bond distances and angles within the ADC ligands (see Tables S7-S12). Calculations without the dispersion correction (BP86) produced ADC ligand geometries with very little out-of-plane distortion: the N1-C1-N2-C11 torsion angles are in the range of $173-179^{\circ}$, and no significant differences in these angles are apparent between the monomesityl and dimesityl series (Figure S11, black bars). Use of the dispersion-corrected functional (BP86-D3), however, reproduced the distortions observed in the X-ray structures of $6 \mathbf{b}-\mathbf{d}$ reasonably well, with calculated N1-C1N2-C11 torsion angles in the range of $164-167^{\circ}$ (Figure S11, green bars). 


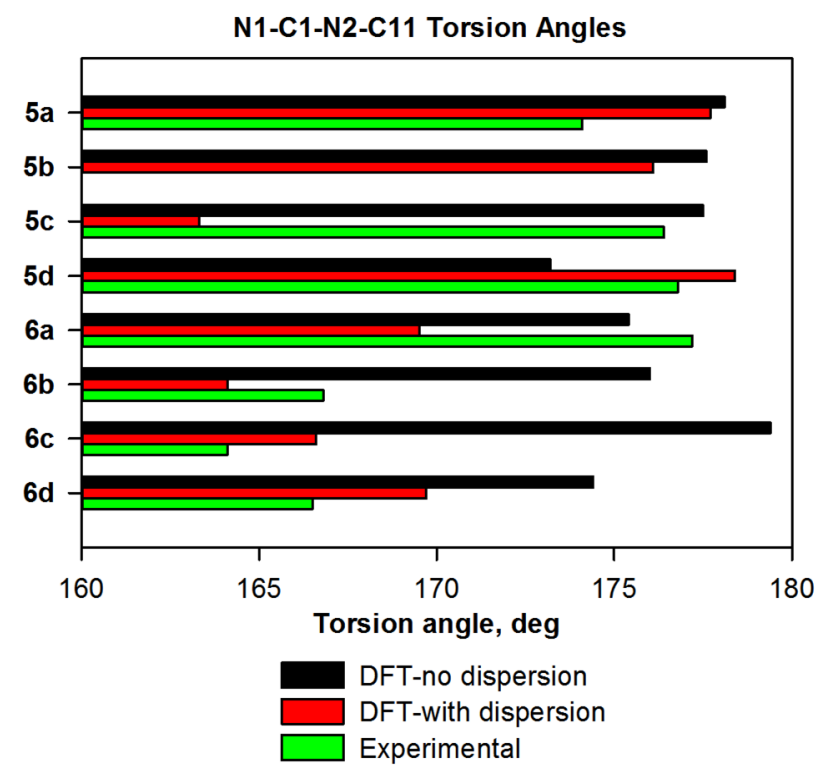

Figure S11. Comparison of experimental (X-ray) and DFT-calculated torsion angles indicating out-of-plane distortion of the biphenyl/terphenyl groups in $\mathrm{Au}(\mathrm{ADC}) \mathrm{Cl}$ complexes.

The BP86-D3-optimized structures of $\mathbf{6 b}-\mathbf{d}$ also exhibit $\mathrm{CH} \cdots \pi$ contacts qualitatively similar to those seen in the X-ray structures (e.g. C-H $\cdots{ }^{C} \mathrm{C}_{\mathrm{Ar}}$ contact of $3.03 \AA$ in $\mathbf{6 d}$ ), although some of them involve different $\mathrm{CH}$ bonds or mesityl carbon atoms (Table S2). In addition, the central aryl rings of the terphenyl are rotated to a significantly larger degree in the BP86-D3optimized structures (C1-N2-C11-C12 torsion angles $\left.117-133^{\circ}\right)$ than in the X-ray geometries (76 $-118^{\circ}$ ). This appears to facilitate noncovalent $\mathrm{Au}^{\cdots} \pi \pi$ interactions (e.g. Au ${ }^{\cdots} \mathrm{C}_{\text {ortho }} 3.21 \AA$ for one mesityl ring of $\mathbf{6 d}$, Table S2) that are not evident in the X-ray structures. Overall, the computational results support the idea that attractive noncovalent interactions contribute to the distortions observed in the dimesityl Au-ADC complexes, while also pointing out the difficulties of modeling such interactions in a large and complex ligand. 
Table S2. Noncovalent interactions involving mesityl aromatic rings in $\mathrm{Au}(\mathrm{ADC})-\mathrm{Cl}$ complexes

\begin{tabular}{|c|c|c|}
\hline Complex & Interaction & Distance $(\AA)$ \\
\hline \multicolumn{3}{|c|}{ X-ray structure } \\
\hline $6 b$ & $t-\mathrm{Bu}-\mathrm{CH}_{2}-\mathrm{H} \cdots$ centroid & 4.30 \\
\hline \multirow[t]{2}{*}{$6 c^{a}$} & $i \operatorname{Pr}-\mathrm{CH}_{2}-\mathrm{H} \cdots \mathrm{C}_{\text {para }}$ & 2.96 \\
\hline & $\mathrm{Me}-\mathrm{CH}_{2}-\mathrm{H} \cdots \mathrm{C}_{\text {ortho }}$ & 3.16 \\
\hline \multirow[t]{2}{*}{ 6d } & $i \mathrm{Pr}-\mathrm{CH}_{2}-\mathrm{H} \cdots \mathrm{C}_{\text {meta }}$ & 2.86 \\
\hline & $i \operatorname{Pr} 2-\mathrm{CH}_{2}-\mathrm{H}^{\cdots} \mathrm{C}_{\text {meta2 }}$ & 3.37 \\
\hline \multicolumn{3}{|c|}{ DFT geometry ${ }^{\mathrm{b}}$} \\
\hline \multirow[t]{2}{*}{$6 b$} & $t-\mathrm{Bu}-\mathrm{CH}_{2}-\mathrm{H} \cdots \mathrm{C}_{\text {meta }}$ & 2.89 \\
\hline & $\mathrm{Au} \cdot \mathrm{C}_{\mathrm{meta}}{ }^{\mathrm{c}}$ & 3.25 \\
\hline \multirow[t]{3}{*}{ 6c } & $\mathrm{Me}-\mathrm{CH}_{2}-\mathrm{H} \cdots \mathrm{C}_{\text {para }}$ & 2.95 \\
\hline & $\mathrm{Me}-\mathrm{CH}_{2}-\mathrm{H} \cdots \mathrm{C}_{\text {meta }}$ & 3.01 \\
\hline & $\mathrm{Au} \cdots \mathrm{C}_{\text {ortho }}{ }^{\mathrm{c}}$ & 3.26 \\
\hline \multirow[t]{2}{*}{ 6d } & $i \operatorname{Pr}-\mathrm{CH}_{2}-\mathrm{H} \cdots \mathrm{C}_{\mathrm{para}}$ & 3.03 \\
\hline & $\mathrm{Au} \cdots \mathrm{C}_{\text {ortho }}{ }^{\mathrm{c}}$ & 3.21 \\
\hline \multicolumn{3}{|c|}{ 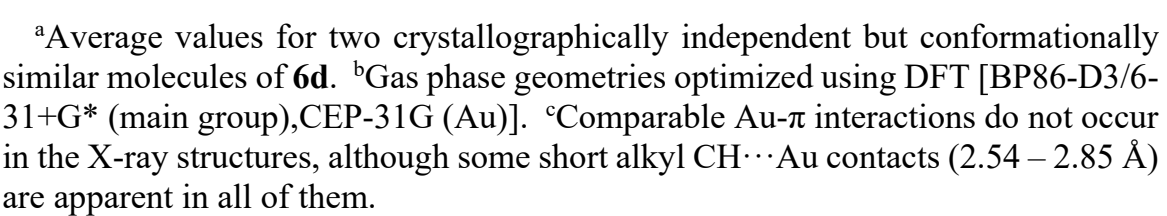 } \\
\hline
\end{tabular}

Yang's method for visualization of noncovalent interactions, ${ }^{5}$ as implemented in the NCIPLOT 3.0 program, ${ }^{6}$ provided further evidence for attractive interactions in the DFToptimized structure of $\mathbf{6 d}$ (Figure S12). Green surfaces represent regions in which the electron density indicates the presence of weak interactions (Figure S12a). ${ }^{5}$ The largest such regions in 6d correspond to the $\mathrm{C}-\mathrm{H} \cdots \pi$ and $\mathrm{Au} \cdots \pi$ interactions discussed above. The attractive nature of these interactions was corroborated using a reported method (Figure S12b). ${ }^{7}$ 
(a)

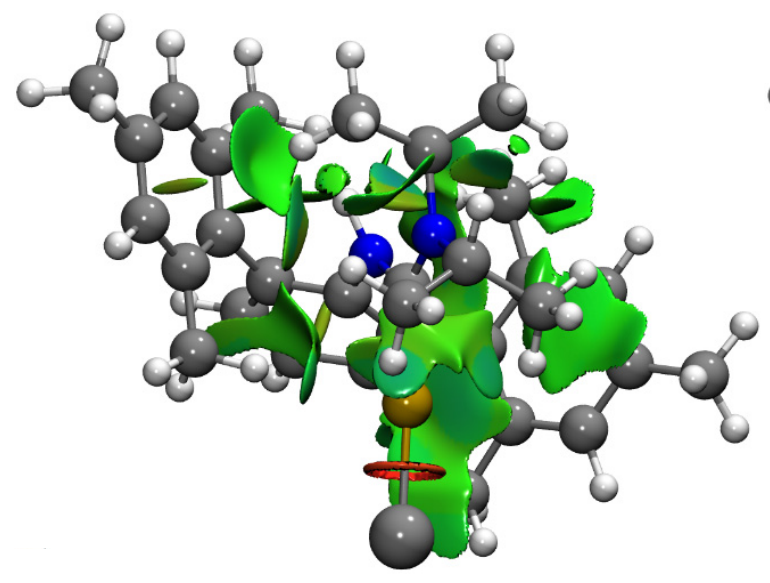

(b)

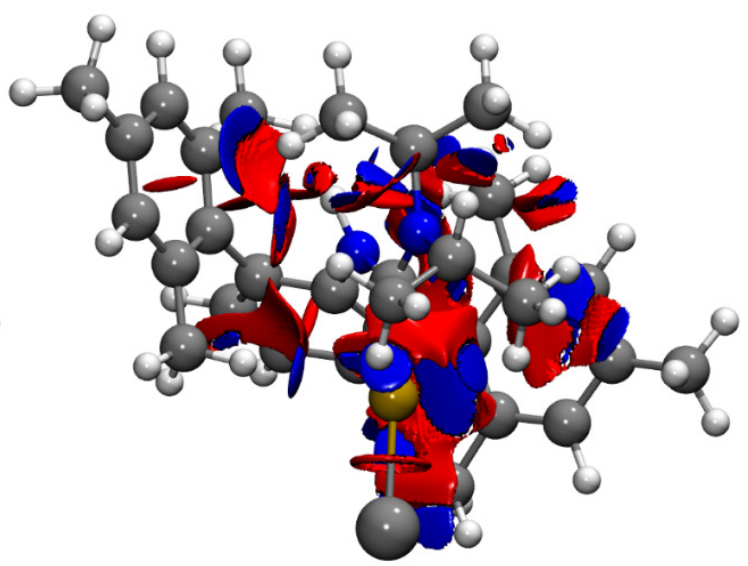

Figure S12. Noncovalent interaction (NCI) plots of the DFT optimized structure of 6d [BP86D3/6-31+G* (main group),CEP-31G (Au)]. (a) Plot generated using NCIPLOT 3.0, ${ }^{6}$ with green surfaces indicating weak noncovalent interactions. (b) Plot generated using NCIPLOT along with a published procedure that differentiates weak attractive (blue) from weak repulsive (red) interactions. $^{7}$

We postulate that some of the discrepancies between the observed and BP86-D3-modeled ligand distortions (e.g. in 6a, Figure S11) may arise from crystal packing interactions, given that the rotation barriers of conjugated amino groups are typically small $\left(\sim \leq 10 \mathrm{kcal} \mathrm{mol}^{-1}\right)$ and thus easily overcome even by weak forces. ${ }^{8}$ Nevertheless, both the solid-state X-ray and gas-phase BP86-D3 structures for $\mathbf{6 b - d}$ suggest a greater propensity for the bulkier dimesityl ADC ligands to undergo torsional deformations, which is also likely to be the case in solution.

The out-of-plane distortions in the dimesityl ADC ligands of $\mathbf{6 b}-\mathbf{d}$ are markedly less than those seen in Hong's sterically demanding tetrasubstituted $\mathrm{ADC}$ ligands, $t-\mathrm{Bu}_{2} \mathrm{Ph}_{2} \mathrm{ADC}$ and $\mathrm{Ad}_{2} \mathrm{Ph}_{2} \mathrm{ADC}$ (Chart 1c), ${ }_{1}^{1}$ despite $\mathbf{6 b}-\mathbf{d}$ having larger $\% V_{\text {bur }}$ parameters (Figure 3, main text). The crystal structures of Hong's $\mathrm{Au}(\mathrm{ADC}) \mathrm{Cl}$ complexes show severe torsional displacements of the two phenyl groups on the "upper" positions the ADCs from the carbene N-C-N planes, with average $\mathrm{N}-\mathrm{C}_{\text {carbene- }} \mathrm{N}-\mathrm{C}_{\mathrm{Ph}}$ torsion angles of $36.0^{\circ}$ for $t-\mathrm{Bu}_{2} \mathrm{Ph}_{2} \mathrm{ADC}$ and $41.0^{\circ}$ for $\mathrm{Ad}_{2} \mathrm{Ph}_{2} \mathrm{ADC}$ (Figure S13). The bulky alkyl groups show more modest degrees of twist similar to those observed for the 2,6-dimesitylphenyl group in $\mathbf{6 b}-\mathbf{d}$, with average $\mathrm{N}-\mathrm{C}_{\text {carbene- }} \mathrm{N}-\mathrm{C}_{\text {alkyl }}$ torsion angles of $165.5^{\circ}$ for $t-\mathrm{Bu}_{2} \mathrm{Ph}_{2} \mathrm{ADC}$ and $163.6^{\circ}$ for $\mathrm{Ad}_{2} \mathrm{Ph}_{2} \mathrm{ADC}$, corresponding to respective deviations of $14.5^{\circ}$ and $16.4^{\circ}$ from the ideal $180^{\circ}$. The pronounced distortions in Hong's ADCs 
appear to result primarily from a need to maximize favorable offset $\pi-\pi$ interactions and minimize repulsive direct $\pi-\pi$ interactions of the adjacent phenyl groups, ${ }^{9}$ as proposed by the authors, although steric interactions of the large $t$ - $\mathrm{Bu}$ and adamantyl groups with the $\mathrm{Au}$ atom may also play a role. ${ }^{1}$ By comparison with these and other sterically encumbered $\mathrm{Au}(\mathrm{ADC}) \mathrm{Cl}$ complexes, ${ }^{10}$ the dimesityl ADC complexes $6 \mathbf{b}-\mathbf{d}$ display a distinctive combination of large $\% V_{\text {bur }}$ and minimal to moderate out-of-plane distortions. We attribute this to a combination of factors: 1) steric bulk that is substantial but somewhat removed from the carbene ligand plane via the terphenyl framework; 2) the presence of no more than one hydrocarbyl substituent in the "upper" position of each ADC ligand, which limits both repulsive and attractive interactions involving these groups; 3 ) the lack of aryl groups on one side of the ADC, which precludes $\pi-\pi$ interactions.
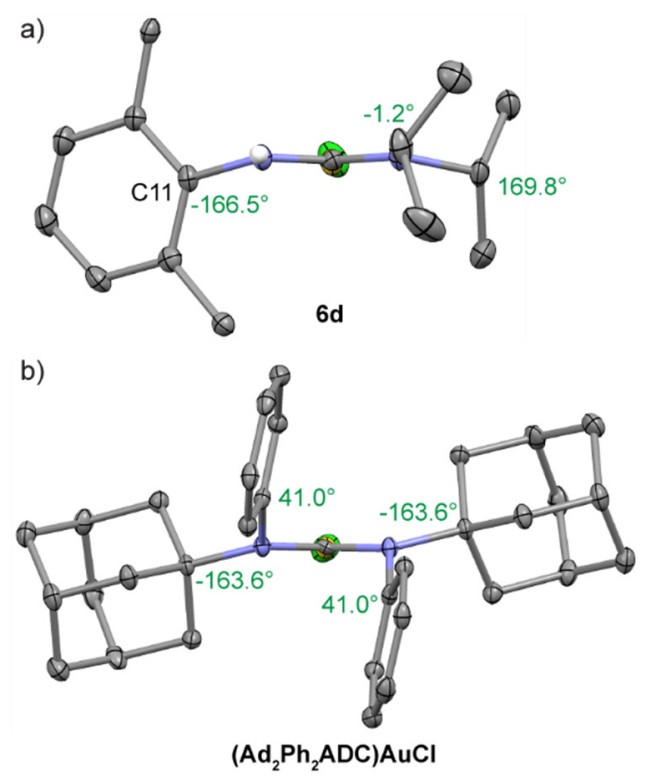

Figure S13. View along the carbene NCN planes for $\mathbf{6 d}$ (only ipso carbons of mesityl rings shown for clarity) and Hong's $\mathrm{Ad}_{2} \mathrm{Ph}_{2} \mathrm{ADC}$ complex, showing out-of-plane distortions of substituents. Numbers in green are torsion angles relative to the $\mathrm{N}_{-} \mathrm{C}_{\text {carbene- }} \mathrm{N}$ unit. 


\section{ADDITIONAL DETAILS OF CATALYTIC STUDIES}

Note on catalyst stability: In 1,6-enyne cyclization/hydroarylation studies conducted with $\mathrm{Au}(\mathrm{ADC}) \mathrm{Cl}$ catalysts with activation by $\mathrm{AgSbF}_{6}$, reaction mixtures eventually exhibited a purplish or bluish tint indicative of the formation of colloidal gold. ${ }^{11}$ This coincided with the end of enyne conversion and product formation as monitored by TLC. For the monomesityl series of catalysts, this catalyst degradation was observed to begin relatively early — within 30 min for 5a, 2-6 hours for 5b-d-suggesting relatively lower stability of these complexes under catalytic conditions. The experiments presented in Table S4 and Figure S14 (below) using monomesityl precatalyst 5d demonstrated that the product ratio (8:9) was nearly identical at low conversions/low reaction times and after $24 \mathrm{~h}$, suggesting that $\mathrm{Au}(\mathrm{ADC}) \mathrm{Cl}$ degradation products are not catalytically active. For the dimesityl catalysts (6a-d) and Dipp2 catalyst 13c, development of this color did not typically begin until after $12 \mathrm{~h}$ of reaction time. Together with the higher yields obtained with these catalysts, this is consistent with increased resistance to degradation in the bulkier $\mathrm{Au}(\mathrm{ADC}) \mathrm{Cl}$ complexes.

Table S3. Solvent effect on yield and regioselectivity in 1,6-enyne cyclization/hydroarylation with $\mathrm{Au}(\mathrm{ADC}) \mathrm{Cl}$ precatalyst 5d.

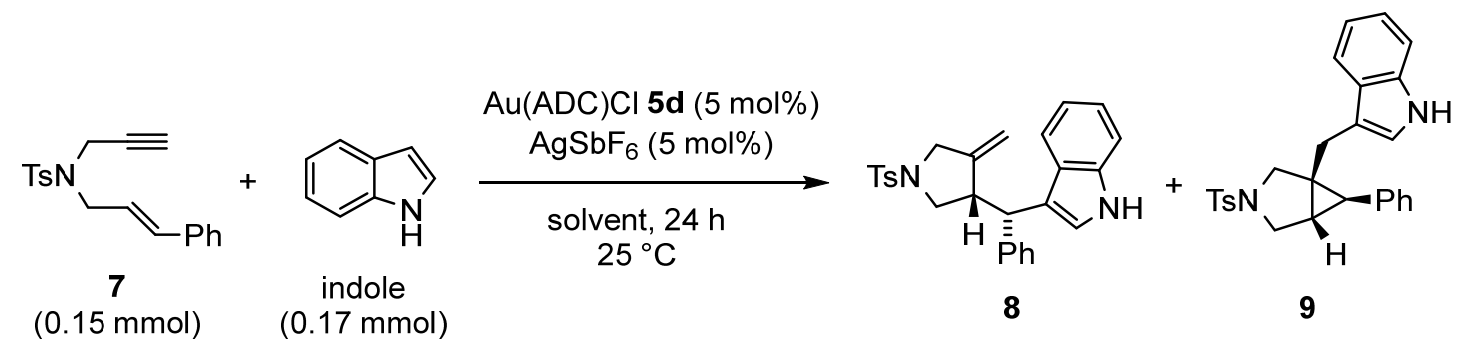

\begin{tabular}{|c|c|c|}
\hline Solvent & Yield $(\%)^{\mathrm{a}}$ & 8:9 Ratio \\
\hline $\mathrm{CH}_{2} \mathrm{Cl}_{2}$ & 9 & $46: 54$ \\
\hline $\mathrm{DCE}$ & 75 & $34: 66$ \\
\hline $\mathrm{CH}_{3} \mathrm{CN}$ & N.D. ${ }^{b}$ & -- \\
\hline THF & 18 & $36: 64$ \\
\hline
\end{tabular}


Table S4. 1,6-Enyne cyclization/hydroarylation product ratio as a function of reaction time and before/after chromatography, with $\mathrm{Au}(\mathrm{ADC}) \mathrm{Cl}$ precatalyst 5d.

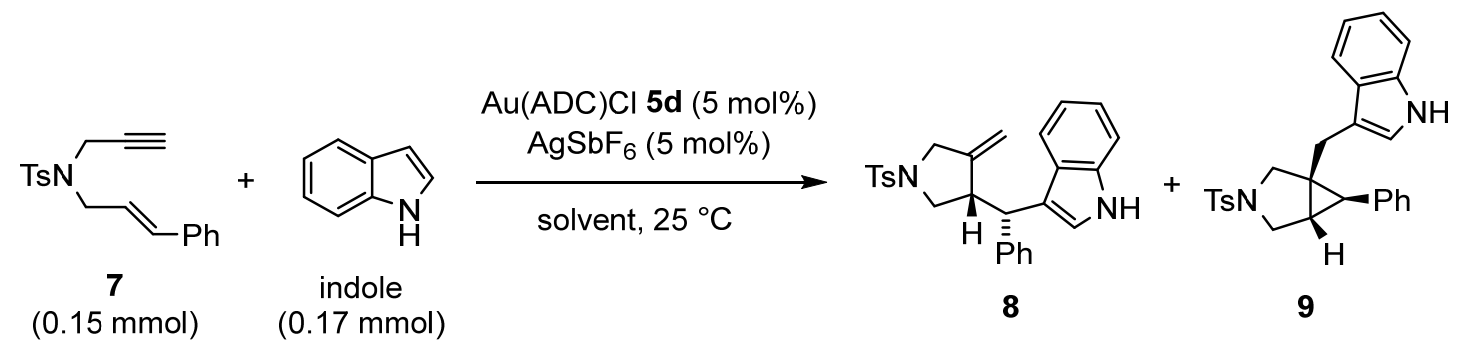

$\begin{array}{lcr}\text { Reaction time } & \text { Yield }(\%) & \mathbf{8 : 9} \text { Ratio } \\ \begin{array}{l}\text { Two parallel reactions in DCE prepared from the same catalyst stock solu } \\ \text { at } 30 \text { min and } 2 \text { h to check product ratio by }{ }^{\mathrm{l}} H\end{array} \text { NMR (see Figure S14, bet } \\ 30 \mathrm{~min} & 16^{\mathrm{a}} & 38: 62^{\mathrm{b}} \\ 2 \mathrm{~h} & 24^{\mathrm{a}} & 36: 64^{\mathrm{b}} \\ 2 \mathrm{~h} & 24^{\mathrm{a}} & 37: 63^{\mathrm{c}}\end{array}$

Sealed $N M R$ tube reaction in $\mathrm{CD}_{2} \mathrm{Cl}_{2}$; product ratio determined noninvasively at each time point; final isolated yield upon chromatography $9 \%$

$10 \min \quad 17^{\mathrm{d}} \quad 44: 56^{\mathrm{b}}$

$40 \mathrm{~min} \quad 18^{\mathrm{d}} \quad 47: 53^{\mathrm{b}}$

$100 \mathrm{~min} \quad 20^{\mathrm{d}} \quad 43: 57^{\mathrm{b}}$

$400 \mathrm{~min} \quad 20^{\mathrm{d}} \quad 46: 54^{\mathrm{b}}$

$6 \mathrm{~h} \quad 20^{\mathrm{d}} \quad 44: 56^{\mathrm{b}}$

$24 \mathrm{~h} \quad 9^{\mathrm{a}} \quad 46: 54^{\mathrm{c}}$

aIsolated yield after silica gel column chromatography. ${ }^{\text {b: }} \mathbf{9}$ ratio determined from crude product mixture. ${ }^{c} \mathbf{8}: 9$ ratio determined from purified product following silica gel chromatography. ${ }^{\mathrm{d}} \mathrm{NMR}$ yield calculated using solvent residual peak as internal standard. 
(a) Enyne cyclization with $\mathbf{5 d}$, crude product after 30 min reaction time

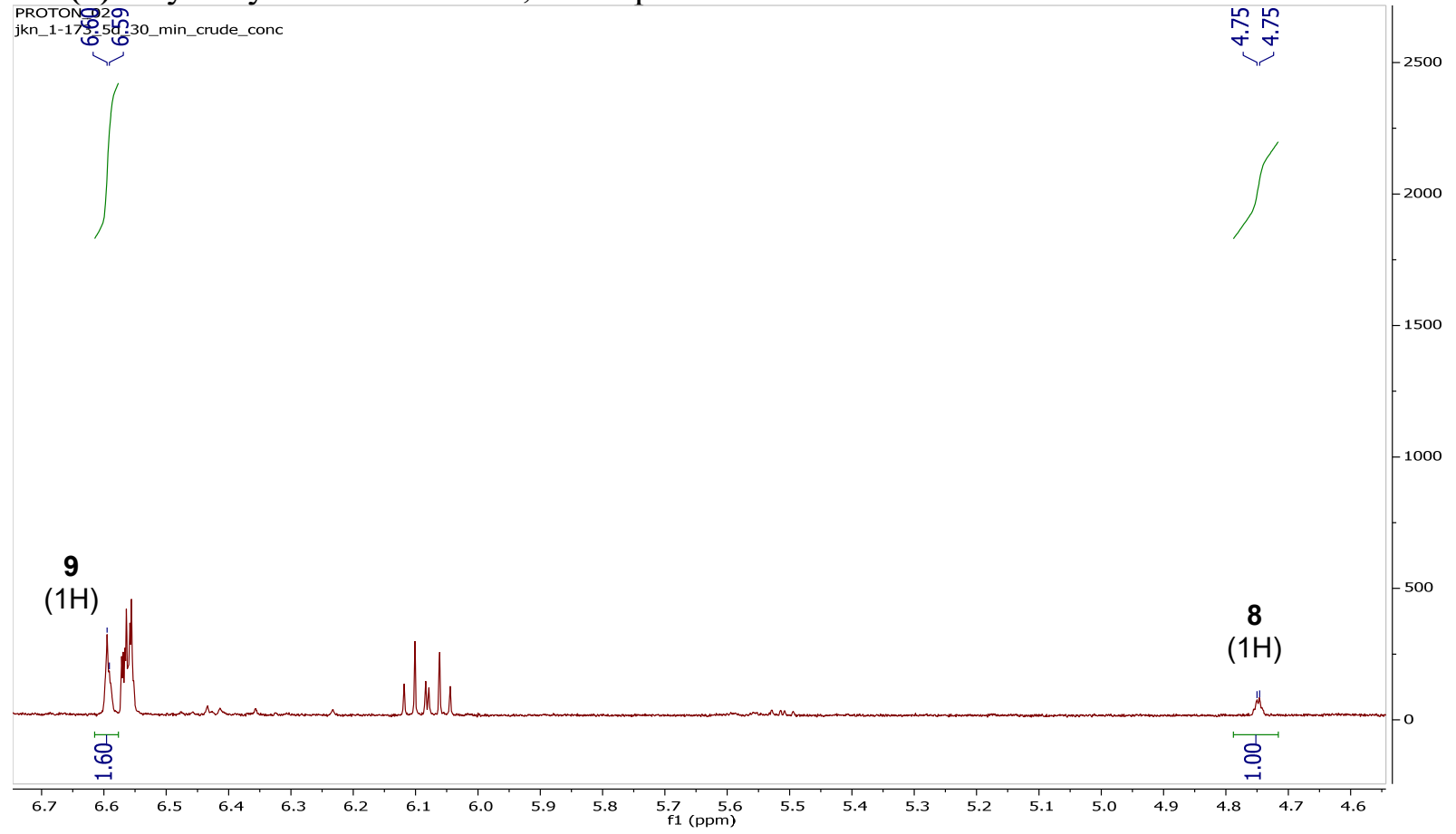

(b) Enyne cyclization with 5d, crude product after $2 \mathrm{~h}$ reaction time PROTON_02
jkn_1-173_5d_2h_crude_conc

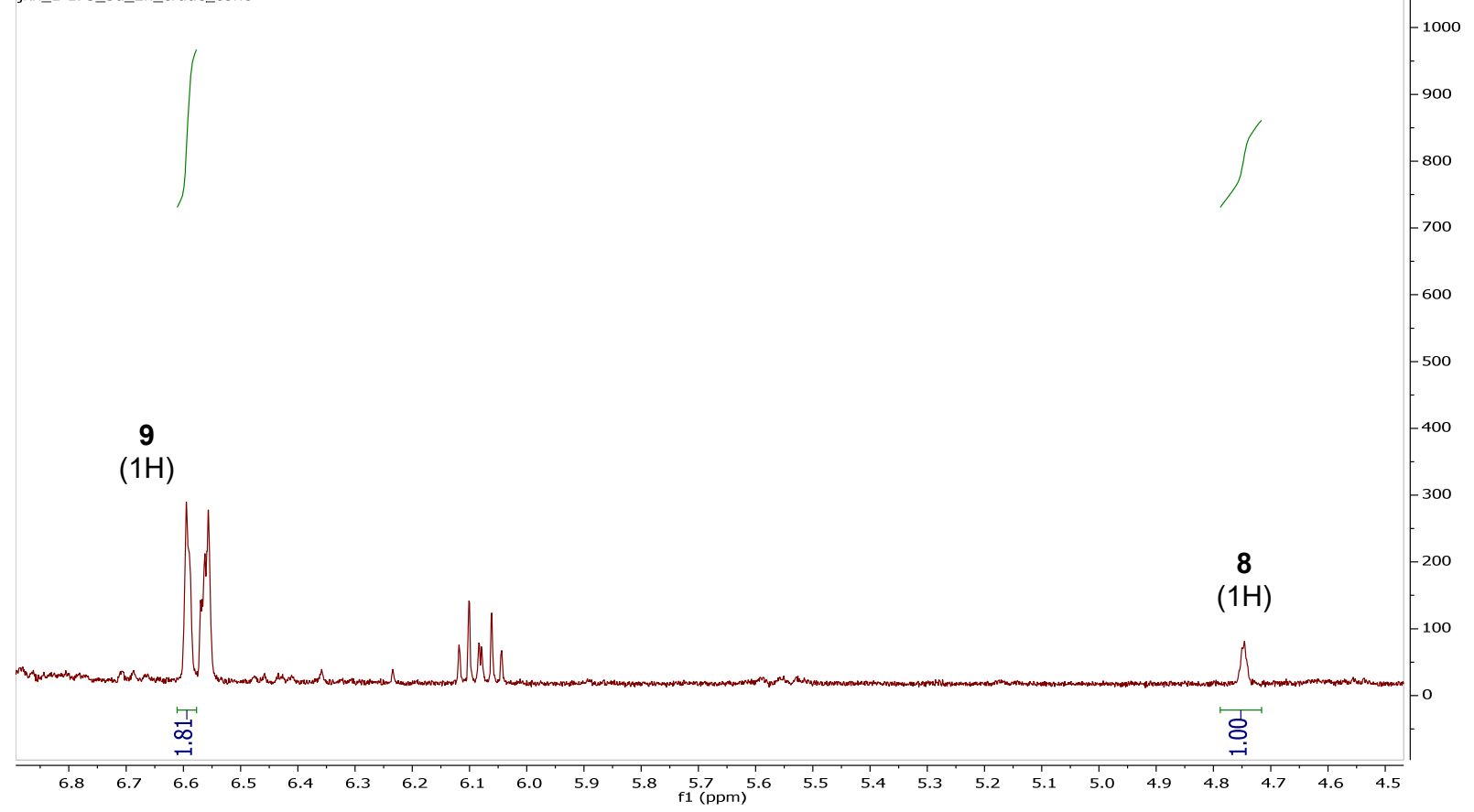


(c) Enyne cyclization with 5d, chromatographed product after $2 \mathrm{~h}$ reaction time

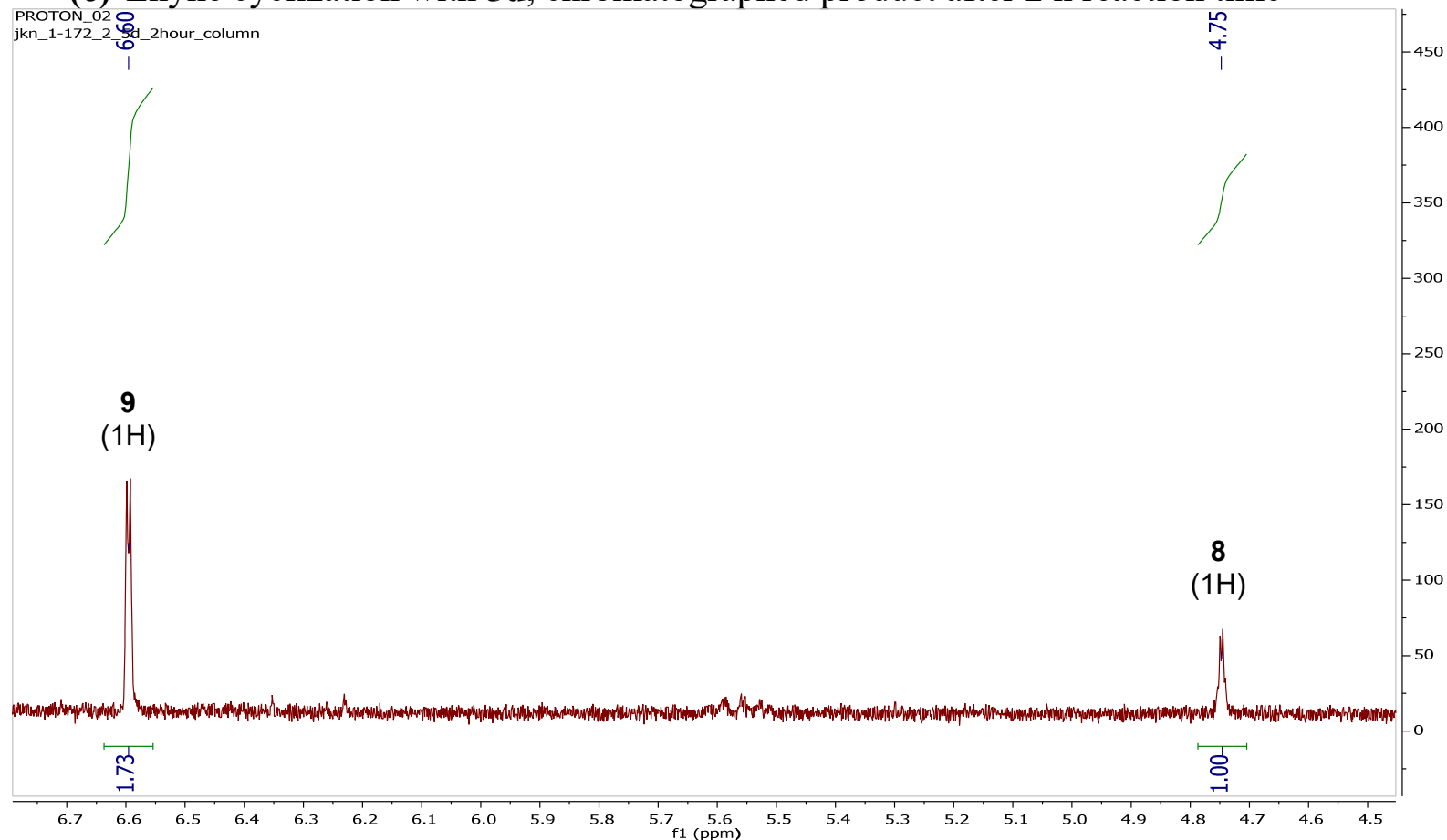

Figure S14. ${ }^{1} \mathrm{H}$ NMR spectra of product mixtures (8/9) from 1,6-enyne cyclization/hydroarylation reactions with indole catalyzed by $\mathrm{Au}(\mathrm{ADC}) \mathrm{Cl}$ complex $\mathbf{5 d}$ in DCE. Although the peak used to quantify 9 is nearly overlapped with a reactant peak in the crude mixtures, the 8:9 product ratios are nearly identical for the crude mixtures for reactions stopped at (a) $30 \mathrm{~min}$ and (b) $2 \mathrm{~h}$, and for (c) the $2 \mathrm{~h}$ reaction mixture after chromatographic purification. 


\section{X-RAY CRYSTALLOGRAPHIC DATA AND PROCEDURES}

General Considerations. For all structurally characterized compounds except for 12, X-ray diffraction data were collected on a Bruker SMART APEX II single crystal diffractometer using graphite-monochromated Mo $k$ - $\alpha$ radiation $(\lambda=0.71073 \AA$, sealed tube $)$ and a combination of $\phi$ and $\omega$ scans. Unit cell determination and data collection utilized the Bruker APEX2 ${ }^{12}$ software package. Data integration employed SAINT. ${ }^{13}$ Multiscan absorption corrections were implemented using SADABS. ${ }^{14}$ Structures were solved by direct methods and refined by fullmatrix least-squares on $F^{2}$ using the SHELXTL software suite ${ }^{15}$ incorporating SHELXL2013. $^{16}$ Non-hydrogen atoms were assigned anisotropic temperature factors, and carbon-bound hydrogen atoms were included in calculated positions (riding model) with isotropic $U$ fixed at 1.5 times the $U_{\text {eq }}$ of the attached atom for $-\mathrm{CH}_{3}$ groups and 1.2 times the $U_{\text {eq }}$ of the attached carbon for other hydrogen atoms. CCDC 1945190-1945201 contain the supplementary crystallographic data for this paper. These data can be obtained free of charge from The Cambridge Crystallographic Data Center via https://www.ccdc.cam.ac.uk/structures/. 

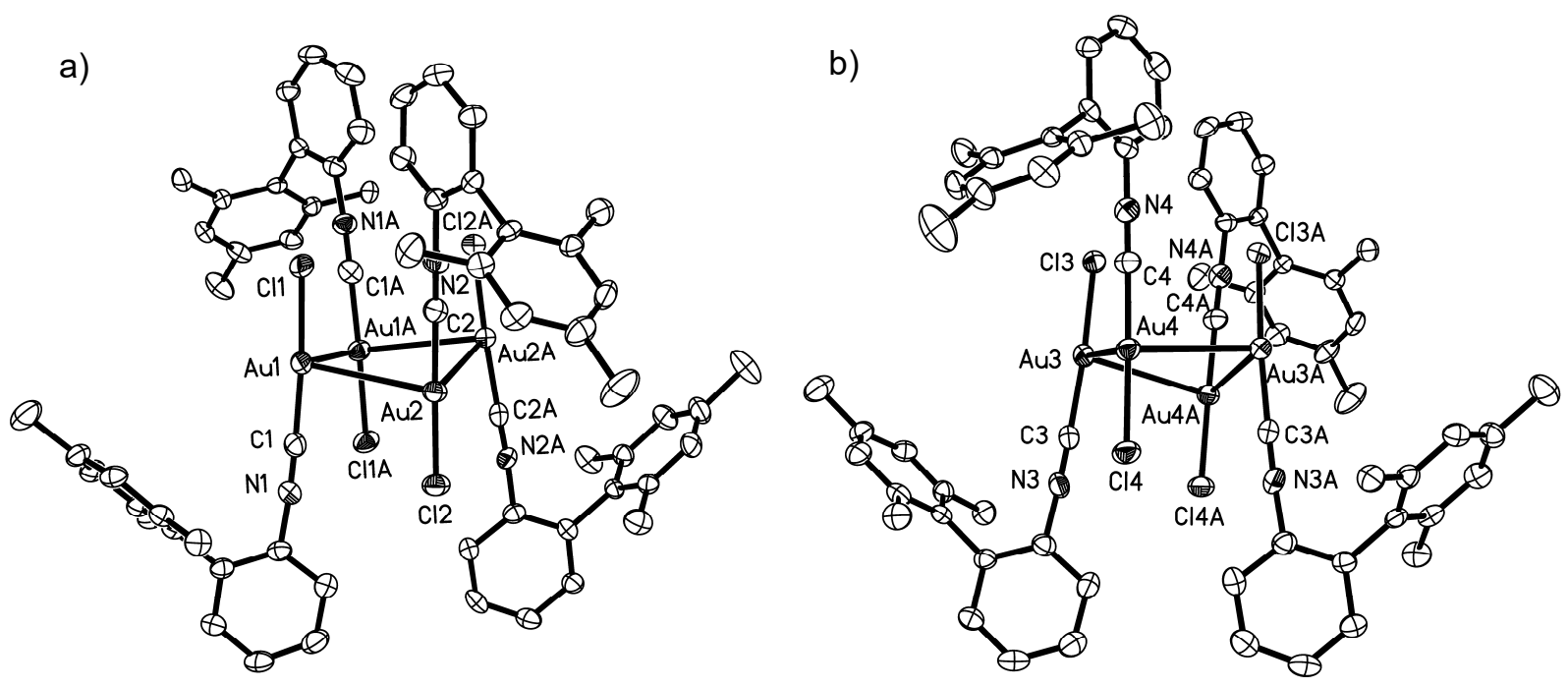

Figure S15. Views of the two crystallographically independent tetramers in the X-ray structure of 3, with displacement ellipsoids drawn at the $50 \%$ probability level. Non-NH hydrogen atoms

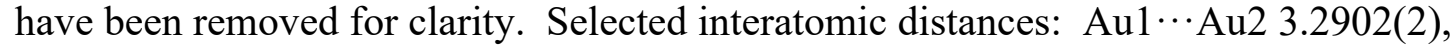

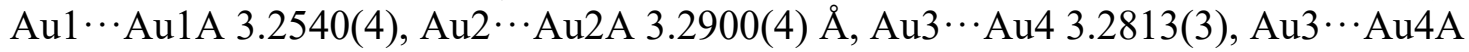

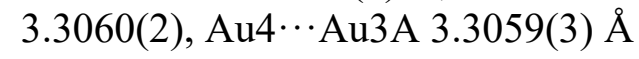

X-ray Crystallographic Analysis of 3. Colorless blocks were obtained by slow diffusion of $n$ hexane into a dichloromethane solution of 3. A sample measuring $0.29 \times 0.25 \times 0.16 \mathrm{~mm}$ was placed on the goniometer of the diffractometer, and reflection data were collected using $40 \mathrm{~s}$ scans. The sample was cooled to 115(2) K during data collection using a Bruker Kryoflex liquid nitrogen cooling device. The asymmetric unit of the refined structure consists of four crystallographically independent gold complexes. The Au1 and Au2 complexes are associated into dimers via weak aurophilic interactions ${ }^{17}$ [Au1 $\cdots$ Au2 3.2902(2) $\AA$ ], and these dimers are further associated into tetramers via aurophilic interactions with an identical Au1-Au2 dimer related to the first via a crystallographic $C_{2}$ axis (Figure $\mathrm{S} 15 \mathrm{a}$ ). The Au3 and Au4 complexes are associated into similar $C_{2}$-symmetric tetramers, albeit with the $C_{2}$ axis oriented roughly parallel to the $\mathrm{ClAuCN}$ axes, rather than perpendicular to them as for the Au1-Au2 tetramers (Figure $\mathrm{S} 15 \mathrm{~b}$ ). $\mathrm{C}_{16} \mathrm{H}_{15} \mathrm{AuClN}, M_{\mathrm{r}}$ $=453.71 \mathrm{~g} \mathrm{~mol}^{-1}$, monoclinic, space group $C 2 / c, a=23.9326(4), b=23.9209(4), c=22.5992(4)$ $\AA, \beta=106.959(1)^{\circ}, V=12375.2(4) \AA^{3}, Z=32, Z^{\prime}=4, \rho_{\text {calcd }}=1.948 \mathrm{~g} \mathrm{~cm}^{-3}, \mu=9.669 \mathrm{~mm}^{-1}, T=$ $115(2) \mathrm{K}, \theta_{\max }=26.338^{\circ}, 68985$ total reflections, 12580 independent $\left(R_{\text {int }}=0.046\right), 9881$ observed $[I>2 \sigma(I)]$. Final $R 1[I>2 \sigma(I)]=0.0241, w R 2$ (all data) $=0.0517$, largest difference peak (hole) $1.067(-0.505)$ e $\AA^{-3}$. CCDC 1945192. 


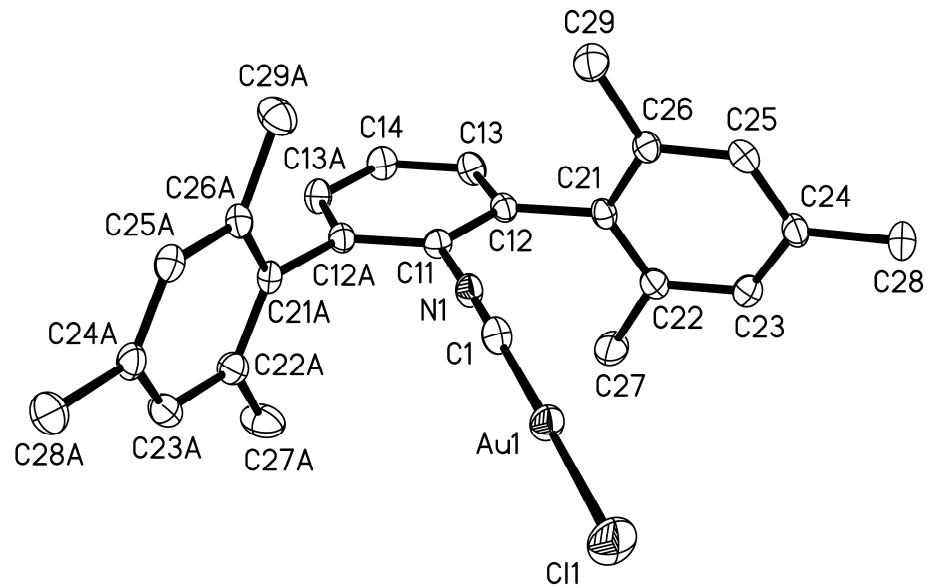

Figure S16. X-ray structure of the monomeric polymorph of complex 4 (4a). C11, Au1, C1, N1, $\mathrm{C} 11$ and $\mathrm{C} 14$ lie on a crystallographic mirror plane. Displacement ellipsoids are drawn at the $50 \%$ probability level. Hydrogen atoms have been removed for clarity.

X-ray Crystallographic Analysis of 4a. Pale golden blocks were obtained by slow diffusion of $n$-hexane into a benzene solution of 4 . A wedge-shaped crystal measuring $0.27 \times 0.23 \times 0.17 \mathrm{~mm}$ was cut from a larger block and placed on the goniometer of the diffractometer, and reflection data were collected using $20 \mathrm{~s}$ scans. The sample was cooled to 115(2) K during data collection using a Bruker Kryoflex liquid nitrogen cooling device. In the refined structural model (Figure S16), the asymmetric unit consistents of $1 / 2$ molecule, as the complex lies on a crystallographic mirror plane. $\mathrm{C}_{25} \mathrm{H}_{25} \mathrm{AuClN}, M_{\mathrm{r}}=571.88 \mathrm{~g} \mathrm{~mol}^{-1}$, orthorhombic, space group Pnma, $a=19.1080(3), b=$ 16.8047(3), $c=6.9313(1) \AA, V=2225.67(6) \AA^{3}, Z=4, Z^{\prime}=0.5, \rho_{\text {calcd }}=1.707 \mathrm{~g} \mathrm{~cm}^{-3}, \mu=6.740$ $\mathrm{mm}^{-1}, T=115(2) \mathrm{K}, \theta_{\max }=30.422^{\circ}, 34639$ total reflections, 3469 independent $\left(R_{\text {int }}=0.034\right), 2473$ observed $[I>2 \sigma(I)]$. Final $R 1[I>2 \sigma(I)]=0.0181, w R 2$ (all data) $=0.0387$, largest difference peak (hole) $0.685(-0.742)$ e $\AA^{-3}$. CCDC 1945190. 


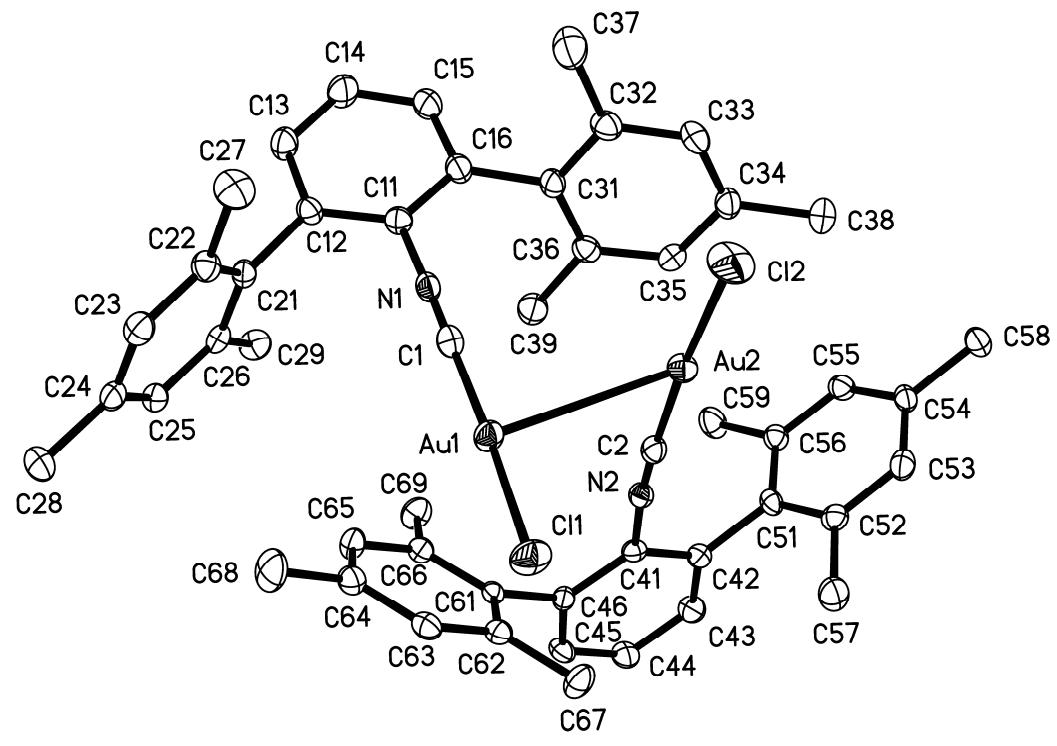

Figure S17. X-ray structure of the dimeric polymorph of complex 4 (4b). Au1 $\cdots A$ Au2 distance is 3.2763(3) A. Displacement ellipsoids are drawn at the 50\% probability level. Hydrogen atoms have been removed for clarity.

X-ray Crystallographic Analysis of 4b. Colorless blocks were obtained by slow diffusion of diethyl ether into a dichloromethane solution of 4. A sample measuring $0.27 \times 0.27 \times 0.20 \mathrm{~mm}$ was placed on the goniometer of the diffractometer, and reflection data were collected using $5 \mathrm{~s}$ scans. The sample was cooled to $125(2) \mathrm{K}$ during data collection using an Oxford Cryostream liquid nitrogen cooling device. The asymmetric unit of the refined structure consists of two crystallographically independent gold complexes, which are associated into dimers via weak

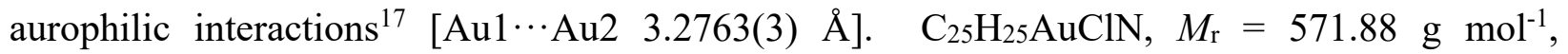
monoclinic, space group $P 21 / n, a=16.3619(18), b=13.0112(14), c=21.402(2) \AA, \beta=$ 105.443(2) $)^{\circ}, V=4391.8(8) \AA^{3}, Z=8, Z^{\prime}=2, \rho_{\text {calcd }}=1.730 \mathrm{~g} \mathrm{~cm}^{-3}, \mu=6.831 \mathrm{~mm}^{-1}, T=125(2) \mathrm{K}$, $\theta_{\max }=30.521^{\circ}, 69533$ total reflections, 13387 independent $\left(R_{\text {int }}=0.047\right), 11167$ observed $[I>$ $2 \sigma(I)]$. Final $R 1[I>2 \sigma(I)]=0.0237, w R 2($ all data $)=0.0510$, largest difference peak (hole) 0.751 $(-0.568)$ e $\AA^{-3}$. CCDC 1945193 . 
a)

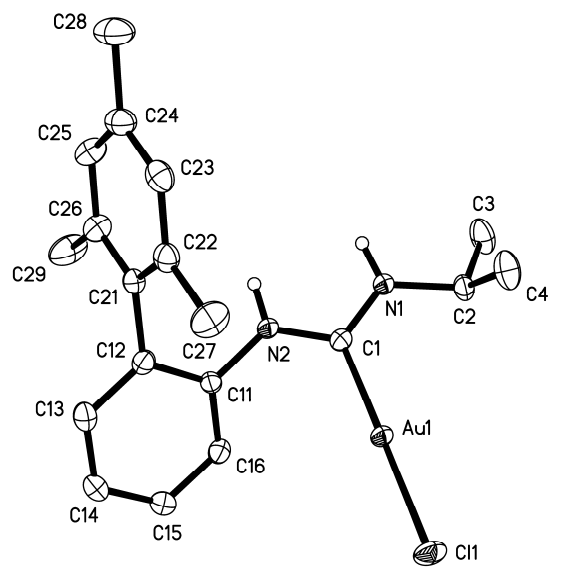

b)

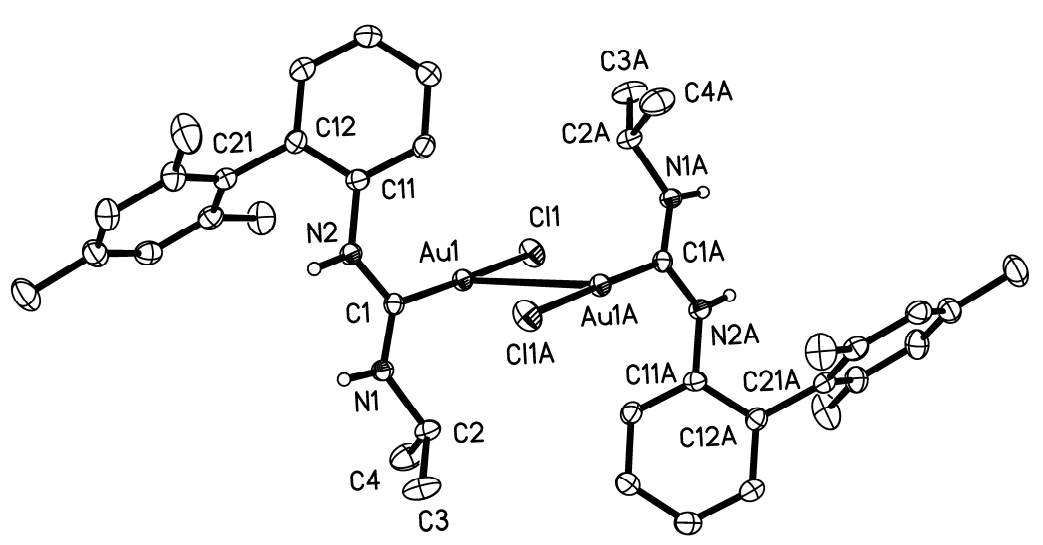

Figure S18. Views of a) the monomeric unit, and b) a centrosymmetric dimer present in the Xray structure of $\mathbf{5 a}$, with displacement ellipsoids drawn at the $50 \%$ probability level.

Aul $\cdots$ AulA distance is 3.2610(2) A. Non-NH hydrogen atoms have been removed for clarity.

X-ray Crystallographic Analysis of 5a. Colorless plates were obtained by slow diffusion of pentane into a dichloromethane solution of 5a. A sample measuring $0.30 \times 0.12 \times 0.04 \mathrm{~mm}$ was cut from a larger plate and placed on the goniometer of the diffractometer, and reflection data were collected using $20 \mathrm{~s}$ scans. The sample was cooled to $115(2) \mathrm{K}$ during data collection using a Bruker Kryoflex liquid nitrogen cooling device. During refinement, the $\mathrm{N}-\mathrm{H}$ bonds were restrained to a target value of $0.89(1) \AA$, with all other positional parameters of the $\mathrm{N}-\mathrm{H}$ groups allowed to refine freely. The asymmetric unit of the refined structure consists of one crystallographically independent gold complex, and these are associated into centrosymmetric dimers via weak aurophilic interactions ${ }^{17}$ between symmetry-related neighboring complexes

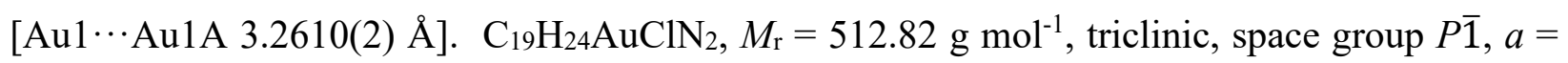
8.0064(1), $b=10.6256(2), c=12.2089(2) \AA, \alpha=95.896(1), \beta=103.015(1), \gamma=105.144(1)^{\circ}, V=$ 962.30(3) $\AA^{3}, Z=2, Z^{\prime}=1, \rho_{\text {calcd }}=1.770 \mathrm{~g} \mathrm{~cm}^{-3}, \mu=7.784 \mathrm{~mm}^{-1}, T=115(2) \mathrm{K}, \theta_{\max }=29.105^{\circ}$, 21739 total reflections, 5112 independent $\left(R_{\text {int }}=0.031\right), 4801$ observed $[I>2 \sigma(I)]$. Final $R 1[I>$ $2 \sigma(I)]=0.0170, w R 2($ all data $)=0.0392$, largest difference peak (hole) $0.911(-0.558)$ e $\AA^{-3}$. CCDC 1945191. 


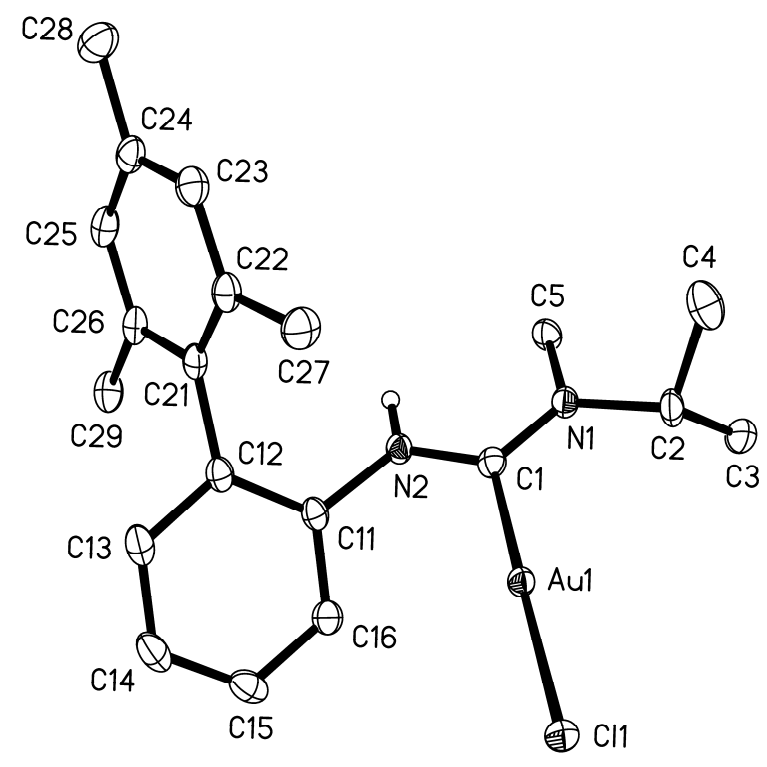

Figure S19. X-ray structure of $\mathbf{5 c}$, with displacement ellipsoids drawn at the $50 \%$ probability level. Non-NH hydrogen atoms have been removed for clarity.

X-ray Crystallographic Analysis of 5c. Flat, colorless needles were obtained by slow diffusion of pentane into a dichloromethane solution of 5c. A sample measuring $0.25 \times 0.20 \times 0.11 \mathrm{~mm}$ was cut from a larger crystal and placed on the goniometer of the diffractometer, and reflection data were collected using $20 \mathrm{~s}$ scans. The sample was cooled to 115(2) K during data collection using a Bruker Kryoflex liquid nitrogen cooling device. During refinement, the N2-HA bond was restrained to a target value of $0.89(1) \AA$, with all other positional parameters of the N-H group allowed to refine freely. $\mathrm{C}_{20} \mathrm{H}_{26} \mathrm{AuClN}_{2}, M_{\mathrm{r}}=526.84 \mathrm{~g} \mathrm{~mol}^{-1}$, monoclinic, space group $P 2{ }_{1} / c, a=$ 12.0932(2), $b=10.3747(1), c=16.2882(2) \AA, \beta=107.833(1)^{\circ}, V=1945.38(5) \AA^{3}, Z=4, Z^{\prime}=1$, $\rho_{\text {calcd }}=1.799 \mathrm{~g} \mathrm{~cm}^{-3}, \mu=7.703 \mathrm{~mm}^{-1}, T=115(2) \mathrm{K}, \theta_{\max }=30.426^{\circ}, 37331$ total reflections, 5887 independent $\left(R_{\text {int }}=0.032\right), 5277$ observed $[I>2 \sigma(I)]$. Final $R 1[I>2 \sigma(I)]=0.0152, w R 2$ (all data) $=0.0330$, largest difference peak (hole) $0.632(-0.442)$ e $\AA^{-3}$. CCDC 1945198. 


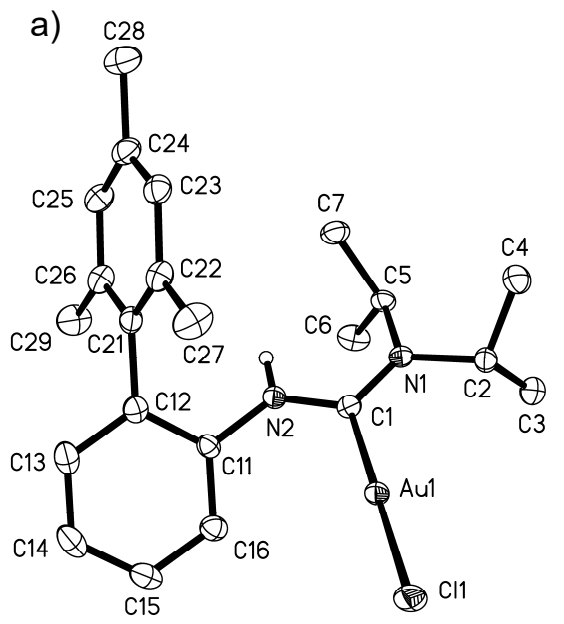

b)

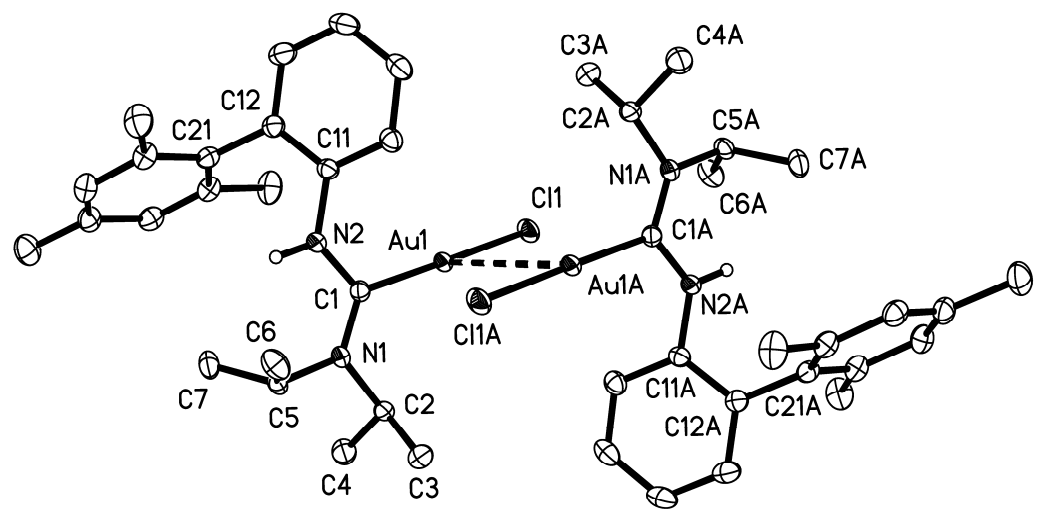

Figure S20. Views of a) the monomeric unit, and b) a centrosymmetric dimer present in the Xray structure of $\mathbf{5 d}$, with displacement ellipsoids drawn at the $50 \%$ probability level.

Au1 $\cdots$ AulA distance is $3.592 \AA$. Non-NH hydrogen atoms and solvent of crystallization have been removed for clarity.

X-ray Crystallographic Analysis of 5d. Colorless blocks were obtained by slow diffusion of pentane into a diethyl ether $/ n$-hexane solution of $\mathbf{5 d}$. A sample measuring $0.43 \times 0.34 \times 0.19 \mathrm{~mm}$ was cut from a larger block and placed on the goniometer of the diffractometer, and reflection data were collected using $10 \mathrm{~s}$ scans. The sample was cooled to $115(2) \mathrm{K}$ during data collection using a Bruker Kryoflex liquid nitrogen cooling device. Reciprocal space plots generated after full data collection revealed signs of non-merohedral twinning, ${ }^{18}$ with one dominant component and two additional weakly diffracting twin components that had not been apparent during crystal screening. The crystal was modeled as a three-component non-merohedral twin during data integration and scaling, with each component having identical cell parameters. Separate scale factors were fitted for single reflections of each component using TWINABS, ${ }^{19}$, and these were combined to scale the composite reflections. The first component dominated the measured diffraction intensities, with reflections assigned to the second and third components having mean $I / \sigma$ values approximately 5\% that of component 1 reflections. Best refinement was obtained when components 2 and 3 were excluded. Final refinement used corrected data only from twin component 1 in HKLF4 format. During refinement, the N2-H2a bond was restrained to a target value of $0.89(1) \AA$, with all other positional parameters of the $\mathrm{N}-\mathrm{H}$ group allowed to refine freely. The asymmetric unit of the refined structure consists of one crystallographically independent gold complex, plus a molecule of dichloromethane that was refined as part of the structural model. The 
gold complexes are associated into centrosymmetric dimers via weak $\mathrm{Au} \cdots \mathrm{Au}$ interactions between symmetry-related neighboring complexes [Au1 $\cdots$ AulA $3.592 \AA]$. $\mathrm{C}_{22} \mathrm{H}_{30} \mathrm{AuClN}_{2} \cdot \mathrm{CH}_{2} \mathrm{Cl}_{2}, M_{\mathrm{r}}=639.82 \mathrm{~g} \mathrm{~mol}^{-1}$, triclinic, space group $P \overline{1}, a=7.6872(3), b=$ 10.9274(4), $c=15.3336(5) \AA, \alpha=86.062(2), \beta=78.745(2), \gamma=79.790(2)^{\circ}, V=1242.49(8) \AA^{3}, Z$ $=2, Z^{\prime}=1, \rho_{\text {calcd }}=1.710 \mathrm{~g} \mathrm{~cm}^{-3}, \mu=6.255 \mathrm{~mm}^{-1}, T=115(2) \mathrm{K}, \theta_{\max }=30.522^{\circ}, 112255$ total reflections, 7525 independent $\left(R_{\text {int }}=0.034\right), 7203$ observed $[I>2 \sigma(I)]$. Final $R 1[I>2 \sigma(I)]=$ $0.0154, w R 2$ (all data) $=0.0407$, largest difference peak (hole) $1.061(-0.665)$ e $\AA^{-3}$. CCDC 1945194. 


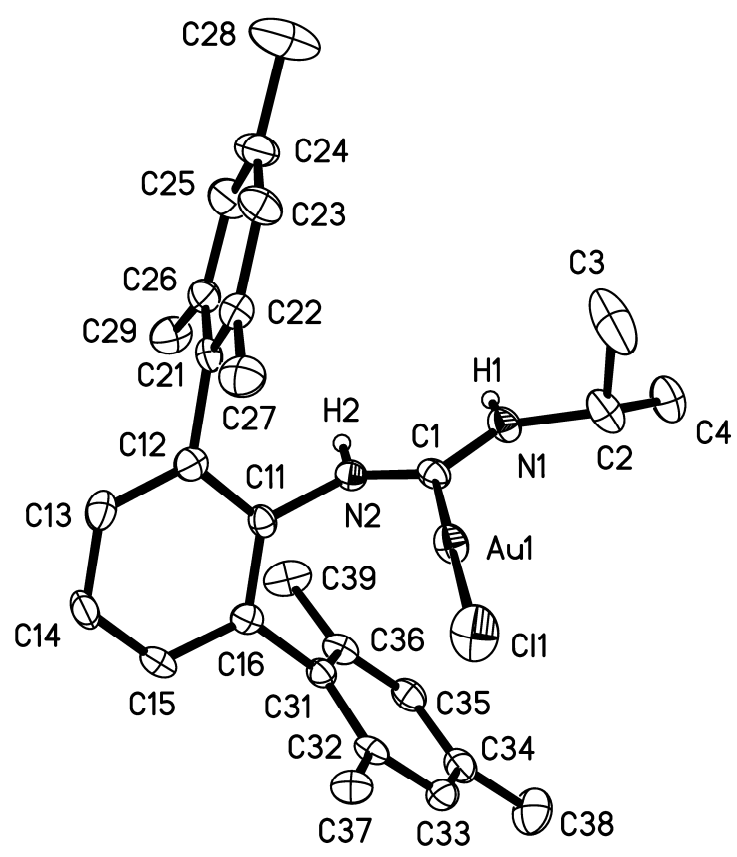

Figure S21. X-ray structure of 6a, with displacement ellipsoids drawn at the $50 \%$ probability level. Non-NH hydrogen atoms have been removed for clarity.

X-ray Crystallographic Analysis of 6a. Colorless blocks were obtained by slow diffusion of pentane into a chloroform solution of 6a. A sample measuring $0.22 \times 0.11 \times 0.10 \mathrm{~mm}$ was placed on the goniometer of the diffractometer, and reflection data were collected using $20 \mathrm{~s}$ scans. The sample was cooled to 115(2) K during data collection using a Bruker Kryoflex liquid nitrogen cooling device. During refinement, the N-H bonds were restrained to a target value of 0.89(1) $\AA$, with all other positional parameters of the $\mathrm{N}-\mathrm{H}$ groups allowed to refine freely. $\mathrm{C}_{28} \mathrm{H}_{34} \mathrm{AuClN}_{2}$, $M_{\mathrm{r}}=630.99 \mathrm{~g} \mathrm{~mol}^{-1}$, orthorhombic, space group Fdd2, $a=28.4766(4), b=32.9002(3), c=$ 11.7962(1) $\AA, V=11051.7(2) \AA^{3}, Z=16, Z^{\prime}=1, \rho_{\text {calcd }}=1.517 \mathrm{~g} \mathrm{~cm}^{-3}, \mu=5.438 \mathrm{~mm}^{-1}, T=115(2)$ $\mathrm{K}, \theta_{\max }=28.186^{\circ}, 29711$ total reflections, 6781 independent $(R$ int $=0.045), 5937$ observed $[I>$ $2 \sigma(I)]$. Final $R 1[I>2 \sigma(I)]=0.0257, w R 2($ all data $)=0.0459$, absolute structure parameter $($ Flack x) -0.007(5), largest difference peak (hole) 0.968 (-0.439) e $\AA^{-3}$. CCDC 1945196. 


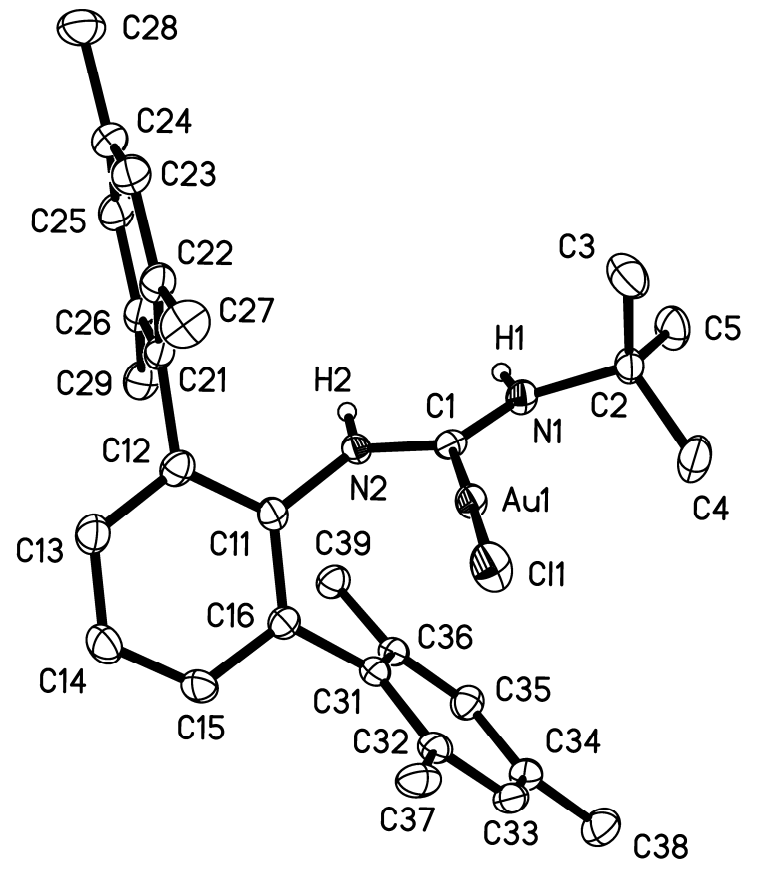

Figure S22. X-ray structure of $\mathbf{6 b}$, with displacement ellipsoids drawn at the $50 \%$ probability level. Non-NH hydrogen atoms have been removed for clarity.

X-ray Crystallographic Analysis of 6b. Colorless blocks were obtained by slow diffusion of pentane into a dichloromethane solution of $6 \mathbf{b}$. A sample measuring $0.25 \times 0.20 \times 0.12 \mathrm{~mm}$ was placed on the goniometer of the diffractometer for analysis. The sample was cooled to 115(2) K during data collection using a Bruker Kryoflex liquid nitrogen cooling device. During refinement, the N-H bonds were restrained to a target value of $0.89(1) \AA$, with all other positional parameters of the N-H groups allowed to refine freely. $\mathrm{C}_{29} \mathrm{H}_{36} \mathrm{AuClN}_{2}, M_{\mathrm{r}}=645.01 \mathrm{~g} \mathrm{~mol}^{-1}$, monoclinic, space group $P 2{ }_{1} / n, a=12.4751(2), b=17.3494(3), c=12.7598(2) \AA, \beta=105.075(1)^{\circ}, V=2666.63(8)$ $\AA^{3}, Z=4, Z^{\prime}=1, \rho_{\text {calcd }}=1.607 \mathrm{~g} \mathrm{~cm}^{-3}, \mu=5.636 \mathrm{~mm}^{-1}, T=115(2) \mathrm{K}, \theta_{\max }=30.427^{\circ}, 34309$ total reflections, 8057 independent $\left(R_{\text {int }}=0.033\right), 6862$ observed $[I>2 \sigma(I)]$. Final $R 1[I>2 \sigma(I)]=$ $0.0201, w R 2$ (all data) $=0.0444$, largest difference peak (hole) $1.083(-0.374)$ e $\AA^{-3}$. CCDC 1945195. 

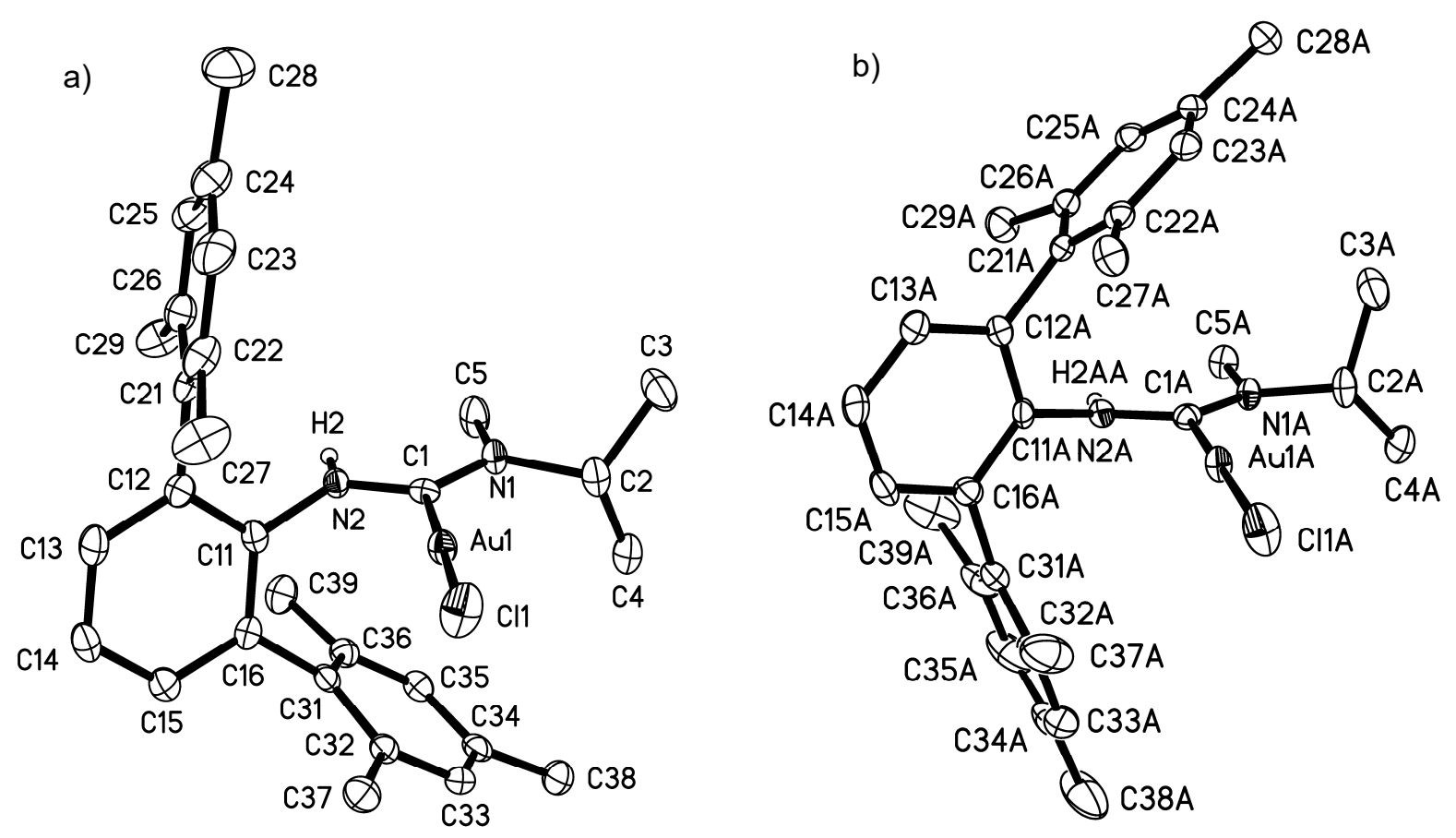

Figure S23. Views of two crystallographically independent complexes present in the X-ray structure of $\mathbf{6 c}$, with displacement ellipsoids drawn at the $50 \%$ probability level. Non-NH hydrogen atoms and solvent of crystallization have been removed for clarity.

X-ray Crystallographic Analysis of 6c. Colorless blocks were obtained by slow diffusion of pentane into a dichloromethane solution of $6 c$. A sample measuring $0.20 \times 0.16 \times 0.14 \mathrm{~mm}$ was placed on the goniometer of the diffractometer, and reflection data were collected using $15 \mathrm{~s}$ scans. The sample was cooled to 115(2) K during data collection using a Bruker Kryoflex liquid nitrogen cooling device. During refinement, the N-H bond lengths were restrained to a target value of 0.89(1) $\AA$, with all other positional parameters of the N-H groups allowed to refine freely. The asymmetric unit consists of two crystallographically independent molecules of $\mathbf{6 c}$, plus a molecule of dichloromethane that was explicitly refined as part of the structural model. $\mathrm{C}_{28} \mathrm{H}_{36} \mathrm{AuClN}_{2} \cdot 0.5$ $\mathrm{CH}_{2} \mathrm{Cl}_{2}, M_{\mathrm{r}}=687.48 \mathrm{~g} \mathrm{~mol}^{-1}$, triclinic, space group $P \overline{1}, a=9.1142(1), b=16.8134(2), c=$ 18.4933(2) $\AA, \alpha=90.555(1), \beta=99.293(1), \gamma=91.230(1)^{\circ}, V=2795.84(5) \AA^{3}, Z=4, Z^{\prime}=2, \rho_{\text {calcd }}$ $=1.633 \mathrm{~g} \mathrm{~cm}^{-3}, \mu=5.473 \mathrm{~mm}^{-1}, T=115(2) \mathrm{K}, \theta_{\max }=28.248^{\circ}, 56400$ total reflections, 13746 independent $(R$ int $=0.037), 11394$ observed $[I>2 \sigma(I)]$. Final $R 1[I>2 \sigma(I)]=0.0252, w R 2($ all data $)=0.0579$, largest difference peak (hole) $1.203(-1.177)$ e $\AA^{-3}$. CCDC 1945197. 


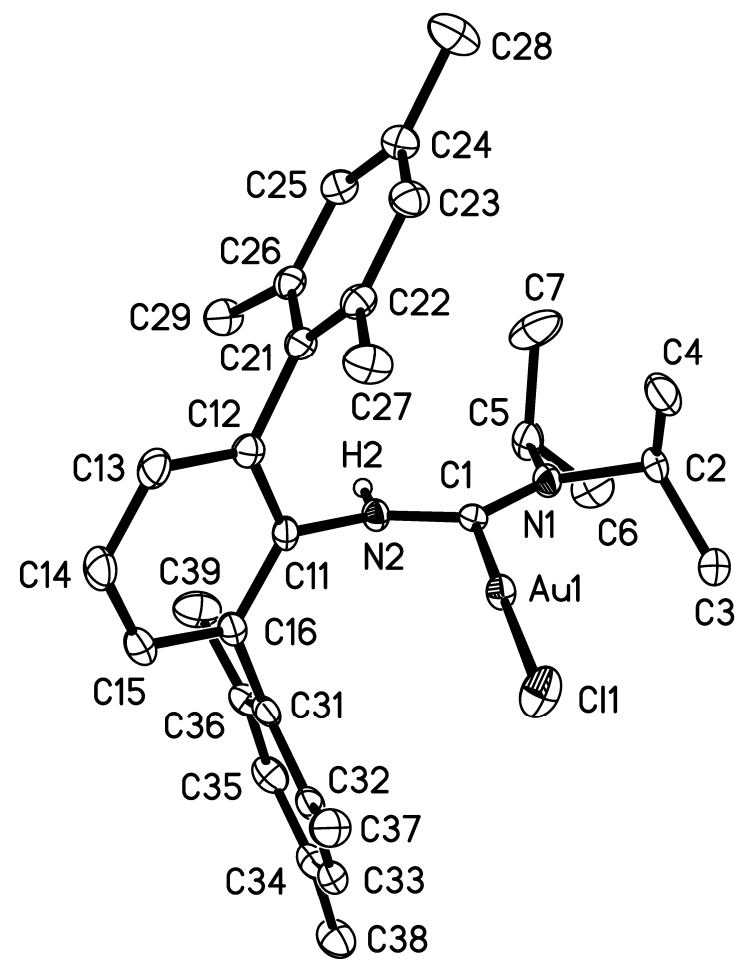

Figure S24. X-ray structure of $6 \mathbf{d}$, with displacement ellipsoids drawn at the $50 \%$ probability level. Non-NH hydrogen atoms have been removed for clarity.

X-ray Crystallographic Analysis of 6d. Colorless blocks were obtained by slow diffusion of pentane into a dichloromethane solution of $6 \mathbf{d}$. A sample measuring $0.25 \times 0.25 \times 0.20 \mathrm{~mm}$ was placed on the goniometer of the diffractometer, and reflection data were collected using $10 \mathrm{~s}$ scans. The sample was cooled to 115(2) K during data collection using a Bruker Kryoflex liquid nitrogen cooling device. During refinement, the N2-H2 bond was restrained to a target value of 0.87(1) $\AA$, with all other positional parameters of the N-H group allowed to refine freely. $\mathrm{C}_{31} \mathrm{H}_{40} \mathrm{AuClN}_{2}, M_{\mathrm{r}}$ $=673.06 \mathrm{~g} \mathrm{~mol}^{-1}$, monoclinic, space group $P 21 / n, a=10.3393(2), b=17.1048(3), c=16.4509(2)$ $\AA, \beta=94.3060(1)^{\circ}, V=2901.16(8) \AA^{3}, Z=4, Z^{\prime}=1, \rho$ calcd $=1.541 \mathrm{~g} \mathrm{~cm}^{-3}, \mu=5.184 \mathrm{~mm}^{-1}, T=$ $115(2) \mathrm{K}, \theta_{\max }=30.428^{\circ}, 50256$ total reflections, 8760 independent $\left(R_{\text {int }}=0.032\right), 7624$ observed $[I>2 \sigma(I)]$. Final $R 1[I>2 \sigma(I)]=0.0181, w R 2($ all data $)=0.0419$, largest difference peak (hole) $0.644(-0.543)$ e $\AA^{-3}$. CCDC 1945199. 


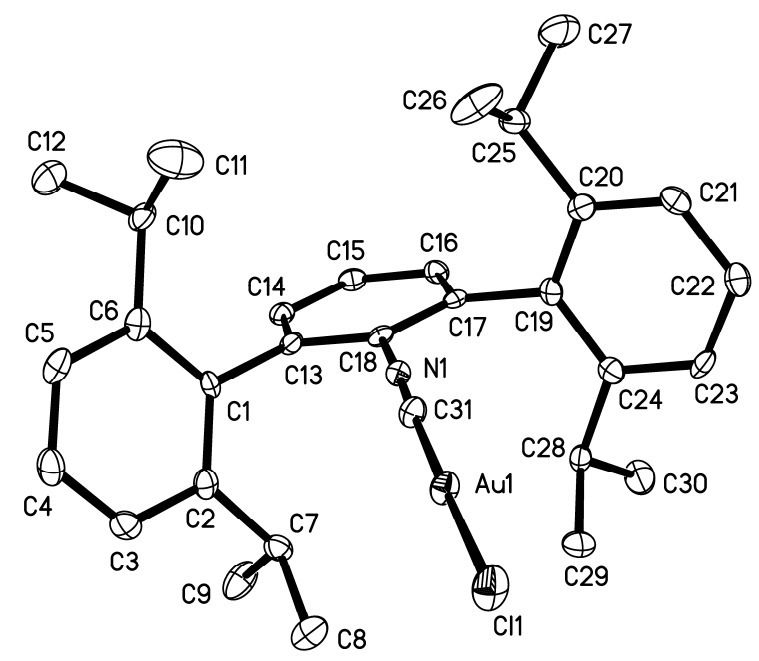

Figure S25. X-ray structure of 12, with displacement ellipsoids drawn at the $50 \%$ probability level. Hydrogen atoms have been removed for clarity.

X-ray Crystallographic Analysis of 12. Colorless blocks were obtained by slow diffusion of pentane into a dichloroethane solution of 12. A sample measuring $0.116 \times 0.097 \times 0.02 \mathrm{~mm}$ was cut from a larger block and placed on the goniometer of the diffractometer, and reflection data were collected using $17 \mathrm{~s}$ scans. The sample was cooled to $100(1) \mathrm{K}$ during data collection using an Oxford Cryostream liquid nitrogen cooling device. $\mathrm{C}_{31} \mathrm{H}_{37} \mathrm{AuClN}, M_{\mathrm{r}}=656.03 \mathrm{~g} \mathrm{~mol}^{-1}$, orthorhombic, space group Pna2 ${ }_{1}, a=19.1190(6), b=12.7284(4), c=11.5929(4) \AA, V=2821.2(2)$ $\AA^{3}, Z=4, Z^{\prime}=1, \rho_{\text {calcd }}=1.545 \mathrm{~g} \mathrm{~cm}^{-3}, \mu=5.328 \mathrm{~mm}^{-1}, T=100(1) \mathrm{K}, \theta_{\max }=26.362^{\circ}, 19962$ total reflections, 5296 independent $(R$ int $=0.035), 4863$ observed $[I>2 \sigma(I)]$. Final $R 1[I>2 \sigma(I)]=$ $0.0176, w R 2($ all data $)=0.0358$, absolute structure parameter $($ Flack $x)-0.020(4)$, largest difference peak (hole) $0.498(-0.320)$ e $\AA^{-3}$. CCDC 1945200. 


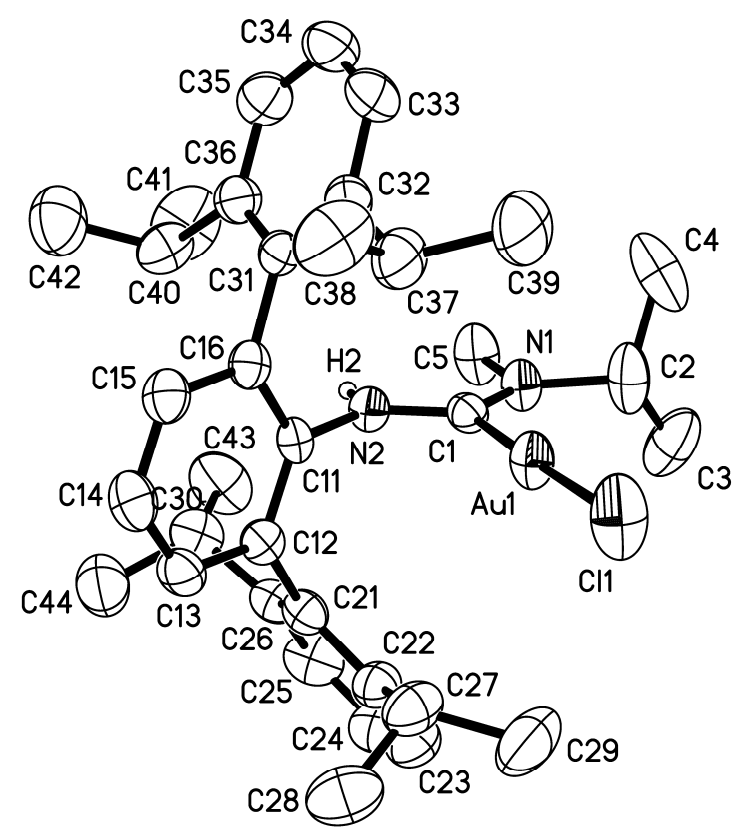

Figure S26. X-ray structure of 13c, with displacement ellipsoids drawn at the $50 \%$ probability level. Non-NH hydrogen atoms have been removed for clarity.

X-ray Crystallographic Analysis of 13c. Colorless blocks were obtained by slow diffusion of $n$ hexane into a dichloromethane solution of 13c. A sample measuring 0.128 x 0.116 x $0.026 \mathrm{~mm}$ was cut from a larger block and placed on the goniometer of the diffractometer for data collection. The sample was cooled to 220(2) K during data collection using an Oxford Cryostream liquid nitrogen cooling device. During refinement, the N2-H2 bond was restrained to a target value of 0.87(1) $\AA$, with all other positional parameters of the $\mathrm{N}-\mathrm{H}$ group allowed to refine freely $\mathrm{C}_{35} \mathrm{H}_{48} \mathrm{AuClN}_{2}, M_{\mathrm{r}}=729.17 \mathrm{~g} \mathrm{~mol}^{-1}$, orthorhombic, space group $P 2{ }_{1}{ }_{1}{ }_{1}, a=8.928(2), b=$ 17.593(4), $c=21.959(5) \AA, V=3449.0(14) \AA^{3}, Z=4, Z^{\prime}=1, \rho_{\text {calcd }}=1.404 \mathrm{~g} \mathrm{~cm}^{-3}, \mu=4.366 \mathrm{~mm}^{-}$ $1, T=220(2) \mathrm{K}, \theta_{\max }=26.854^{\circ}, 36320$ total reflections, 7381 independent $\left(R_{\text {int }}=0.039\right), 6706$ observed $[I>2 \sigma(I)]$. Final $R 1[I>2 \sigma(I)]=0.0223, w R 2$ (all data) $=0.0430$, absolute structure parameter (Flack $x$ ) 0.002(4), largest difference peak (hole) $0.299(-0.467)$ e $\AA^{-3}$. CCDC 1945201. 
Table S5. Geometric parameters of 2,6-Dipp $2 \mathrm{Ph}$-containing $\mathrm{Au}(\mathrm{ADC}) \mathrm{Cl}$ complex 13c in comparison with dimesityl $\mathrm{Au}(\mathrm{ADC}) \mathrm{Cl}$ complexes $\mathbf{6 c}$ and $\mathbf{6 d}$.
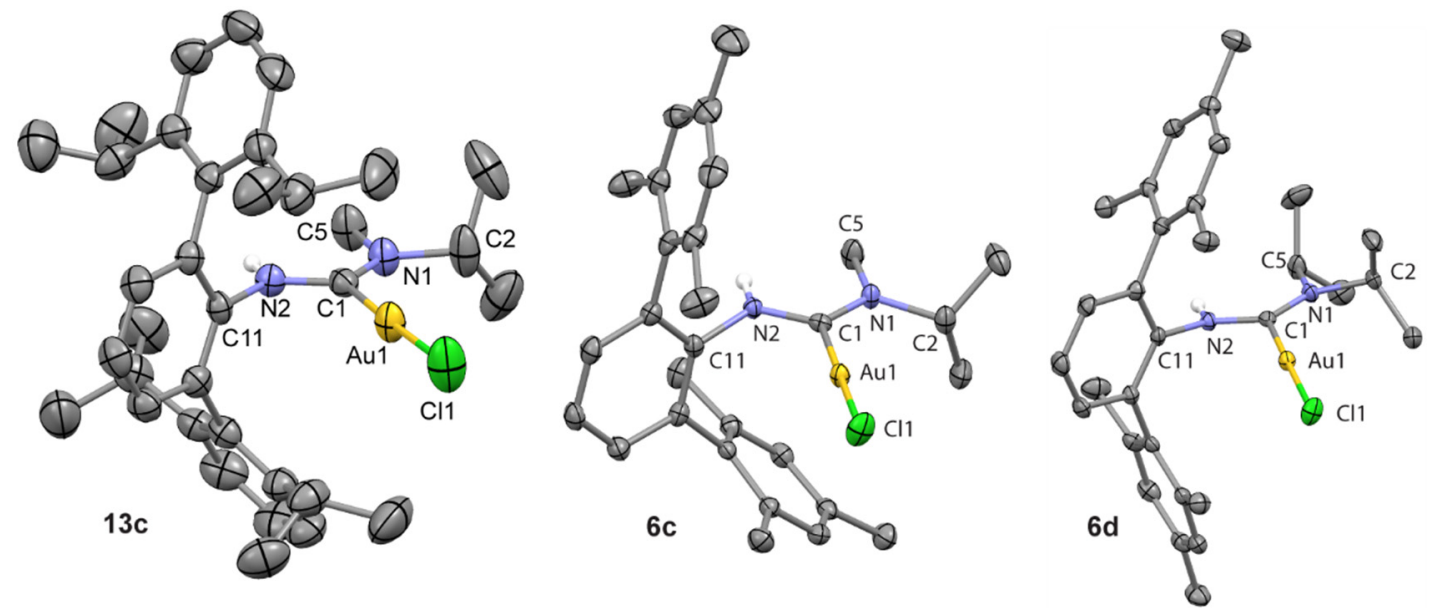

\begin{tabular}{|c|c|c|c|}
\hline & $13 \mathrm{c}$ & $6 c^{a}$ & 6d \\
\hline \multicolumn{4}{|l|}{ Distances $(\AA)$} \\
\hline $\mathrm{Au}-\mathrm{C}_{\text {carbene }}$ & $1.991(5)$ & $1.992(3)$ & $2.001(2)$ \\
\hline $\mathrm{Au}-\mathrm{Cl}$ & $2.279(1)$ & $2.2846(8)$ & $2.2928(5)$ \\
\hline $\mathrm{C}_{\text {carbene-N1 }}$ & $1.333(5)$ & $1.332(4)$ & $1.334(2)$ \\
\hline $\mathrm{C}_{\text {carbene }} \mathrm{N} 2$ & $1.336(5)$ & $1.343(4)$ & $1.345(2)$ \\
\hline \multicolumn{4}{|l|}{ Angles $\left({ }^{\circ}\right)$} \\
\hline $\mathrm{N} 1-\mathrm{C} 1-\mathrm{N} 2$ & $117.0(4)$ & $117.5(3)$ & $119.2(2)$ \\
\hline $\mathrm{Au}-\mathrm{C} 1-\mathrm{N} 1$ & $121.8(3)$ & $123.3(2)$ & $123.2(1)$ \\
\hline $\mathrm{Au}-\mathrm{C} 1-\mathrm{N} 2$ & $121.1(3)$ & $119.2(2)$ & $117.4(1)$ \\
\hline yaw angle & $0.4(2)$ & $2.1(1)$ & $2.90(7)$ \\
\hline \multicolumn{4}{|l|}{$\begin{array}{l}\text { ADC substituent } \\
\text { torsion angles }\left({ }^{\circ}\right)\end{array}$} \\
\hline $\mathrm{N} 1-\mathrm{C} 1-\mathrm{N} 2-\mathrm{C} 11$ & $178.2(4)$ & 164.1(3) & $166.5(2)^{\mathrm{c}}$ \\
\hline N2-C1-N1-C2 & $174.6(4)$ & $-172.0(3)$ & $-169.8(2)^{c}$ \\
\hline \multicolumn{4}{|l|}{ Other } \\
\hline $\begin{array}{l}\text { Aryl dihedral from } \\
\text { NCN plane }\left(^{\circ}\right)^{\mathrm{d}}\end{array}$ & 91.9 & $96.3,85.0^{\mathrm{e}}$ & 83.7 \\
\hline $\begin{array}{l}\text { C11 deviation from } \\
\text { NCN plane }(\AA)\end{array}$ & $0.038(8)$ & $0.330(4)$ & $0.286(3)$ \\
\hline
\end{tabular}

${ }^{a}$ Listed structural parameters are averages for the two crystallographically independent molecules of $\mathbf{6 c}$ in the asymmetric unit, except as noted. ${ }^{b}$ Yaw angle $=[(\mathrm{Au}-\mathrm{C} 1-\mathrm{N} 1)-(\mathrm{Au}-\mathrm{C} 2-\mathrm{N} 2)] / 2\left(\right.$ see Crabtree et $\left.\mathrm{al}^{20}\right) .{ }^{\mathrm{c}}$ Sign of torsion angle reversed for ease of comparison with other complexes. ${ }^{\mathrm{d}}$ Angles $>90^{\circ}$ signify that top of aryl ring (C12) is tilted away from Au. ${ }^{\mathrm{e}} \mathrm{Dihedral}$ angles shown separately, as they differ for the two crystallographically independent molecules. 


\section{DETAILS OF COMPUTATIONAL STUDIES}

Table S6. DFT-calculated geometric parameters of monomesityl and dimesityl Au(ADC)Cl complexes. Method: BP86/6-31+G* (main group), CEP-31G (Au). Values in italics are from calculations using the same method, but with Grimme's D3 dispersion correction ${ }^{3}$ added.

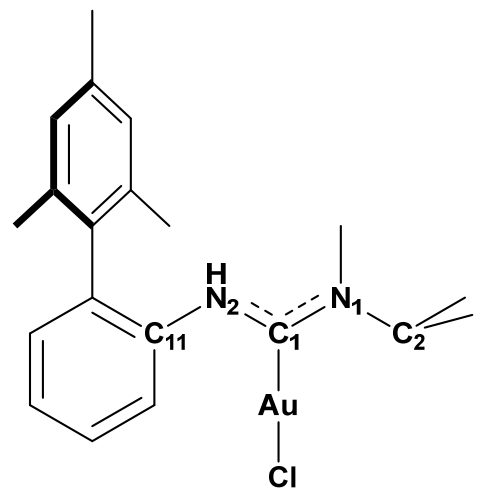

\begin{tabular}{|c|c|c|c|c|c|c|c|c|}
\hline & $5 a$ & $5 b$ & $5 c$ & $5 d$ & $6 \mathbf{a}$ & $6 b$ & $6 c$ & 6d \\
\hline \multicolumn{9}{|l|}{ Distances $(\AA)$} \\
\hline \multirow[t]{2}{*}{$\mathrm{Au}-\mathrm{C}_{\text {carbene }}$} & 2.017 & 2.015 & 2.024 & 2.029 & 2.012 & 2.013 & 2.021 & 2.022 \\
\hline & 2.015 & 2.018 & 2.022 & 2.029 & 2.012 & 2.015 & 2.018 & 2.023 \\
\hline \multirow[t]{2}{*}{$\mathrm{Au}-\mathrm{Cl}$} & 2.317 & 2.320 & 2.321 & 2.323 & 2.326 & 2.327 & 2.329 & 2.334 \\
\hline & 2.316 & 2.317 & 2.319 & 2.321 & 2.325 & 2.325 & 2.330 & 2.330 \\
\hline \multirow[t]{2}{*}{$\mathrm{C}_{\text {carbene }}-\mathrm{N} 1$} & 1.352 & 1.352 & 1.357 & 1.358 & 1.350 & 1.350 & 1.356 & 1.357 \\
\hline & 1.349 & 1.349 & 1.354 & 1.355 & 1.349 & 1.348 & 1.357 & 1.355 \\
\hline \multirow{2}{*}{$\mathrm{C}_{\text {carbene-N}} \mathrm{N} 2$} & 1.363 & 1.365 & 1.366 & 1.366 & 1.361 & 1.362 & 1.362 & 1.370 \\
\hline & 1.362 & 1.365 & 1.366 & 1.365 & 1.359 & 1.361 & 1.360 & 1.367 \\
\hline \multicolumn{9}{|l|}{ Angles $\left(^{\circ}\right)$} \\
\hline \multirow[t]{2}{*}{$\mathrm{N} 1-\mathrm{C} 1-\mathrm{N} 2$} & 113.2 & 112.7 & 114.9 & 116.5 & 114.2 & 113.5 & 115.6 & 116.3 \\
\hline & 114.4 & 113.4 & 115.1 & 116.4 & 114.1 & 113.6 & 114.5 & 115.6 \\
\hline \multirow[t]{2}{*}{$\mathrm{Au}-\mathrm{C} 1-\mathrm{N} 1$} & 120.6 & 123.4 & 122.4 & 122.8 & 121.3 & 124.0 & 122.4 & 124.3 \\
\hline & 122.5 & 125.0 & 123.5 & 123.0 & 121.7 & 124.5 & 122.0 & 125.2 \\
\hline \multirow[t]{2}{*}{$\mathrm{Au}-\mathrm{C} 1-\mathrm{N} 2$} & 126.2 & 123.9 & 122.6 & 120.6 & 124.2 & 122.3 & 121.8 & 119.2 \\
\hline & 123.0 & 121.5 & 121.3 & 120.5 & 124.0 & 121.7 & 123.5 & 118.9 \\
\hline \multirow{2}{*}{$\mathrm{C} 1-\mathrm{Au}-\mathrm{Cl}$} & 179.0 & 179.2 & 178.6 & 178.6 & 176.3 & 176.6 & 176.7 & 177.0 \\
\hline & \multicolumn{8}{|c|}{ torsion angles $\left(^{\circ}\right)$} \\
\hline \multirow[t]{2}{*}{ N1-C1-N2-C11 } & 178.1 & 177.6 & 177.5 & 173.2 & 175.4 & 176.0 & 179.4 & 174.4 \\
\hline & -177.7 & -176.1 & -163.3 & -178.4 & 169.5 & 164.1 & -166.6 & 169.7 \\
\hline \multirow[t]{2}{*}{ N2-C1-N1-C2 } & 179.4 & 176.8 & 176.8 & 175.6 & 174.8 & 175.6 & 178.7 & 168.1 \\
\hline & 170.5 & 175.4 & 178.1 & 176.7 & 173.2 & -179.1 & -179.9 & 172.8 \\
\hline Aryl dihedral & 165.1 & 153.1 & 141.6 & 135.2 & 116.2 & 114.6 & 109.7 & 110.0 \\
\hline $\begin{array}{l}\text { from NCN plane } \\
\left({ }^{\circ}\right)^{\mathrm{a}}\end{array}$ & 129.8 & 129.7 & 126.3 & 130.3 & 121.1 & 118.5 & 123.2 & 119.1 \\
\hline \multicolumn{9}{|l|}{ C11 Deviation } \\
\hline from NCN plane & 0.035 & 0.045 & 0.048 & 0.136 & 0.090 & 0.079 & 0.012 & 0.113 \\
\hline$(\AA)$ & 0.046 & 0.077 & 0.336 & 0.031 & 0.204 & 0.310 & 0.260 & 0.200 \\
\hline
\end{tabular}

${ }^{\text {a Angles }}>90^{\circ}$ signify that top of aryl ring $(\mathrm{C} 12)$ is tilted away from Au. 
Benchmark Study. A screen of several commonly used DFT functionals, basis sets, and effective core potential was undertaken in order to identity an optimal computational method for modeling structure features of the series of $\mathrm{Au}(\mathrm{ADC}) \mathrm{Cl}$ complexes, using $\mathbf{5 b}$ as a representative example. All calculations used the Gaussian09 software package. ${ }^{21}$ For initial benchmarking, the functionals were used without a dispersion correction, with the exception of one that intrinsically includes Grimme's dispersion correction (B97D). ${ }^{22}$ Geometrical parameters shown in the tables below are obtained from energetic minima that were validated through frequency calculations showing no imaginary frequencies.

Over a range of basis set/effective core potential combinations, the B3LYP, M06, and B97D functionals generally provided poorer agreement of calculated bond lengths and angles with the experimental (X-ray) values that the other functionals. In addition, M06 and B97D overestimated the amount of steric distortion of the carbene ligand as judged by torsion angles. Overall, the BP86 functional, ${ }^{23}$ in combination with the Pople 6-31+G(d) basis $\operatorname{set}^{24}$ for main group elements and the CEP-31G core potential/valence basis set ${ }^{25}$ for $\mathrm{Au}$, provided the best balance of accurate structural modeling, reliability in locating minima, and computational cost.

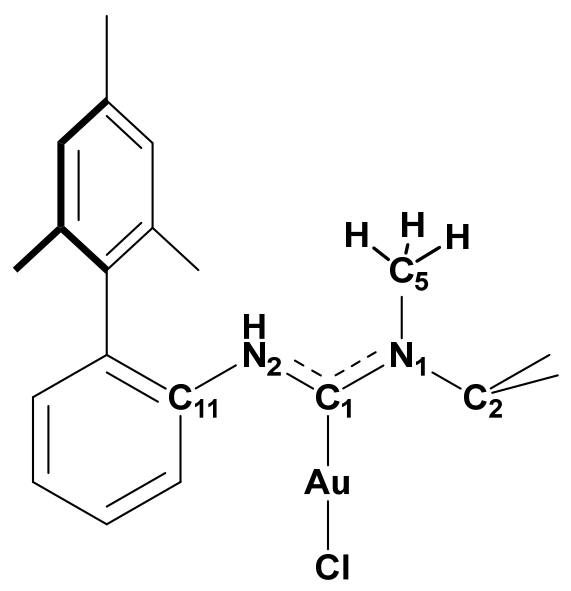

Figure S27. Model and relevant atom labels used in benchmark study 


\section{Table S7. Benchmark Study of 5c, Round 1}

Main group elements: CEP-31G(d) core potential/basis set combination, with Pople dpolarization functions added

Au: CEP-31G effective core potential/basis set combination

Percent error between calculated structural parameters and X-ray values shown in parentheses.

\begin{tabular}{|c|c|c|c|c|c|c|c|}
\hline Distance & X-Ray & B3LYP & B3PW91 & BP86 & B3P86 & M06 & B97D \\
\hline \multirow{2}{*}{$\mathrm{Au}-\mathrm{C}_{1}$} & \multirow{2}{*}{2.006} & 2.051 & 2.031 & 2.029 & 2.026 & 2.067 & 2.046 \\
\hline & & $(2.23 \%)$ & (1.23\%) & (1.14\%) & (1.00\%) & (3.02\%) & (2.00\%) \\
\hline \multirow{2}{*}{$\mathrm{Au}-\mathrm{Cl}$} & \multirow{2}{*}{2.292} & 2.376 & 2.357 & 2.368 & 2.352 & 2.370 & 2.382 \\
\hline & & (3.67\%) & $(2.85 \%)$ & (3.33\%) & $(2.62 \%)$ & (3.40\%) & (3.92\%) \\
\hline \multirow{2}{*}{$\mathrm{C}_{1}-\mathrm{N}_{1}$} & \multirow{2}{*}{1.334} & 1.373 & 1.369 & 1.385 & 1.367 & 1.367 & 1.373 \\
\hline & & (2.89\%) & (2.59\%) & (3.81\%) & (2.47\%) & (2.50\%) & (2.93\%) \\
\hline \multirow{2}{*}{$\mathrm{C}_{1}-\mathrm{N}_{2}$} & \multirow{2}{*}{1.348} & 1.381 & 1.376 & 1.386 & 1.374 & 1.375 & 1.381 \\
\hline & & $(2.41 \%)$ & (2.07\%) & $(2.84 \%)$ & (1.93\%) & (1.98\%) & (2.44\%) \\
\hline Angles & X-Ray & B3LYP & B3PW91 & BP86 & B3Р86 & M06 & B97D \\
\hline \multirow{2}{*}{$\mathrm{C}_{1}-\mathrm{Au}-\mathrm{Cl}$} & \multirow{2}{*}{178.3} & 178.9 & 178.8 & 179.3 & 179.0 & 179.2 & 177.7 \\
\hline & & $(0.32 \%)$ & $(0.30 \%)$ & $(0.57 \%)$ & (0.39\%) & (0.51\%) & $(-.34 \%)$ \\
\hline \multirow{2}{*}{$\mathrm{N}_{1}-\mathrm{C}_{1}-\mathrm{N}_{2}$} & \multirow{2}{*}{117.7} & 114.9 & 114.8 & 114.1 & 114.7 & 115.0 & 115.1 \\
\hline & & $(-2.4 \%)$ & $(-2.5 \%)$ & $(-3.1 \%)$ & $(-2.6 \%)$ & $(-2.3 \%)$ & $(-2.2 \%)$ \\
\hline \multirow{2}{*}{$\mathrm{Au}-\mathrm{C}_{1}-\mathrm{N}_{1}$} & \multirow{2}{*}{121.7} & 122.2 & 122.2 & 121.0 & 122.0 & 122.9 & $123.8^{\prime}$ \\
\hline & & $(0.43 \%)$ & (0.41\%) & $(-0.59 \%)$ & $(0.25 \%)$ & (0.99\%) & $(1.7 \%)$ \\
\hline \multirow{2}{*}{$\mathrm{Au}-\mathrm{C}_{1}-\mathrm{N}_{2}$} & \multirow{2}{*}{120.6} & 122.9 & 123.0 & 124.9 & 123.3 & 122.0 & 120.8 \\
\hline & & $(1.88 \%)$ & $(1.95 \%)$ & (3.59\%) & $(2.24 \%)$ & $(1.15 \%)$ & (0.19\%) \\
\hline $\begin{array}{l}\text { Torsion } \\
\text { Angles }\end{array}$ & X-Ray & B3LYP & B3PW91 & BP86 & B3P86 & M06 & B97D \\
\hline \multirow{2}{*}{$\mathrm{N}_{1}-\mathrm{C}_{1}-\mathrm{N}_{2}-\mathrm{C}_{11}$} & \multirow{2}{*}{176.4} & 177.1 & 177.0 & 178.2 & 177.5 & -173.0 & -169.2 \\
\hline & & $(0.39 \%)$ & $(0.32 \%)$ & (1.00\%) & $(0.62 \%)$ & $(-198 \%)$ & $(-196 \%)$ \\
\hline \multirow{2}{*}{$\mathrm{N}_{2}-\mathrm{C}_{1}-\mathrm{N}_{1}-\mathrm{C}_{2}$} & \multirow{2}{*}{176.6} & 177.5 & 177.3 & 179.4 & 177.4 & 177.5 & 178.6 \\
\hline & & $(0.52 \%)$ & (0.41\%) & (1.6\%) & (0.45\%) & (0.49\%) & $(1.2 \%)$ \\
\hline \multirow{2}{*}{$\mathrm{N}_{2}-\mathrm{C}_{1}-\mathrm{N}_{1}-\mathrm{C}_{5}$} & \multirow{2}{*}{-6.9} & -2.1 & -2.3 & -0.8 & -2.2 & 4.0 & 10.4 \\
\hline & & $(-70 \%)$ & $(-67 \%)$ & $(-89.94 \%)$ & $(-68.1 \%)$ & $(-159 \%)$ & $(-251 \%)$ \\
\hline
\end{tabular}


Table S8. Benchmark Study of 5c, Round 2

Main group elements: def2-TZVPP basis set

\section{Au: CEP-31G effective core potential/basis set combination}

Percent error between calculated structural parameters and X-ray values shown in parentheses.

\begin{tabular}{|c|c|c|c|c|c|c|c|}
\hline Distance & X-Ray & B3LYP & B3PW91 & BP86 & B3Р86 & M06 & B97D \\
\hline \multirow{2}{*}{$\mathrm{Au}-\mathrm{C}_{1}$} & \multirow{2}{*}{2.006} & 2.039 & 2.017 & 2.016 & 2.012 & 2.057 & 2.037 \\
\hline & & (1.62\%) & $(0.53 \%)$ & $(0.48 \%)$ & $(0.32 \%)$ & $(2.52 \%)$ & (1.54\%) \\
\hline \multirow{2}{*}{$\mathrm{Au}-\mathrm{Cl}$} & \multirow{2}{*}{2.292} & 2.313 & 2.291 & 2.301 & 2.286 & 2.309 & 2.313 \\
\hline & & $(0.91 \%)$ & $(-0.03 \%)$ & (0.38\%) & $(-0.24 \%)$ & $(0.73 \%)$ & (0.90\%) \\
\hline \multirow{2}{*}{$\mathrm{C}_{1}-\mathrm{N}_{1}$} & \multirow{2}{*}{1.334} & 1.339 & 1.336 & 1.350 & 1.335 & 1.332 & 1.346 \\
\hline & & $(0.38 \%)$ & $(0.18 \%)$ & (1.21\%) & $(0.04 \%)$ & $(-0.13 \%)$ & $(0.89 \%)$ \\
\hline \multirow{2}{*}{$\mathrm{C}_{1}-\mathrm{N}_{2}$} & \multirow{2}{*}{1.348} & 1.348 & 1.346 & 1.359 & 1.344 & 1.341 & 1.356 \\
\hline & & $(0.03 \%)$ & $(-0.16 \%)$ & $(0.83 \%)$ & $(-0.28 \%)$ & $(-0.53 \%)$ & $(0.61 \%)$ \\
\hline Angles & X-Ray & B3LYP & B3PW91 & BP86 & B3Р86 & M06 & B97D \\
\hline \multirow{2}{*}{$\mathrm{C}_{1}-\mathrm{Au}-\mathrm{Cl}$} & \multirow{2}{*}{178.3} & 178.8 & 178.8 & 178.8 & 178.9 & 179.1 & 177.6 \\
\hline & & $(0.28 \%)$ & $(0.28 \%)$ & $(0.27 \%)$ & $(0.33 \%)$ & $(0.45 \%)$ & $(-0.42 \%)$ \\
\hline \multirow{2}{*}{$\mathrm{N}_{1}-\mathrm{C}_{1}-\mathrm{N}_{2}$} & \multirow{2}{*}{117.7} & 115.3 & 115.0 & 114.7 & 114.9 & 115.8 & 115.3 \\
\hline & & $(-2.06 \%)$ & $(-2.31 \%)$ & $(-2.54 \%)$ & $(-2.35 \%)$ & $(-1.64 \%)$ & $(-2.00 \%)$ \\
\hline \multirow{2}{*}{$\mathrm{Au}-\mathrm{C}_{1}-\mathrm{N}_{1}$} & \multirow{2}{*}{121.7} & 122.4 & 122.4 & 122.1 & 122.4 & 123.3 & 123.7 \\
\hline & & (0.59\%) & $(0.56 \%)$ & $(0.30 \%)$ & $(0.54 \%)$ & (1.34\%) & (1.67\%) \\
\hline \multirow{2}{*}{$\mathrm{Au}-\mathrm{C}_{1}-\mathrm{N}_{2}$} & \multirow{2}{*}{120.6} & 122.3 & 122.6 & 123.2 & 122.7 & 120.9 & 120.7 \\
\hline & & $(1.38 \%)$ & $(1.65 \%)$ & $(2.15 \%)$ & $(1.72 \%)$ & $(0.21 \%)$ & $(0.10 \%)$ \\
\hline $\begin{array}{c}\text { Torsion } \\
\text { Angles }\end{array}$ & X-Ray & B3LYP & B3PW91 & BP86 & B3P86 & M06 & B97D \\
\hline \multirow{2}{*}{$\mathrm{N}_{1}-\mathrm{C}_{1}-\mathrm{N}_{2}-\mathrm{C}_{11}$} & \multirow{2}{*}{176.4} & 178.4 & 178.3 & 177.6 & 179.0 & -167.9 & -165.9 \\
\hline & & (1.12\%) & (1.06\%) & $(0.69 \%)$ & $(1.47 \%)$ & $(-195 \%)$ & $(-194 \%)$ \\
\hline \multirow{2}{*}{$\mathrm{N}_{2}-\mathrm{C}_{1}-\mathrm{N}_{1}-\mathrm{C}_{2}$} & \multirow{2}{*}{176.6} & 177.9 & 177.7 & 177.2 & 177.9 & 174.0 & -179.9 \\
\hline & & $(0.76 \%)$ & (0.64\%) & $(0.35 \%)$ & $(0.75 \%)$ & $(-1.5 \%)$ & $(-202 \%)$ \\
\hline \multirow{2}{*}{$\mathrm{N}_{2}-\mathrm{C}_{1}-\mathrm{N}_{1}-\mathrm{C}_{5}$} & \multirow{2}{*}{-6.9} & -1.4 & -1.6 & -2.0 & -1.4 & 4.6 & 11.4 \\
\hline & & $(-80 \%)$ & $(-77 \%)$ & $(-70 \%)$ & $(-79 \%)$ & $(-167 \%)$ & $(-266 \%)$ \\
\hline
\end{tabular}


Table S9. Benchmark Study of 5c, Round 3

Main group elements: def2-TZVPP basis set Au: Stuttgart 60-core-electron effective core potential/basis set combination (MWB60)

Percent error between calculated structural parameters and X-ray values shown in parentheses.

\begin{tabular}{|c|c|c|c|c|c|c|c|}
\hline Distance & X-Ray & B3LYP & B3PW91 & BP86 & B3Р86 & M06 & $B 97 D^{a}$ \\
\hline \multirow{2}{*}{$\mathrm{Au}-\mathrm{C}_{1}$} & \multirow{2}{*}{2.006} & 2.038 & 2.017 & 2.016 & 2.013 & 2.056 & \\
\hline & & (1.60\%) & $(0.53 \%)$ & $(0.48 \%)$ & $(0.32 \%)$ & $(2.48 \%)$ & \\
\hline \multirow{2}{*}{$\mathrm{Au}-\mathrm{Cl}$} & \multirow{2}{*}{2.292} & 2.307 & 2.286 & 2.295 & 2.281 & 2.304 & \\
\hline & & $(0.67 \%)$ & $(-0.26 \%)$ & $(0.13 \%)$ & $(-0.48 \%)$ & $(0.52 \%)$ & \\
\hline \multirow{2}{*}{$\mathrm{C}_{1}-\mathrm{N}_{1}$} & \multirow{2}{*}{1.334} & 1.339 & 1.337 & 1.351 & 1.335 & 1.332 & \\
\hline & & $(0.40 \%)$ & $(0.20 \%)$ & (1.24\%) & $(0.06 \%)$ & $(-0.11 \%)$ & \\
\hline \multirow{2}{*}{$\mathrm{C}_{1}-\mathrm{N}_{2}$} & \multirow{2}{*}{1.348} & 1.349 & 1.346 & 1.360 & 1.344 & 1.341 & \\
\hline & & $(0.05 \%)$ & $(-0.15 \%)$ & $(0.86 \%)$ & $(-0.27 \%)$ & $(-0.54 \%)$ & \\
\hline Angles & X-Ray & B3LYP & B3PW91 & BP86 & B3P86 & M06 & B97D \\
\hline \multirow{2}{*}{$\mathrm{C}_{1}-\mathrm{Au}-\mathrm{Cl}$} & \multirow{2}{*}{178.3} & 178.8 & 178.7 & 178.7 & 178.8 & 178.9 & \\
\hline & & $(0.26 \%)$ & $(0.25 \%)$ & $(0.22 \%)$ & $(0.30 \%)$ & $(0.34 \%)$ & \\
\hline \multirow{2}{*}{$\mathrm{N}_{1}-\mathrm{C}_{1}-\mathrm{N}_{2}$} & \multirow{2}{*}{117.7} & 115.2 & 114.9 & 114.7 & 114.9 & 115.7 & \\
\hline & & $(-2.11 \%)$ & $(-2.34 \%)$ & $(-2.58 \%)$ & $(-2.38 \%)$ & $(-1.72 \%)$ & \\
\hline \multirow{2}{*}{$\mathrm{Au}-\mathrm{C}_{1}-\mathrm{N}_{1}$} & \multirow{2}{*}{121.7} & 122.5 & 122.5 & 122.2 & 122.4 & 123.3 & \\
\hline & & (0.64\%) & (0.62\%) & $(0.41 \%)$ & $(0.59 \%)$ & (1.29\%) & \\
\hline \multirow{2}{*}{$\mathrm{Au}-\mathrm{C}_{1}-\mathrm{N}_{2}$} & \multirow{2}{*}{120.6} & 122.3 & 122.6 & 123.1 & 122.6 & 121.0 & \\
\hline & & $(1.37 \%)$ & (1.62\%) & $(2.08 \%)$ & (1.69\%) & $(0.33 \%)$ & \\
\hline $\begin{array}{c}\text { Torsion } \\
\text { Angles } \\
\end{array}$ & X-Ray & B3LYP & B3PW91 & BP86 & B3P86 & M06 & $B 97 D^{a}$ \\
\hline \multirow{2}{*}{$N_{1}-C_{1}-N_{2}-C_{11}$} & \multirow{2}{*}{176.4} & 178.4 & 178.2 & 177.6 & 179.0 & -168.8 & \\
\hline & & (1.11\%) & (1.04\%) & $(.67 \%)$ & (1.47\%) & $(-196 \%)$ & \\
\hline \multirow{2}{*}{$\mathrm{N}_{2}-\mathrm{C}_{1}-\mathrm{N}_{1}-\mathrm{C}_{2}$} & \multirow{2}{*}{176.6} & 177.9 & 177.7 & 177.2 & 177.9 & 175.2 & \\
\hline & & $(0.72 \%)$ & (0.61\%) & $(0.32 \%)$ & $(0.73 \%)$ & $(-0.77 \%)$ & \\
\hline \multirow{2}{*}{$\mathrm{N}_{2}-\mathrm{C}_{1}-\mathrm{N}_{1}-\mathrm{C}_{5}$} & \multirow{2}{*}{-6.9} & -1.5 & -1.7 & -2.2 & -1.5 & 4.6 & \\
\hline & & $(-78 \%)$ & $(-75 \%)$ & $(-68 \%)$ & $(-78 \%)$ & $(-166 \%)$ & \\
\hline
\end{tabular}

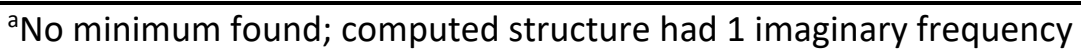


Table S10. Benchmark Study of 5c, Round 4

\section{Main group elements: Pople 6-31G(d) basis set Au: CEP-31G effective core potential/basis set combination}

Percent error between calculated structural parameters and X-ray values shown in parentheses.

\begin{tabular}{|c|c|c|c|c|c|c|c|}
\hline Distance & X-Ray & B3LYP & B3PW91 & BP86 & B3P86 & $\mathrm{M06}^{\mathrm{a}}$ & B97D \\
\hline \multirow{2}{*}{$A u-C_{1}$} & \multirow{2}{*}{2.006} & 2.049 & 2.029 & 2.026 & 2.024 & & 2.048 \\
\hline & & $(2.13 \%)$ & (1.12\%) & (0.98\%) & $(0.89 \%)$ & & (2.10\%) \\
\hline \multirow{2}{*}{$\mathrm{Au}-\mathrm{Cl}$} & \multirow{2}{*}{2.292} & 2.328 & 2.308 & 2.317 & 2.303 & & 2.329 \\
\hline & & (1.55\%) & $(0.69 \%)$ & (1.11\%) & $(0.46 \%)$ & & (1.63\%) \\
\hline \multirow{2}{*}{$\mathrm{C}_{1}-\mathrm{N}_{1}$} & \multirow{2}{*}{1.334} & 1.346 & 1.343 & 1.357 & 1.341 & & 1.353 \\
\hline & & $(0.92 \%)$ & $(0.69 \%)$ & $(1.75 \%)$ & $(0.56 \%)$ & & $(1.41 \%)$ \\
\hline \multirow{2}{*}{$\mathrm{C}_{1}-\mathrm{N}_{2}$} & \multirow{2}{*}{1.348} & 1.354 & 1.351 & 1.365 & 1.350 & & 1.362 \\
\hline & & $(0.45 \%)$ & $(0.24 \%)$ & (1.25\%) & $(0.12 \%)$ & & $(1.07 \%)$ \\
\hline Angles & X-Ray & B3LYP & B3PW91 & BP86 & B3P86 & $\mathrm{M06}^{\mathrm{a}}$ & B97D \\
\hline \multirow{2}{*}{$\mathrm{C}_{1}-\mathrm{Au}-\mathrm{Cl}$} & \multirow{2}{*}{178.3} & 178.8 & 178.8 & 178.7 & 178.9 & & 177.8 \\
\hline & & $(0.28 \%)$ & $(0.25 \%)$ & $(0.23 \%)$ & $(0.31 \%)$ & & $(-0.27 \%)$ \\
\hline \multirow{2}{*}{$N_{1}-C_{1}-N_{2}$} & \multirow{2}{*}{117.7} & 115.2 & 115.0 & 114.7 & 115.0 & & 115.3 \\
\hline & & $(-2.15 \%)$ & $(-2.26 \%)$ & $(-2.56 \%)$ & $(-2.31 \%)$ & & $(-2.00 \%)$ \\
\hline \multirow{2}{*}{$\mathrm{Au}-\mathrm{C}_{1}-\mathrm{N}_{1}$} & \multirow{2}{*}{121.7} & 122.6 & 122.5 & 122.3 & 122.5 & & 123.9 \\
\hline & & $(0.71 \%)$ & $(0.67 \%)$ & $(0.45 \%)$ & (0.64\%) & & $(1.82 \%)$ \\
\hline \multirow{2}{*}{$\mathrm{Au}-\mathrm{C}_{1}-\mathrm{N}_{2}$} & \multirow{2}{*}{120.6} & 122.2 & 122.4 & 123.0 & 122.5 & & 120.6 \\
\hline & & $(1.35 \%)$ & $(1.50 \%)$ & $(2.02 \%)$ & (1.59\%) & & $(-0.03 \%)$ \\
\hline $\begin{array}{c}\text { Torsion } \\
\text { Angles }\end{array}$ & X-Ray & B3LYP & B3PW91 & BP86 & B3P86 & $\mathrm{M06}^{\mathrm{a}}$ & B97D \\
\hline \multirow{2}{*}{$\mathrm{N}_{1}-\mathrm{C}_{1}-\mathrm{N}_{2}-\mathrm{C}_{11}$} & \multirow{2}{*}{176.4} & 179.3 & 178.8 & 178.2 & 179.7 & & -164.8 \\
\hline & & (1.65\%) & $(1.37 \%)$ & (1.03\%) & (1.86\%) & & $(-193 \%)$ \\
\hline \multirow{2}{*}{$\mathrm{N}_{2}-\mathrm{C}_{1}-\mathrm{N}_{1}-\mathrm{C}_{2}$} & \multirow{2}{*}{176.6} & 177.9 & 177.5 & 177.0 & 177.8 & & 179.7 \\
\hline & & $(.72 \%)$ & $(.53 \%)$ & $(.24 \%)$ & (.69\%) & & $(1.8 \%)$ \\
\hline \multirow{2}{*}{$\mathrm{N}_{2}-\mathrm{C}_{1}-\mathrm{N}_{1}-\mathrm{C}_{5}$} & \multirow{2}{*}{-6.9} & -1.4 & -1.8 & -2.1 & -1.4 & & 11.9 \\
\hline & & $(-79 \%)$ & $(-75 \%)$ & $(-69 \%)$ & $(-79 \%)$ & & $(-273 \%)$ \\
\hline
\end{tabular}

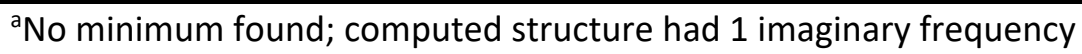


Table S11. Benchmark Study of 5c, Round 5

\section{Main group elements: Pople 6-311G(d) basis set Au: CEP-31G effective core potential/basis set combination}

Percent error between calculated structural parameters and X-ray values shown in parentheses.

\begin{tabular}{|c|c|c|c|c|c|c|c|}
\hline Distance & X-Ray & B3LYP & B3PW91 & BP86 & B3P86 & M06 & $B 97 D^{a}$ \\
\hline \multirow{2}{*}{$\mathrm{Au}-\mathrm{C}_{1}$} & \multirow{2}{*}{2.006} & 2.049 & 2.027 & 2.025 & 2.023 & 2.067 & \\
\hline & & (2.17\%) & (1.06\%) & $(0.97 \%)$ & $(0.83 \%)$ & (3.03\%) & \\
\hline \multirow{2}{*}{$\mathrm{Au}-\mathrm{Cl}$} & \multirow{2}{*}{2.292} & 2.336 & 2.314 & 2.325 & 2.308 & 2.328 & \\
\hline & & (1.92\%) & (0.94\%) & (1.44\%) & $(0.72 \%)$ & (1.55\%) & \\
\hline \multirow{2}{*}{$\mathrm{C}_{1}-\mathrm{N}_{1}$} & \multirow{2}{*}{1.334} & 1.343 & 1.340 & 1.354 & 1.338 & 1.336 & \\
\hline & & $(0.66 \%)$ & (0.44\%) & (1.48\%) & $(0.31 \%)$ & $(0.12 \%)$ & \\
\hline \multirow{2}{*}{$\mathrm{C}_{1}-\mathrm{N}_{2}$} & \multirow{2}{*}{1.348} & 1.352 & 1.349 & 1.363 & 1.348 & 1.344 & \\
\hline & & $(0.30 \%)$ & (0.10\%) & (1.09\%) & $(-0.03 \%)$ & $(-0.29 \%)$ & \\
\hline Angles & X-Ray & B3LYP & B3PW91 & BP86 & B3Р86 & M06 & $\mathrm{B}^{2} \mathrm{D}^{\mathrm{a}}$ \\
\hline \multirow{2}{*}{$\mathrm{C}_{1}-\mathrm{Au}-\mathrm{Cl}$} & \multirow{2}{*}{178.3} & 178.9 & 178.8 & 178.8 & 179.0 & 179.3 & \\
\hline & & $(0.33 \%)$ & $(0.30 \%)$ & $(0.30 \%)$ & $(0.37 \%)$ & (0.56\%) & \\
\hline \multirow{2}{*}{$\mathrm{N}_{1}-\mathrm{C}_{1}-\mathrm{N}_{2}$} & \multirow{2}{*}{117.7} & 115.4 & 115.2 & 115.0 & 115.2 & 116.0 & \\
\hline & & $(-1.92 \%)$ & $(-2.10 \%)$ & $(-2.33 \%)$ & $(-2.14 \%)$ & $(-1.44 \%)$ & \\
\hline \multirow{2}{*}{$\mathrm{Au}-\mathrm{C}_{1}-\mathrm{N}_{1}$} & \multirow{2}{*}{121.7} & 122.4 & 122.5 & 122.2 & 122.4 & 123.4 & \\
\hline & & (0.62\%) & (0.65\%) & (0.39\%) & (0.61\%) & (1.36\%) & \\
\hline \multirow[b]{2}{*}{$\mathrm{Au}-\mathrm{C}_{1}-\mathrm{N}_{2}$} & \multirow{2}{*}{120.6} & 122.1 & 122.3 & 122.8 & 122.3 & 120.6 & \\
\hline & & $(1.23 \%)$ & $(1.37 \%)$ & $(1.86 \%)$ & $(1.44 \%)$ & $(-0.01 \%)$ & \\
\hline $\begin{array}{l}\text { Torsion } \\
\text { Angles }\end{array}$ & X-Ray & B3LYP & B3PW91 & BP86 & B3Р86 & M06 & $B 97 D^{a}$ \\
\hline \multirow{2}{*}{$\mathrm{N}_{1}-\mathrm{C}_{1}-\mathrm{N}_{2}-\mathrm{C}_{11}$} & \multirow{2}{*}{176.4} & 178.5 & 178.4 & 177.7 & 179.2 & -167.2 & \\
\hline & & $(1.2 \%)$ & $(1.1 \%)$ & $(0.74 \%)$ & (1.6\%) & $(-195 \%)$ & \\
\hline \multirow{2}{*}{$\mathrm{N}_{2}-\mathrm{C}_{1}-\mathrm{N}_{1}-\mathrm{C}_{2}$} & \multirow{2}{*}{176.6} & 177.6 & 177.4 & 176.8 & 177.6 & 173.9 & \\
\hline & & (0.55\%) & $(0.44 \%)$ & (0.11\%) & (0.58\%) & $(-1.6 \%)$ & \\
\hline \multirow{2}{*}{$\mathrm{N}_{2}-\mathrm{C}_{1}-\mathrm{N}_{1}-\mathrm{C}_{5}$} & \multirow{2}{*}{-6.9} & -1.7 & -1.9 & -2.3 & -1.6 & 4.6 & \\
\hline & & $(-76 \%)$ & $(-73 \%)$ & $(-67 \%)$ & $(-77 \%)$ & $(-167 \%)$ & \\
\hline
\end{tabular}

${ }^{a}$ No minimum found; computed structure had 1 imaginary frequency 
Table S12. Benchmark Study of 5c, Round 6

\section{Main group elements: Pople 6-31+G(d) basis set Au: CEP-31G effective core potential/basis set combination}

Percent error between calculated structural parameters and X-ray values shown in parentheses.

M06 and B97D were not tested given their poor performance in previous rounds.

\begin{tabular}{|c|c|c|c|c|c|}
\hline Distance & X-Ray & B3LYP & B3PW91 & BP86 & B3P86 \\
\hline $\mathrm{Au}-\mathrm{C}_{1}$ & 2.006 & $\begin{array}{c}2.048 \\
(2.09 \%)\end{array}$ & $\begin{array}{c}2.027 \\
(1.05 \%)\end{array}$ & $\begin{array}{c}2.024 \\
(0.90 \%)\end{array}$ & $\begin{array}{c}2.022 \\
(0.80 \%)\end{array}$ \\
\hline $\mathrm{Au}-\mathrm{Cl}$ & 2.292 & $\begin{array}{c}2.332 \\
(1.75 \%)\end{array}$ & $\begin{array}{c}2.311 \\
(0.83 \%)\end{array}$ & $\begin{array}{c}2.321 \\
(1.28 \%)\end{array}$ & $\begin{array}{c}2.306 \\
(0.61 \%)\end{array}$ \\
\hline $\mathrm{C}_{1}-\mathrm{N}_{1}$ & 1.334 & $\begin{array}{c}1.346 \\
(0.90 \%)\end{array}$ & $\begin{array}{c}1.343 \\
(0.67 \%)\end{array}$ & $\begin{array}{c}1.357 \\
(1.75 \%)\end{array}$ & $\begin{array}{c}1.341 \\
(0.52 \%)\end{array}$ \\
\hline $\mathrm{C}_{1}-\mathrm{N}_{2}$ & 1.348 & $\begin{array}{c}1.356 \\
(0.59 \%)\end{array}$ & $\begin{array}{c}1.352 \\
(0.30 \%)\end{array}$ & $\begin{array}{c}1.366 \\
(1.36 \%)\end{array}$ & $\begin{array}{c}1.351 \\
(0.22 \%)\end{array}$ \\
\hline Angles & X-Ray & B3LYP & B3PW91 & BP86 & B3P86 \\
\hline $\mathrm{C}_{1}-\mathrm{Au}-\mathrm{Cl}$ & 178.3 & $\begin{array}{c}178.8 \\
(0.28 \%)\end{array}$ & $\begin{array}{c}178.7 \\
(0.22 \%)\end{array}$ & $\begin{array}{c}178.6 \\
(0.18 \%)\end{array}$ & $\begin{array}{c}178.8 \\
(0.28 \%)\end{array}$ \\
\hline $\mathrm{N}_{1}-\mathrm{C}_{1}-\mathrm{N}_{2}$ & 117.7 & $\begin{array}{c}115.4 \\
(-1.95 \%)\end{array}$ & $\begin{array}{c}115.2 \\
(-2.12 \%)\end{array}$ & $\begin{array}{c}114.9 \\
(-2.38 \%)\end{array}$ & $\begin{array}{c}115.2 \\
(-2.12 \%)\end{array}$ \\
\hline $\mathrm{Au}-\mathrm{C}_{1}-\mathrm{N}_{1}$ & 121.7 & $\begin{array}{c}122.7 \\
(0.82 \%)\end{array}$ & $\begin{array}{c}122.7 \\
(0.82 \%)\end{array}$ & $\begin{array}{c}122.4 \\
(0.61 \%)\end{array}$ & $\begin{array}{c}122.7 \\
(0.82 \%)\end{array}$ \\
\hline $\mathrm{Au}-\mathrm{C}_{1}-\mathrm{N}_{2}$ & 120.6 & $\begin{array}{c}121.9 \\
(1.08 \%)\end{array}$ & $\begin{array}{c}122.1 \\
(1.24 \%)\end{array}$ & $\begin{array}{c}122.6 \\
(1.67 \%)\end{array}$ & $\begin{array}{c}122.1 \\
(1.24 \%)\end{array}$ \\
\hline Torsion Angle & X-Ray & B3LYP & B3PW91 & BP86 & B3P86 \\
\hline $\mathrm{N}_{1}-\mathrm{C}_{1}-\mathrm{N}_{2}-\mathrm{C}_{11}$ & 176.4 & $\begin{array}{c}178.3 \\
(1.08 \%)\end{array}$ & $\begin{array}{c}178.2 \\
(1.02 \%)\end{array}$ & $\begin{array}{c}177.5 \\
(0.65 \%)\end{array}$ & $\begin{array}{c}179.2 \\
(1.59 \%)\end{array}$ \\
\hline $\mathrm{N}_{2}-\mathrm{C}_{1}-\mathrm{N}_{1}-\mathrm{C}_{2}$ & 176.6 & $\begin{array}{c}177.5 \\
(0.51 \%)\end{array}$ & $\begin{array}{c}177.3 \\
(0.40 \%)\end{array}$ & $\begin{array}{c}176.8 \\
(0.13 \%)\end{array}$ & $\begin{array}{c}177.6 \\
(0.57 \%) \\
\end{array}$ \\
\hline
\end{tabular}




\section{REFERENCES}

(1) Seo, H.; Roberts, B. P.; Abboud, K. A.; Merz, K. M., Jr.; Hong, S. Novel acyclic diaminocarbene ligands with increased steric demand and their application in gold catalysis. Org. Lett. 2010, 12, 4860-4863.

(2) Nishio, M.; Hirota, M.; Umezawa, Y. The CH/ $\pi$ Interaction: Evidence, Nature, and Consequences; Wiley-VCH: New York, 1998.

(3) Grimme, S.; Antony, J.; Ehrlich, S.; Krieg, H. A consistent and accurate ab initio parametrization of density functional dispersion correction (DFT-D) for the 94 elements H$\mathrm{Pu}$. The Journal of Chemical Physics 2010, 132, 154104.

(4) (a) Grimme, S.; Djukic, J.-P. Cation-Cation "Attraction": When London Dispersion Attraction Wins over Coulomb Repulsion. Inorganic Chemistry 2011, 50, 2619-2628. (b) Ehrlich, S.; Bettinger, H. F.; Grimme, S. Dispersion-Driven Conformational Isomerism in $\sigma$-Bonded Dimers of Larger Acenes. Angewandte Chemie International Edition 2013, 52, 10892-10895. (c) Guo, J.-D.; Liptrot, D. J.; Nagase, S.; Power, P. P. The multiple bonding in heavier group 14 element alkene analogues is stabilized mainly by dispersion force effects. Chemical Science 2015, 6, 6235-6244. (d) Schweighauser, L.; Strauss, M. A.; Bellotto, S.; Wegner, H. A. Attraction or Repulsion? London Dispersion Forces Control Azobenzene Switches. Angewandte Chemie International Edition 2015, 54, 13436-13439.

(5) Johnson, E. R.; Keinan, S.; Mori-Sánchez, P.; Contreras-García, J.; Cohen, A. J.; Yang, W. Revealing Noncovalent Interactions. J. Am. Chem. Soc. 2010, 132, 6498-6506.

(6) Contreras-García, J.; Johnson, E. R.; Keinan, S.; Chaudret, R.; Piquemal, J.-P.; Beratan, D. N.; Yang, W. NCIPLOT: A Program for Plotting Noncovalent Interaction Regions. $J$. Chem. Theory Comput. 2011, 7, 625-632.

(7) Blanco-Diaz, E. G.; Vazquez-Montelongo, E. A.; Cisneros, G. A.; Castrejon-Gonzalez, E. O. Computational investigation of non-covalent interactions in 1-butyl 3methylimidazolium/bis(trifluoromethylsulfonyl)imide [bmim][Tf2N] in EMD and NEMD. J. Chem. Phys. 2018, 148, 054303/1-054303/10.

(8) (a) Forlani, L.; Lunazzi, L.; Medici, A. Conformational studies by dynamic nuclear magnetic resonance Part XI. The detection of restricted rotation in 2-NNdimethylaminothiazoles. Tetrahedron Lett. 1977, 18, 4525-4526. (b) Alder, R. W.; Blake, M. E.; Oliva, J. M. Diaminocarbenes; calculations of barriers to rotation about $\mathrm{C}_{\text {carbene-N }} \mathrm{N}$ bonds, barriers to dimerization, proton affinities, and ${ }^{13} \mathrm{C}$ NMR shifts. J. Phys. Chem. A 1999, 103, 11200-11211.

(9) Hunter, C. A.; Sanders, J. K. M. The nature of $\pi-\pi$ interactions. J. Am. Chem. Soc 1990, $112,5525-5534$.

(10) (a) Bartolomé, C.; Ramiro, Z.; García-Cuadrado, D.; Pérez-Galán, P.; Raducan, M.; Bour, C.; Echavarren, A. M.; Espinet, P. Nitrogen acyclic gold(I) carbenes: Excellent and easily accessible catalysts in reactions of 1,6-enynes. Organometallics 2010, 29, 951-956. (b) Hashmi, A. S. K.; Hengst, T.; Lothschütz, C.; Rominger, F. New and easily accessible nitrogen acyclic gold(I) carbenes: Structures and application in the gold-catalyzed phenol synthesis as well as the hydration of alkynes. Adv. Synth. Catal. 2010, 352, 1315-1337. 
(11) Voliani, V. Gold Nanoparticles: An Introduction to Synthesis, Properties and Applications; De Gruyter: Berlin, 2020.

(12) APEX2, Version 2.0; Bruker AXS: Madison, WI, USA, 2007.

(13) SAINT; Bruker AXS: Madison, WI, USA, 2007.

(14) Sheldrick, G. M. SADABS, Version 2.10; Bruker AXS Inc.: Madison, WI, USA, 2000.

(15) Sheldrick, G. M. SHELXTL; Bruker AXS Inc.: Madison, WI, USA, 2008.

(16) Sheldrick, G. Crystal structure refinement with SHELXL. Acta Crystallogr., Sect. C: Struct. Chem. 2015, 71, 3-8.

(17) Schmidbaur, H.; Schier, A. A briefing on aurophilicity. Chem. Soc. Rev. 2008, 37, 19311951.

(18) Parsons, S. Introduction to twinning. Acta Crystallogr., Sect. D 2003, D59, 1995-2003.

(19) Sheldrick, G. M. TWINABS, Version 1.05; Bruker AXS: Madison, WI, USA, 2002.

(20) Leung, C. H.; Incarvito, C. D.; Crabtree, R. H. Interplay of Linker, N-Substituent, and Counterion Effects in the Formation and Geometrical Distortion of N-Heterocyclic Biscarbene Complexes of Rhodium(I). Organometallics 2006, 25, 6099-6107.

(21) Frisch, M. J.; Trucks, G. W.; Schlegel, H. B.; Scuseria, G. E.; Robb, M. A.; Cheeseman, J. R.; Scalmani, G.; Barone, V.; Mennucci, B.; Petersson, G. A.; Nakatsuji, H.; Caricato, M.; Li, X.; Hratchian, H. P.; Izmaylov, A. F.; Bloino, J.; Zheng, G.; Sonnenberg, J. L.; Hada, M.; Ehara, M.; Toyota, K.; Fukuda, R.; Hasegawa, J.; Ishida, M.; Nakajima, T.; Honda, Y.; Kitao, O.; Nakai, H.; Vreven, T.; Montgomery Jr., J. A.; Peralta, J. E.; Ogliaro, F.; Bearpark, M. J.; Heyd, J.; Brothers, E. N.; Kudin, K. N.; Staroverov, V. N.; Kobayashi, R.; Normand, J.; Raghavachari, K.; Rendell, A. P.; Burant, J. C.; Iyengar, S. S.; Tomasi, J.; Cossi, M.; Rega, N.; Millam, N. J.; Klene, M.; Knox, J. E.; Cross, J. B.; Bakken, V.; Adamo, C.; Jaramillo, J.; Gomperts, R.; Stratmann, R. E.; Yazyev, O.; Austin, A. J.; Cammi, R.; Pomelli, C.; Ochterski, J. W.; Martin, R. L.; Morokuma, K.; Zakrzewski, V. G.; Voth, G. A.; Salvador, P.; Dannenberg, J. J.; Dapprich, S.; Daniels, A. D.; Farkas, Ö.; Foresman, J. B.; Ortiz, J. V.; Cioslowski, J.; Fox, D. J. Gaussian 09, Revision D.01; Gaussian, Inc.: Wallingford, CT, USA, 2009.

(22) Grimme, S. Semiempirical GGA-type density functional constructed with a long-range dispersion correction. J. Comput. Chem. 2006, 27, 1787-1799.

(23) (a) Perdew, J. P. Density-functional approximation for the correlation energy of the inhomogeneous electron gas. Phys. Rev. B 1986, 33, 8822-8824. (b) Becke, A. D. Densityfunctional exchange-energy approximation with correct asymptotic behavior. Phys. Rev. A 1988, 38, 3098-3100.

(24) Hariharan, P. C.; Pople, J. A. Accuracy of $\mathrm{AH}_{\mathrm{n}}$ equilibrium geometries by single determinant molecular orbital theory. Mol. Phys. 1974, 27, 209-214.

(25) Krauss, M.; Stevens, W. J.; Basch, H.; Jasien, P. G. Relativistic compact effective potentials and efficient, shared-exponent basis-sets for the 3rd-row, 4th-row, and 5th-row elements. Can. J. Chem. 1992, 70, 612-630. 


\section{${ }^{1} \mathrm{H}$ AND ${ }^{13} \mathrm{C}$ NMR SPECTRA}

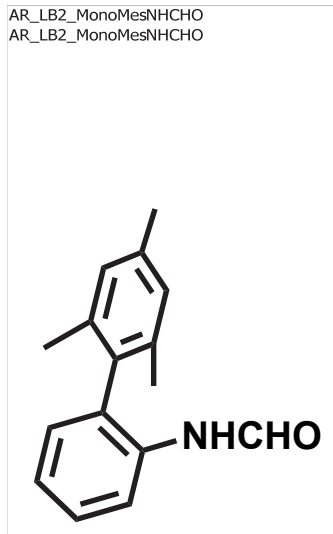

${ }^{1} \mathrm{H} N M R$

$\left(600 \mathrm{MHz}, \mathrm{CDCl}_{3}\right)$

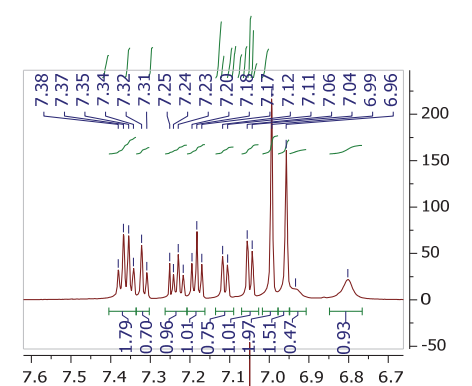

.
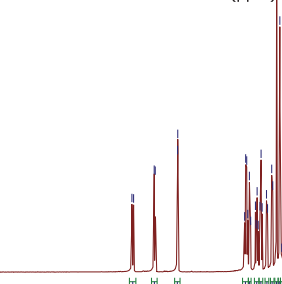

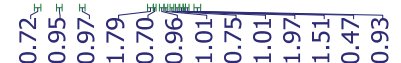

$\begin{array}{lllllllll}13 & 12 & 11 & 10 & 9 & 8 & 7 & \begin{array}{c}1 \\ \mathrm{f} 1(\mathrm{ppm})\end{array} & 5\end{array}$

Figure S28. ${ }^{1} \mathrm{H}$ NMR spectrum of $N-\left(2^{\prime}, 4^{\prime}, 6^{\prime}\right.$-trimethyl-[1,1'-biphenyl]-2-yl)formamide $\left(\mathrm{CDCl}_{3}\right)$.

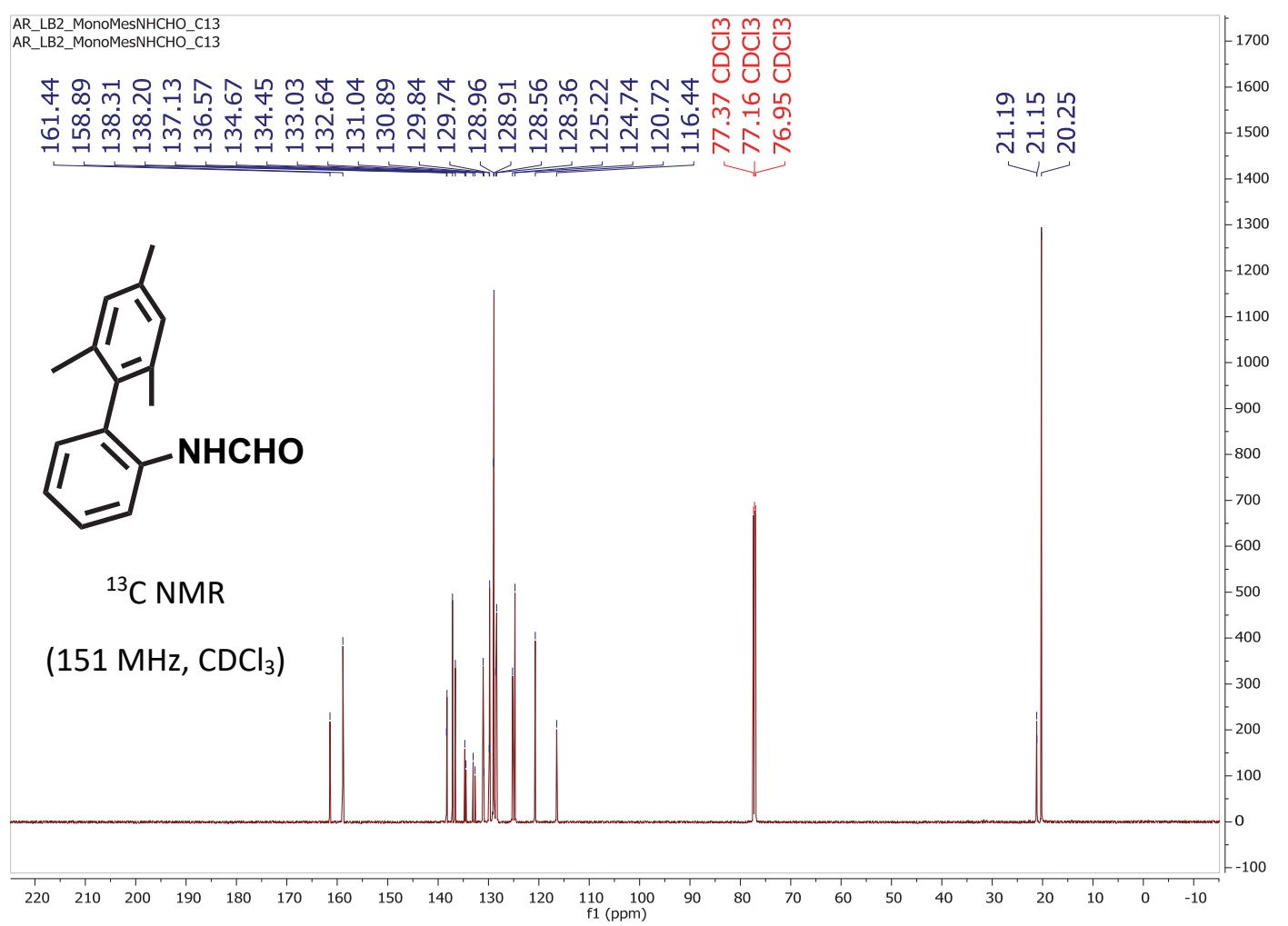

Figure S29. ${ }^{13} \mathrm{C}$ NMR spectrum of $N-\left(2^{\prime}, 4^{\prime}, 66^{\prime}\right.$-trimethyl-[1,1'-biphenyl]-2-yl)formamide $\left(\mathrm{CDCl}_{3}\right)$. 


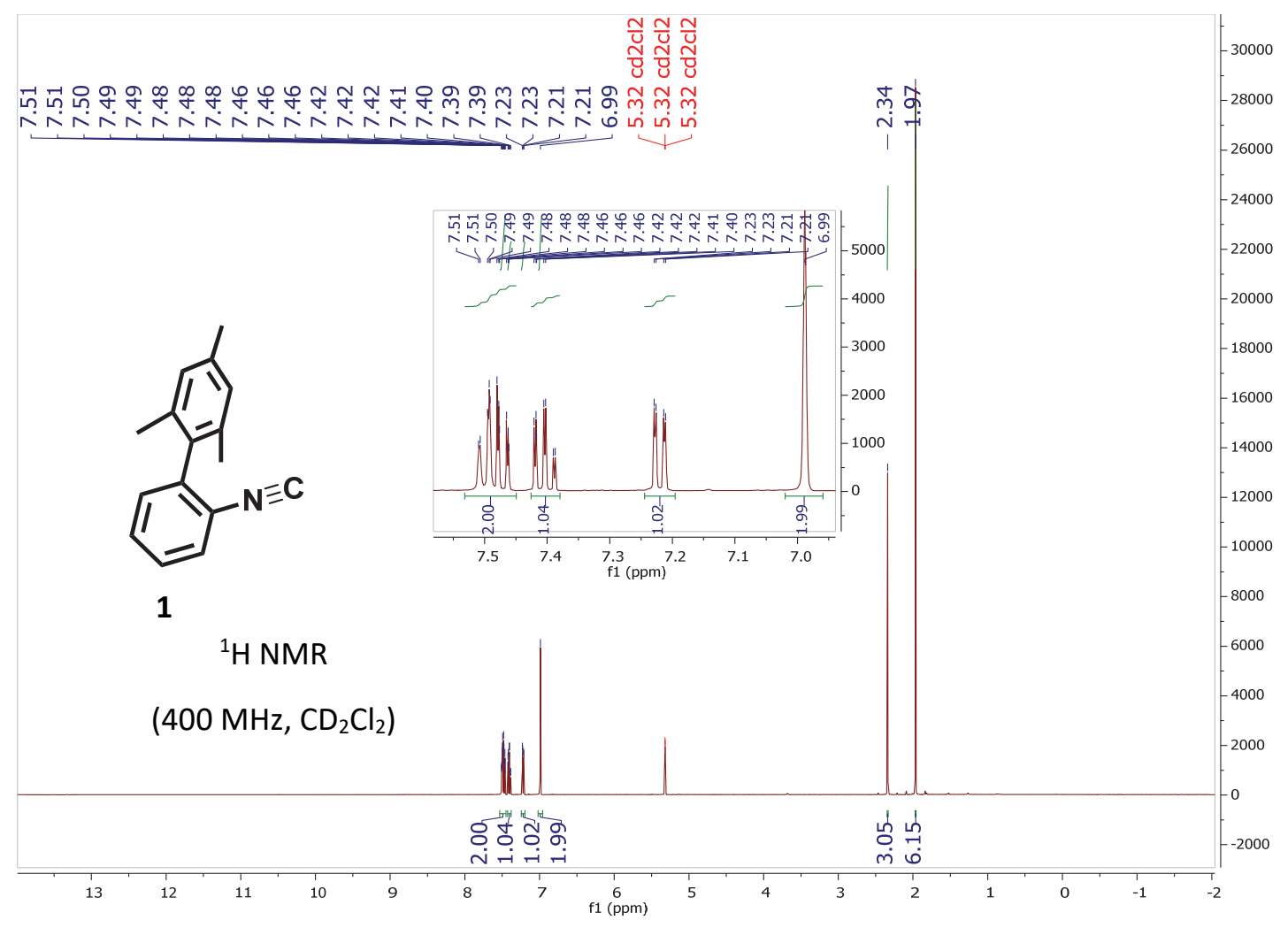

Figure S30. ${ }^{1} \mathrm{H}$ NMR spectrum of 2-mesitylphenylisocyanide (1) in $\mathrm{CD}_{2} \mathrm{Cl}_{2}$ at $400 \mathrm{MHz}$.

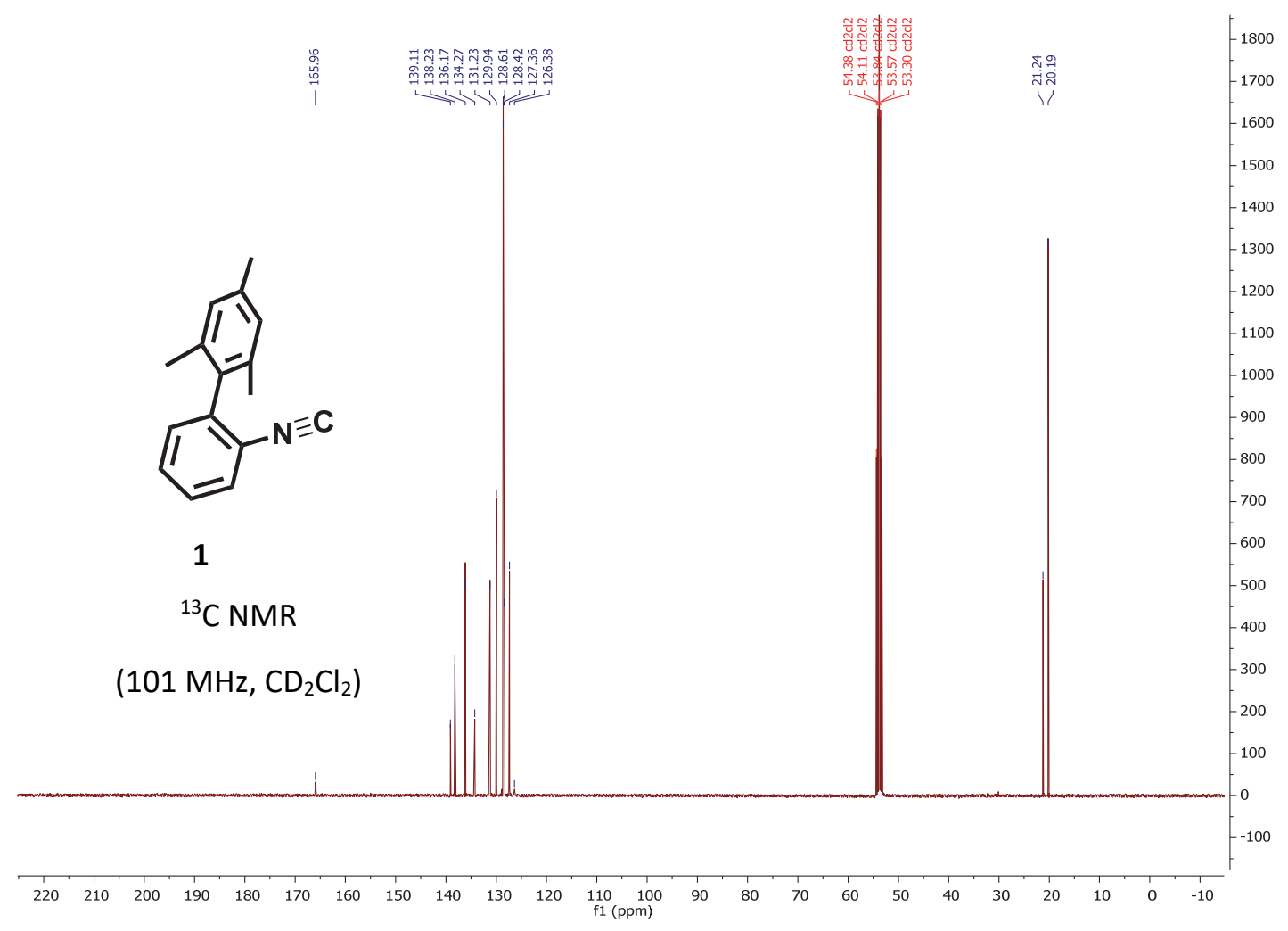

Figure S31. ${ }^{13} \mathrm{C}$ NMR spectrum of 2-mesitylphenylisocyanide (1) in $\mathrm{CD}_{2} \mathrm{Cl}_{2}$ at $101 \mathrm{MHz}$. 


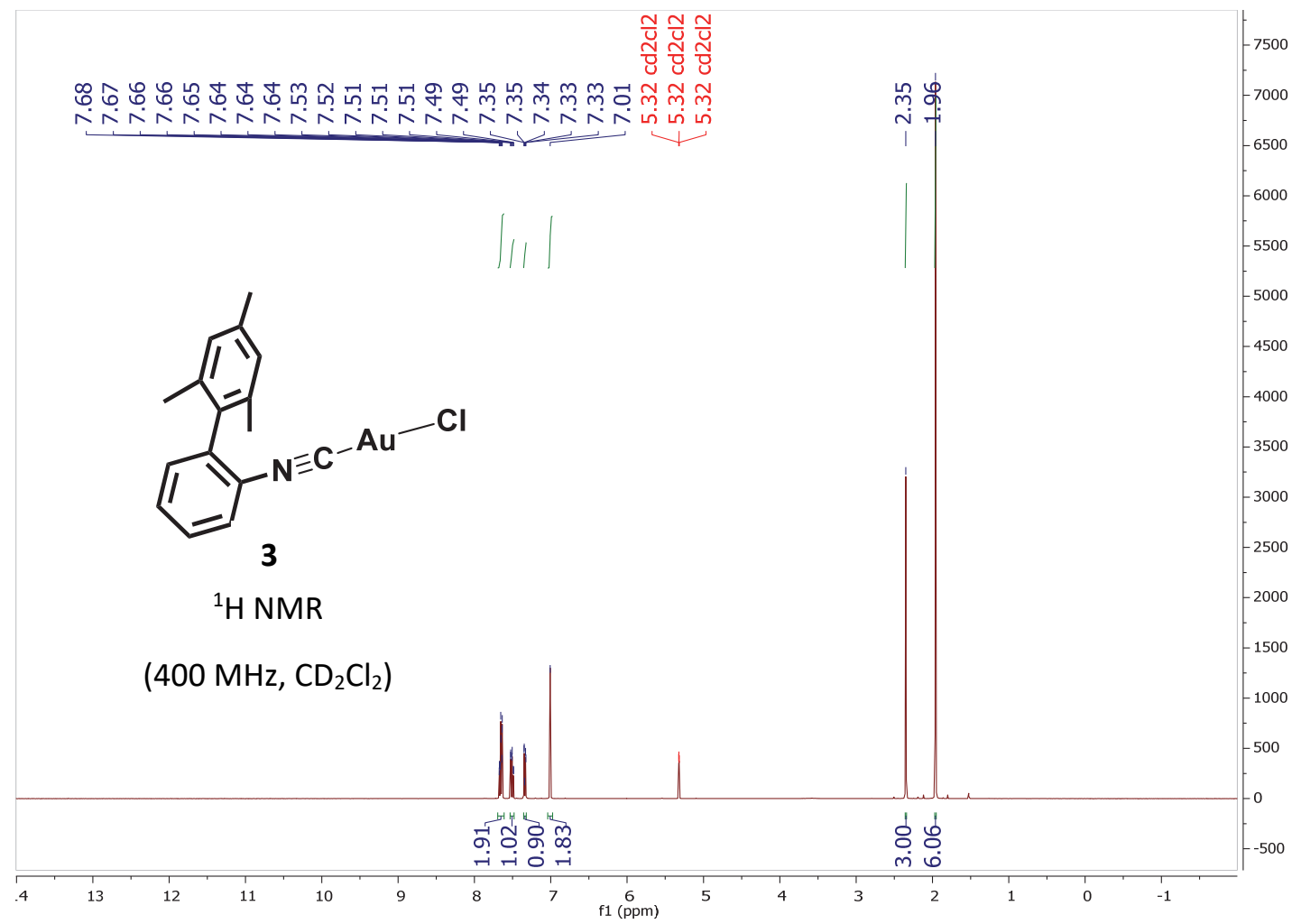

Figure S32. ${ }^{1} \mathrm{H}$ NMR spectrum of monomesityl isocyanide gold complex (3) in $\mathrm{CD}_{2} \mathrm{Cl}_{2}$ at $400 \mathrm{MHz}$.

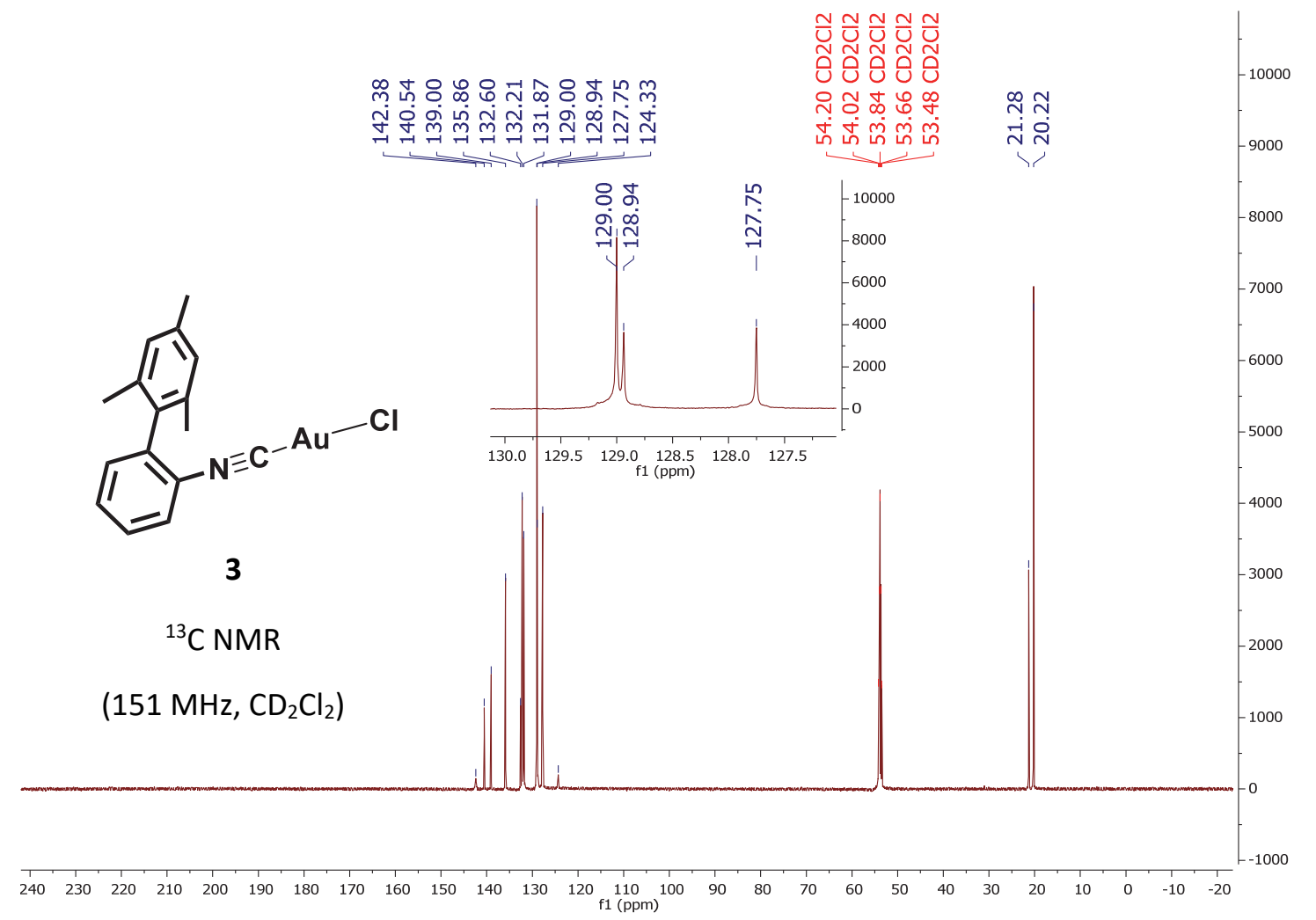

Figure S33. ${ }^{13} \mathrm{C}$ NMR spectrum of monomesityl isocyanide gold complex (3) in $\mathrm{CD}_{2} \mathrm{Cl}_{2}$ at $151 \mathrm{MHz}$. 


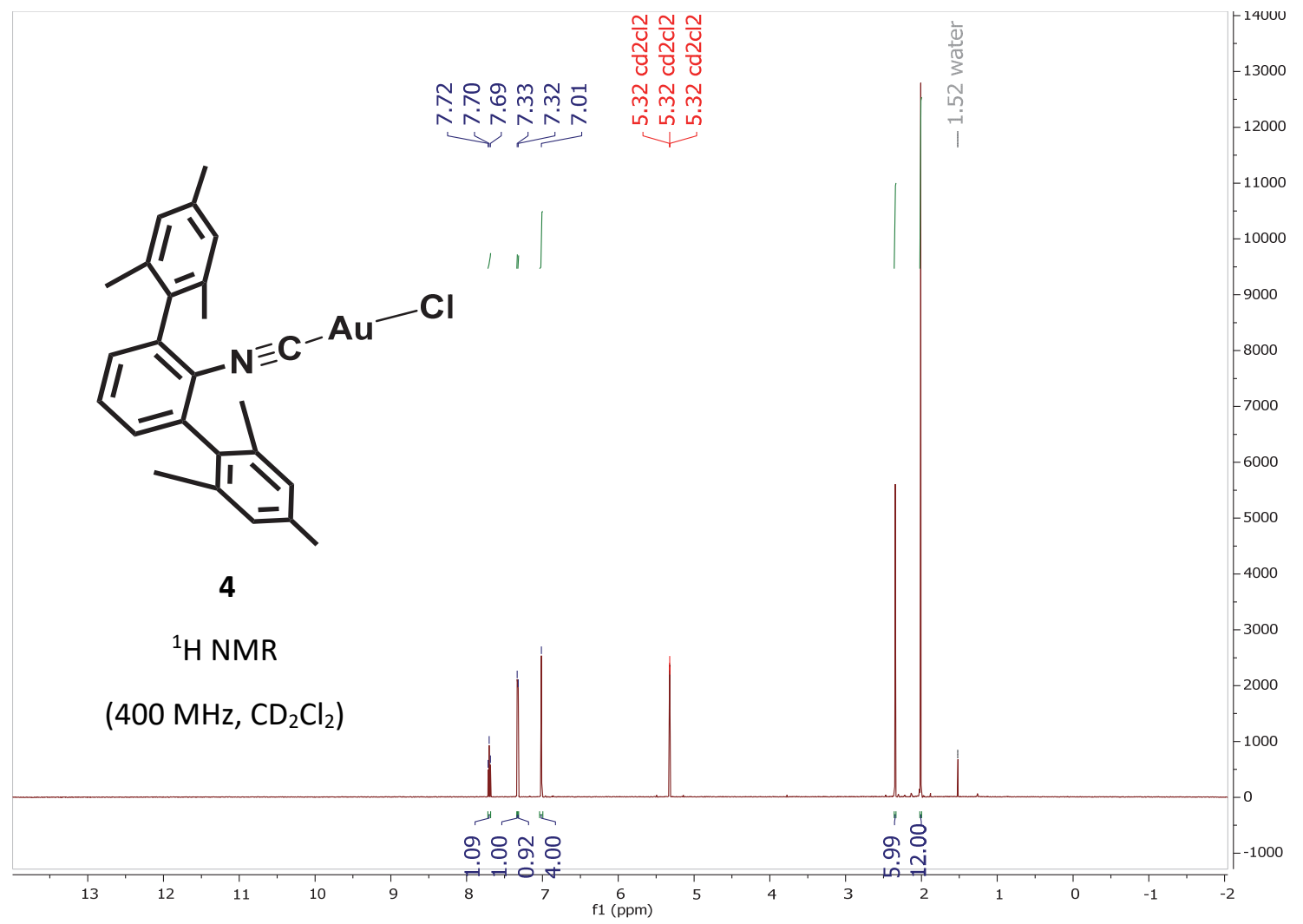

Figure S34. ${ }^{1} \mathrm{H}$ NMR spectrum of dimesityl isocyanide gold complex (4) in $\mathrm{CD}_{2} \mathrm{Cl}_{2}$ at $400 \mathrm{MHz}$.
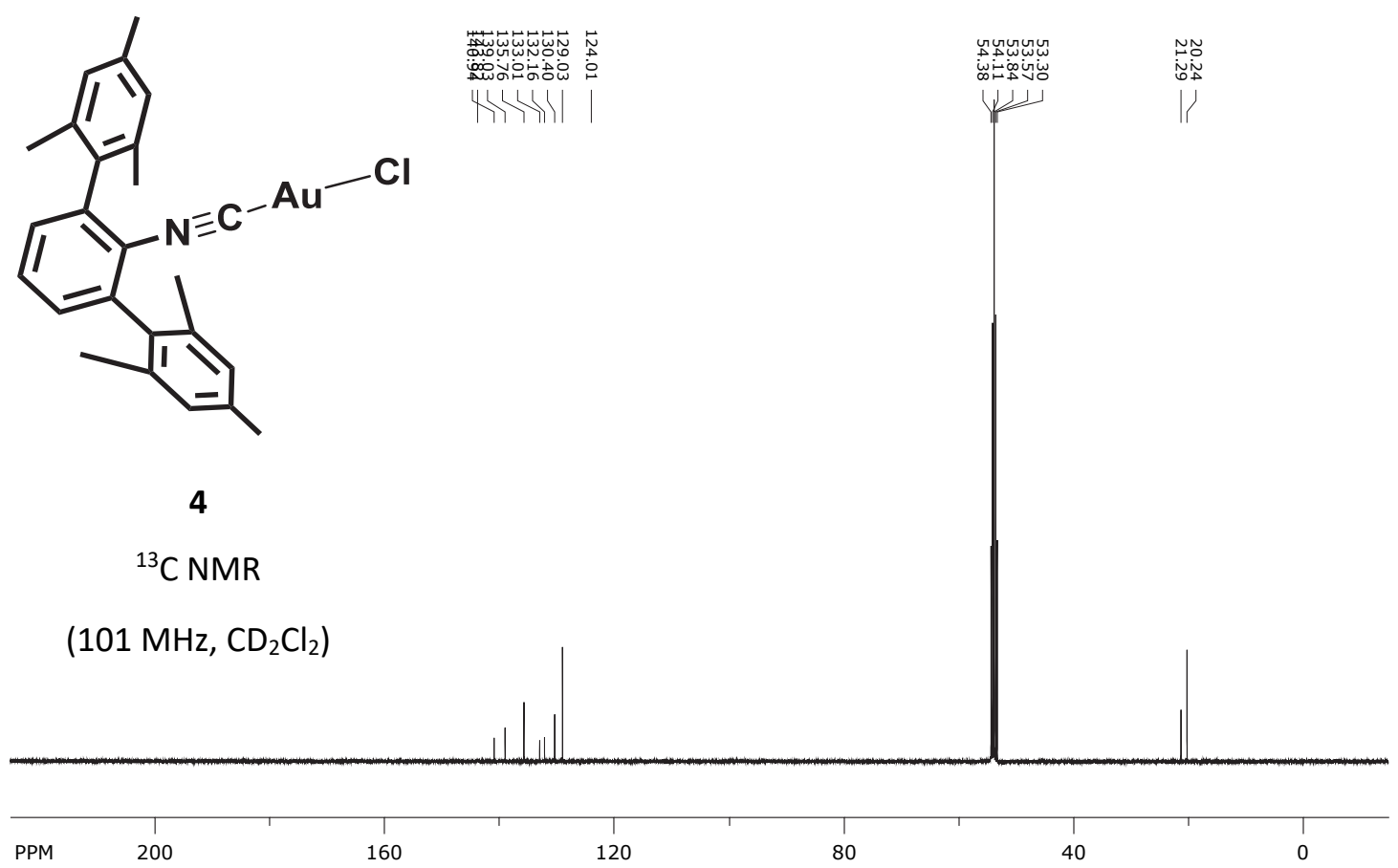

Figure S35. ${ }^{13} \mathrm{C}$ NMR spectrum of dimesityl isocyanide gold complex (4) in $\mathrm{CD}_{2} \mathrm{Cl}_{2}$ at $101 \mathrm{MHz}$. 


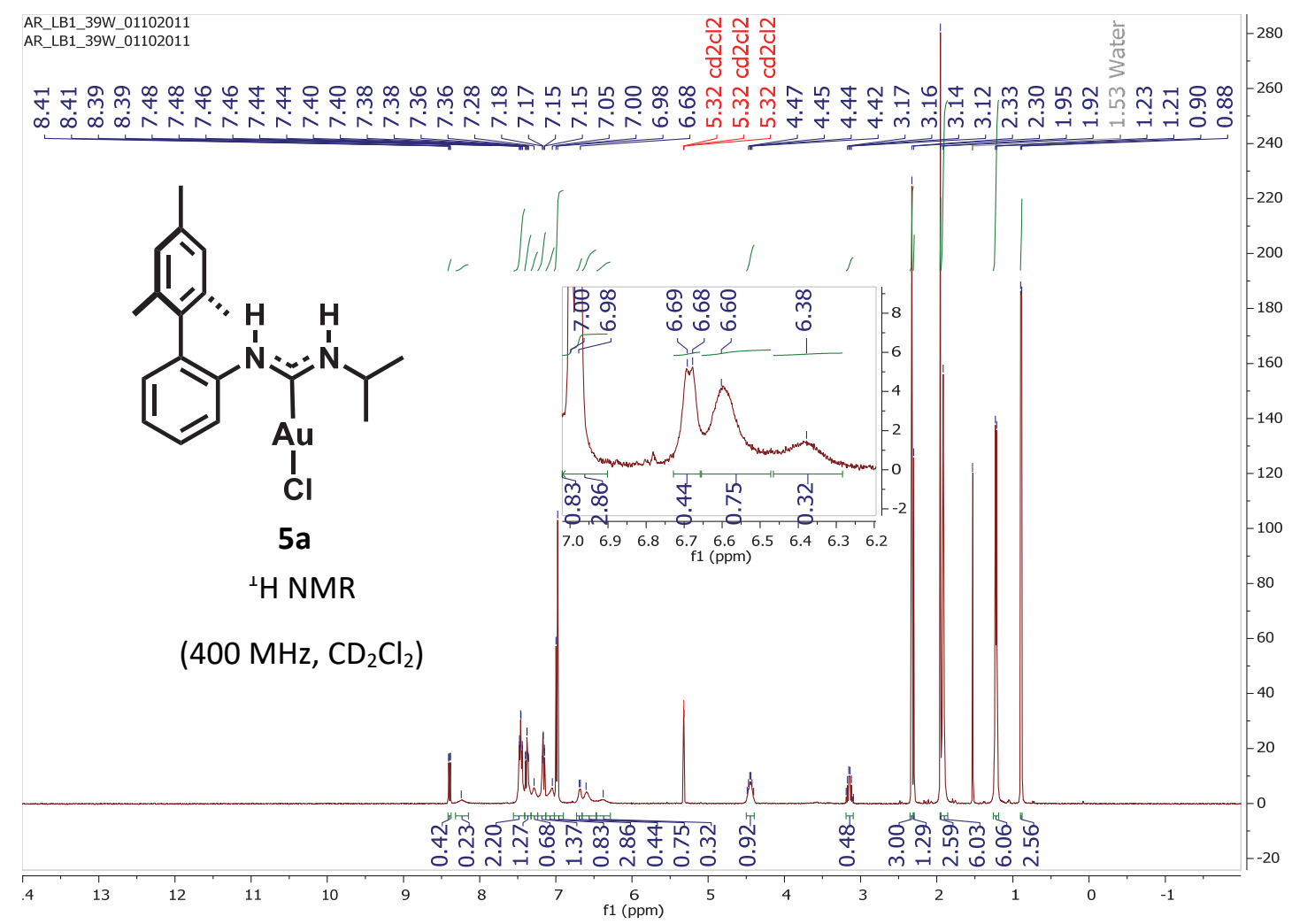

Figure S36. ${ }^{1} \mathrm{H}$ NMR spectrum of monomesityl $\mathrm{Au}(\mathrm{ADC}) \mathrm{Cl}$ complex 5a in $\mathrm{CD}_{2} \mathrm{Cl}_{2}$ at $400 \mathrm{MHz}$.

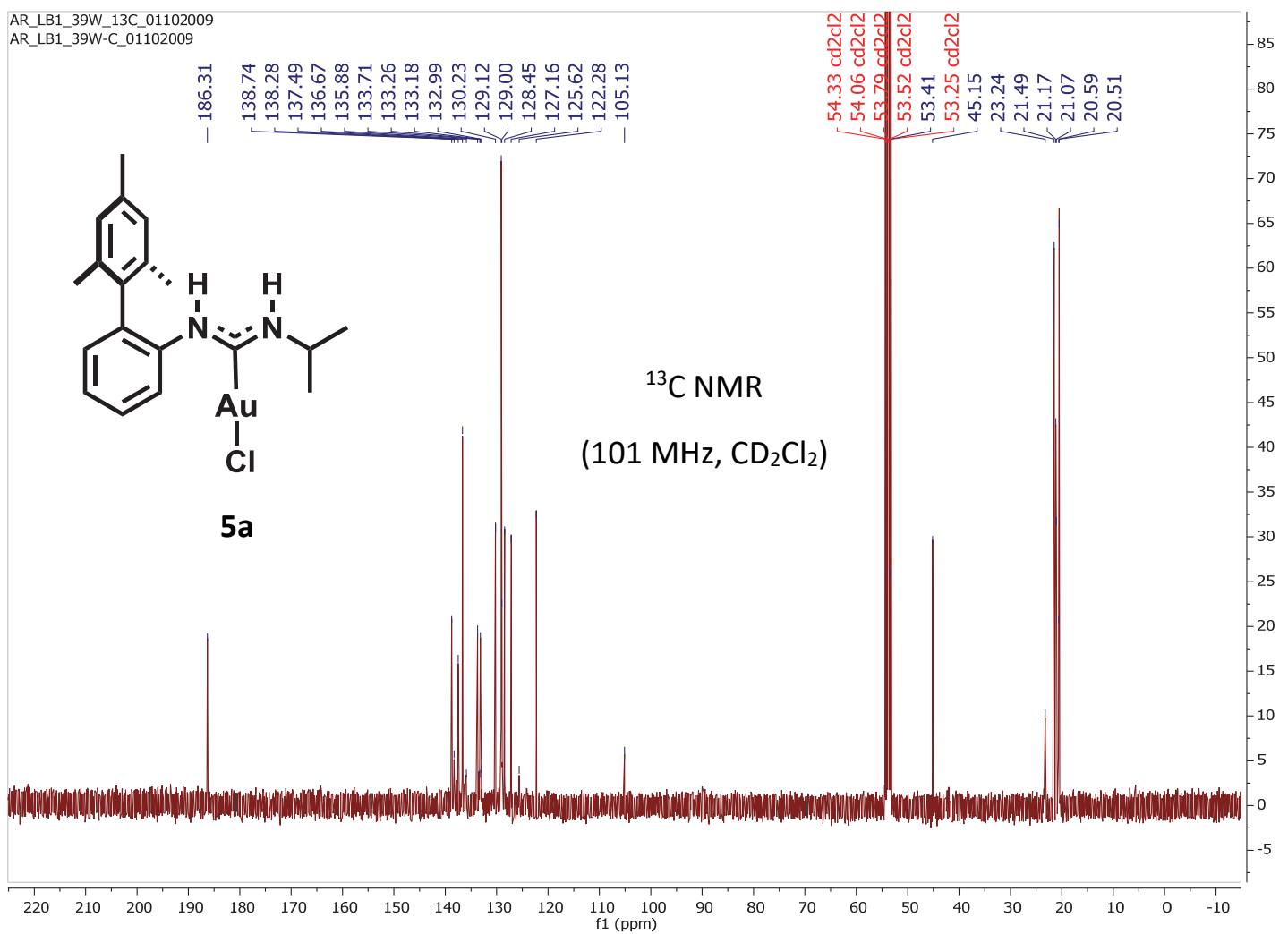

Figure S37. ${ }^{13} \mathrm{C}$ NMR spectrum of monomesityl $\mathrm{Au}(\mathrm{ADC}) \mathrm{Cl}$ complex 5a in $\mathrm{CD}_{2} \mathrm{Cl}_{2}$ at $101 \mathrm{MHz}$. 


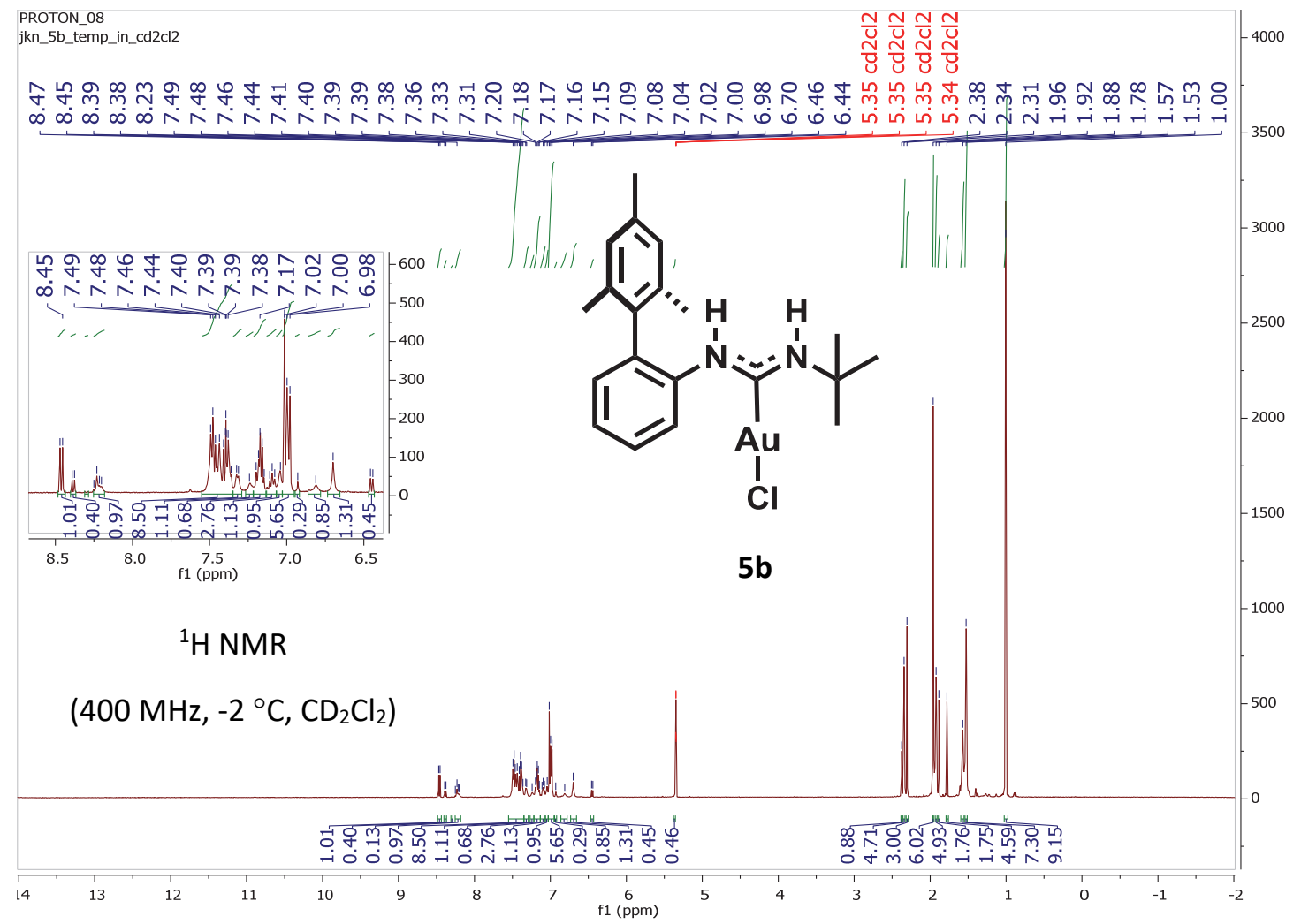

Figure S38. ${ }^{1} \mathrm{H}$ NMR spectrum of monomesityl $\mathrm{Au}(\mathrm{ADC}) \mathrm{Cl}$ complex $\mathbf{5 b}$ in $\mathrm{CD}_{2} \mathrm{Cl}_{2}$ at $400 \mathrm{MHz},-2^{\circ} \mathrm{C}$.

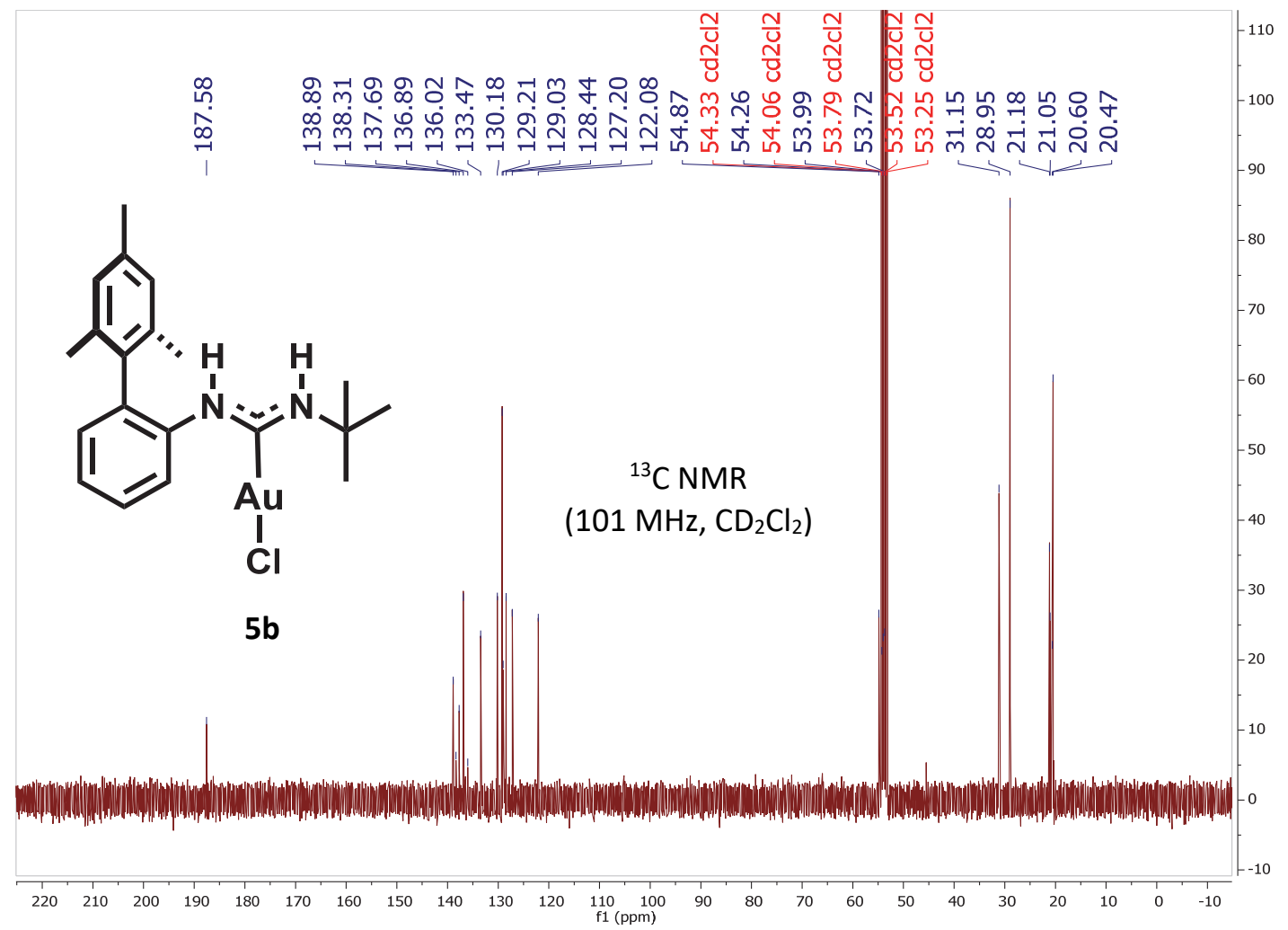

Figure S39. ${ }^{13} \mathrm{C}$ NMR spectrum of monomesityl $\mathrm{Au}(\mathrm{ADC}) \mathrm{Cl}$ complex $\mathbf{5 b}$ in $\mathrm{CD}_{2} \mathrm{Cl}_{2}$ at $101 \mathrm{MHz}, 25^{\circ} \mathrm{C}$. 


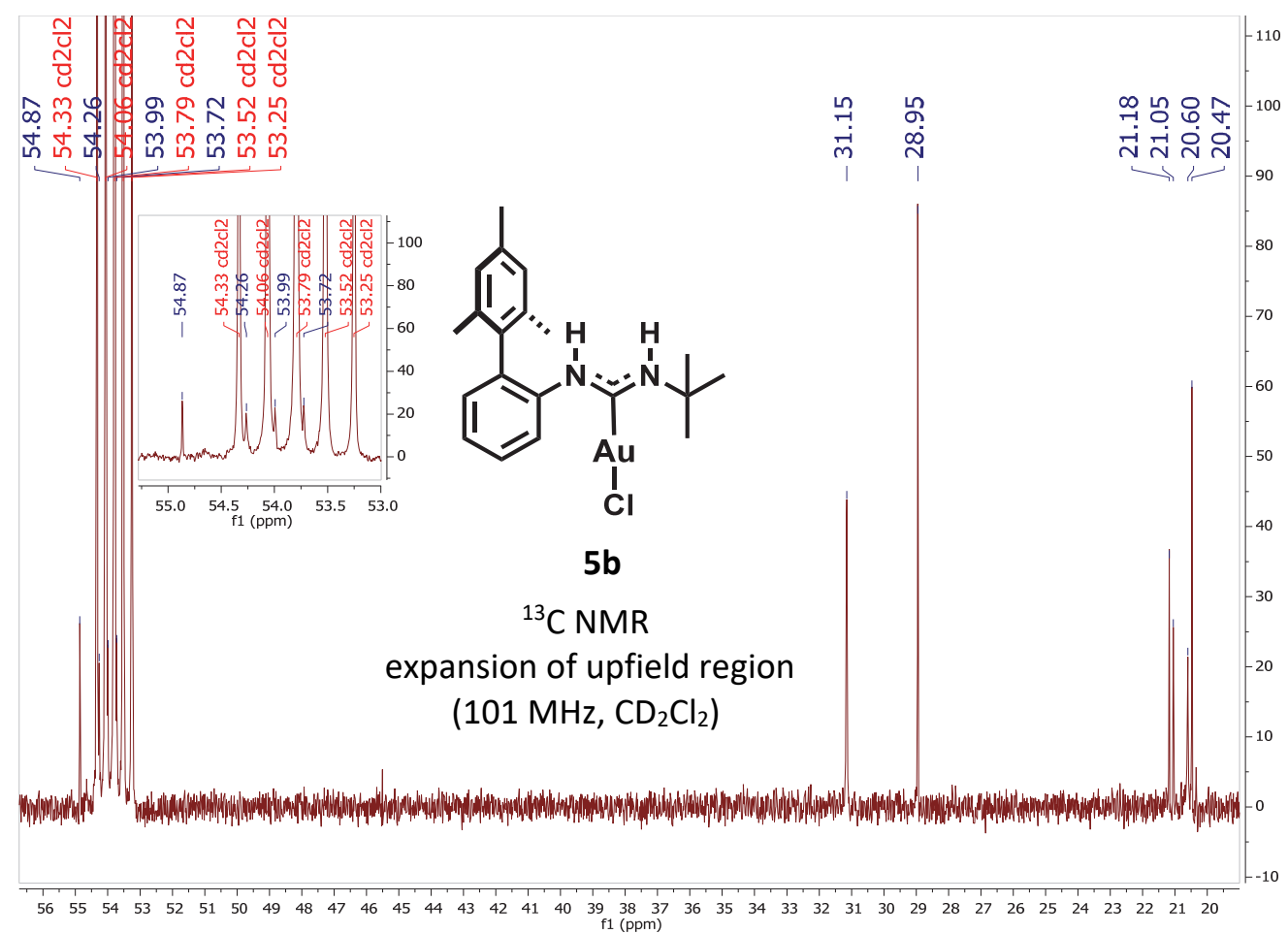

Figure S40. Expansion of upfield region of ${ }^{13} \mathrm{C}$ NMR spectrum of $\mathrm{Au}(\mathrm{ADC}) \mathrm{Cl}$ complex $\mathbf{5 b}$ in $\mathrm{CD}_{2} \mathrm{Cl}_{2}$.

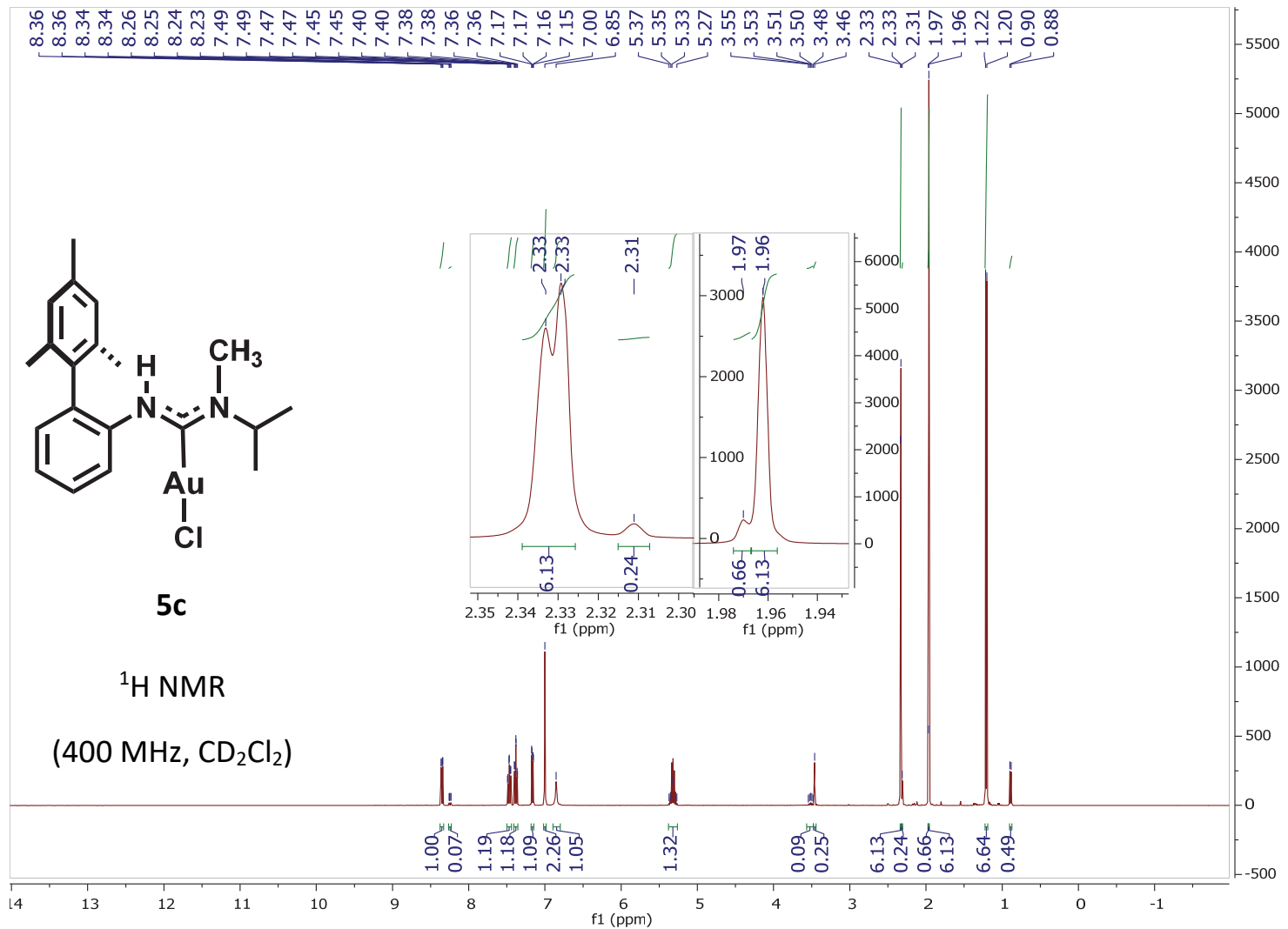

Figure S41. ${ }^{1} \mathrm{H}$ NMR spectrum of monomesityl $\mathrm{Au}(\mathrm{ADC}) \mathrm{Cl}$ complex $\mathbf{5 c}$ in $\mathrm{CD}_{2} \mathrm{Cl}_{2}$ at $400 \mathrm{MHz}$. 


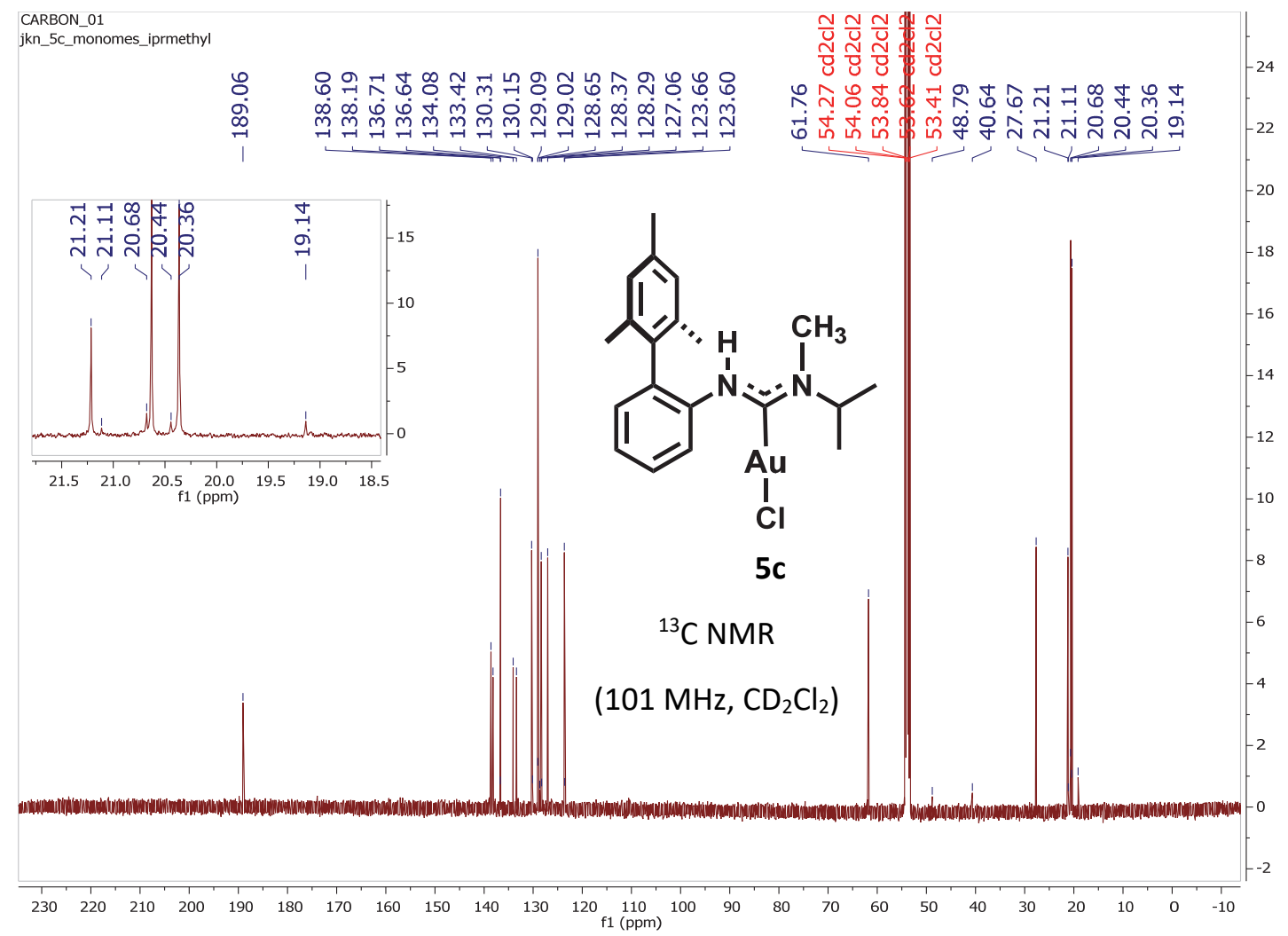

Figure S42. ${ }^{13} \mathrm{C}$ NMR spectrum of monomesityl $\mathrm{Au}(\mathrm{ADC}) \mathrm{Cl}$ complex $\mathbf{5 c}$ in $\mathrm{CD}_{2} \mathrm{Cl}_{2}$ at $101 \mathrm{MHz}$.

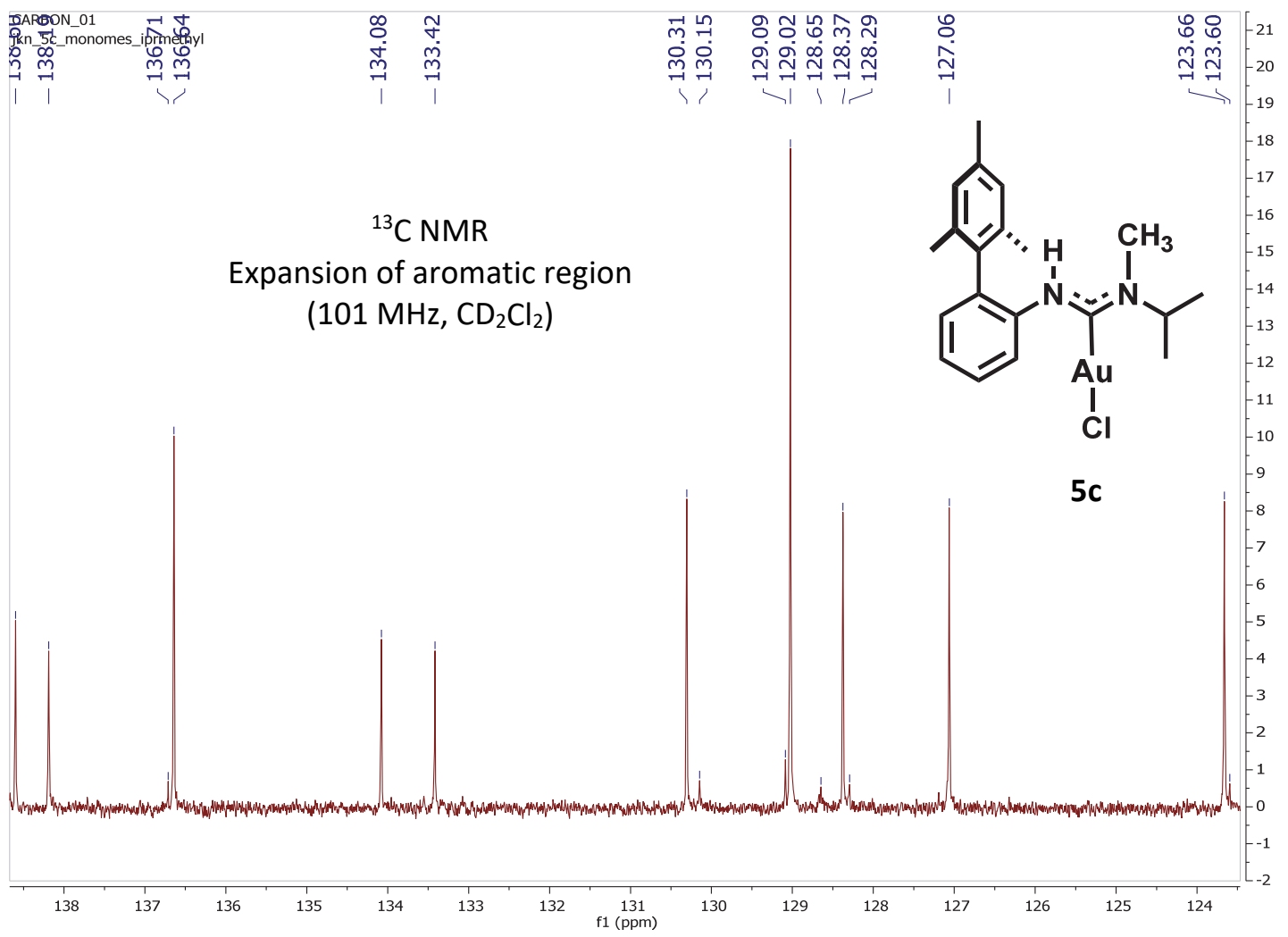

Figure S43. Expansion of aromatic region of ${ }^{13} \mathrm{C}$ NMR spectrum of $\mathrm{Au}(\mathrm{ADC}) \mathrm{Cl}$ complex $\mathbf{5 c}$ in $\mathrm{CD}_{2} \mathrm{Cl}_{2}$. 


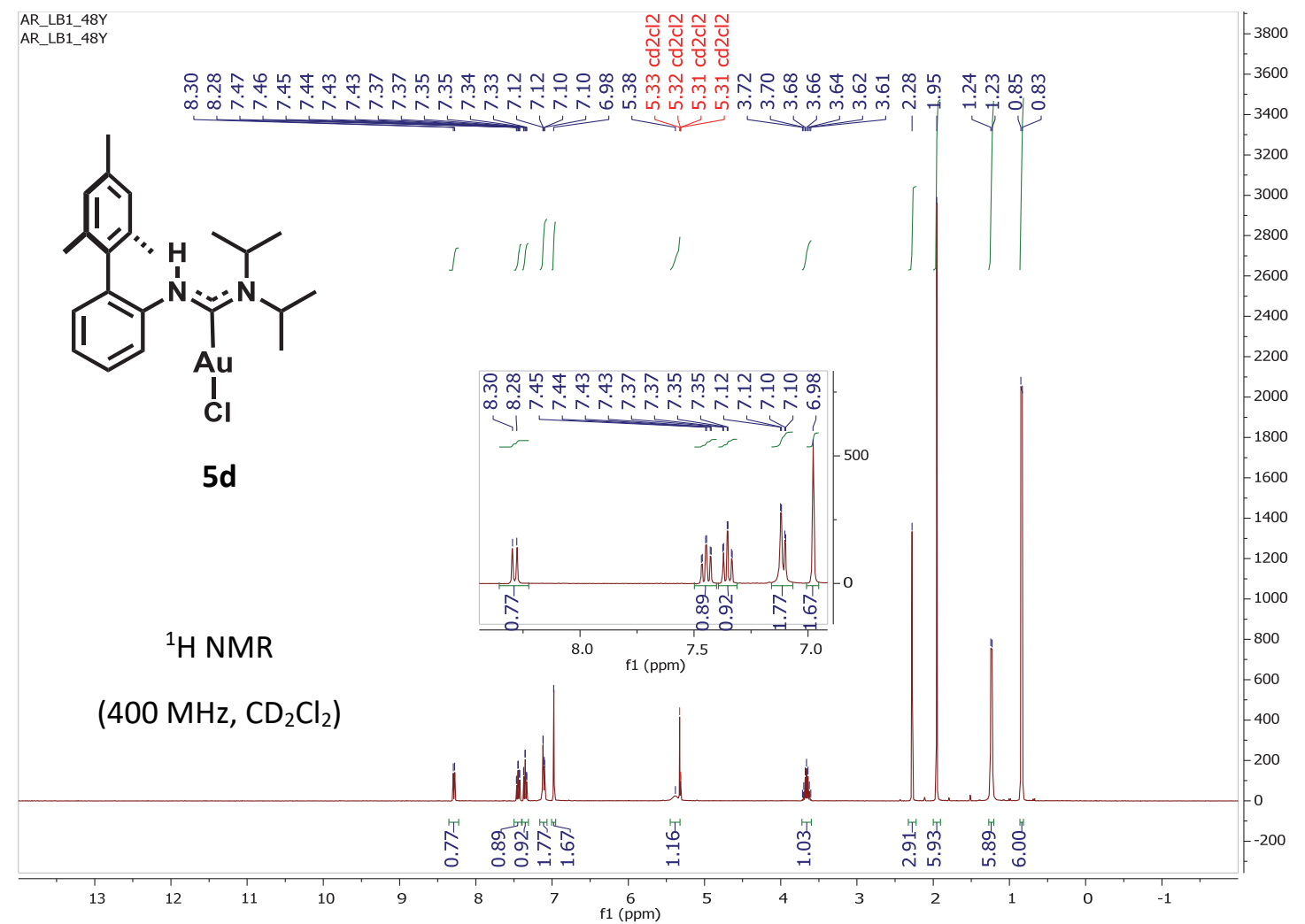

Figure S44. ${ }^{1} \mathrm{H}$ NMR spectrum of monomesityl $\mathrm{Au}(\mathrm{ADC}) \mathrm{Cl}$ complex $\mathbf{5 d}$ in $\mathrm{CD}_{2} \mathrm{Cl}_{2}$ at $400 \mathrm{MHz}$.

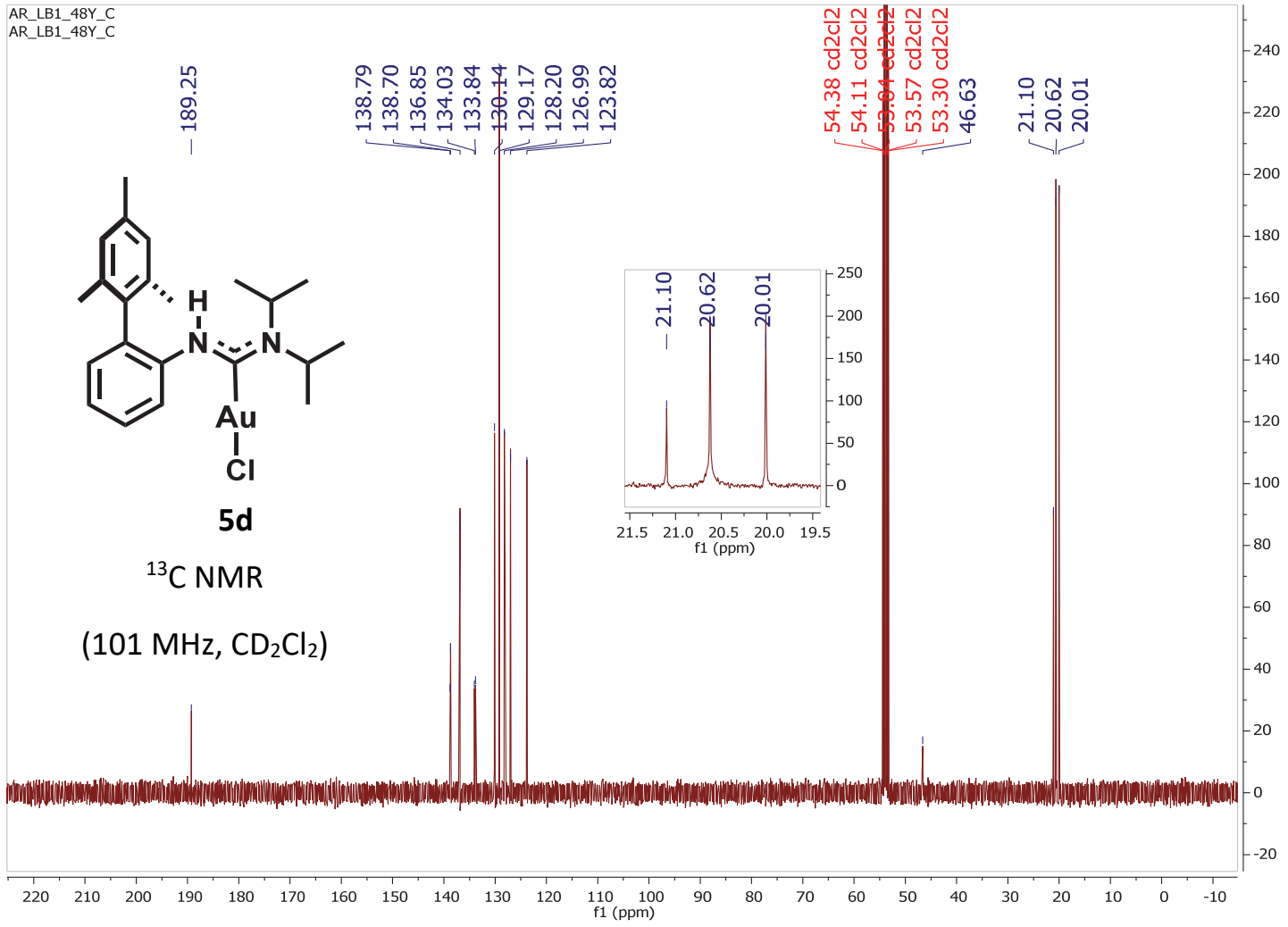

Figure S45. ${ }^{13} \mathrm{C}$ NMR spectrum of monomesityl $\mathrm{Au}(\mathrm{ADC}) \mathrm{Cl}$ complex $\mathbf{5 d}$ in $\mathrm{CD}_{2} \mathrm{Cl}_{2}$ at $101 \mathrm{MHz}$. 


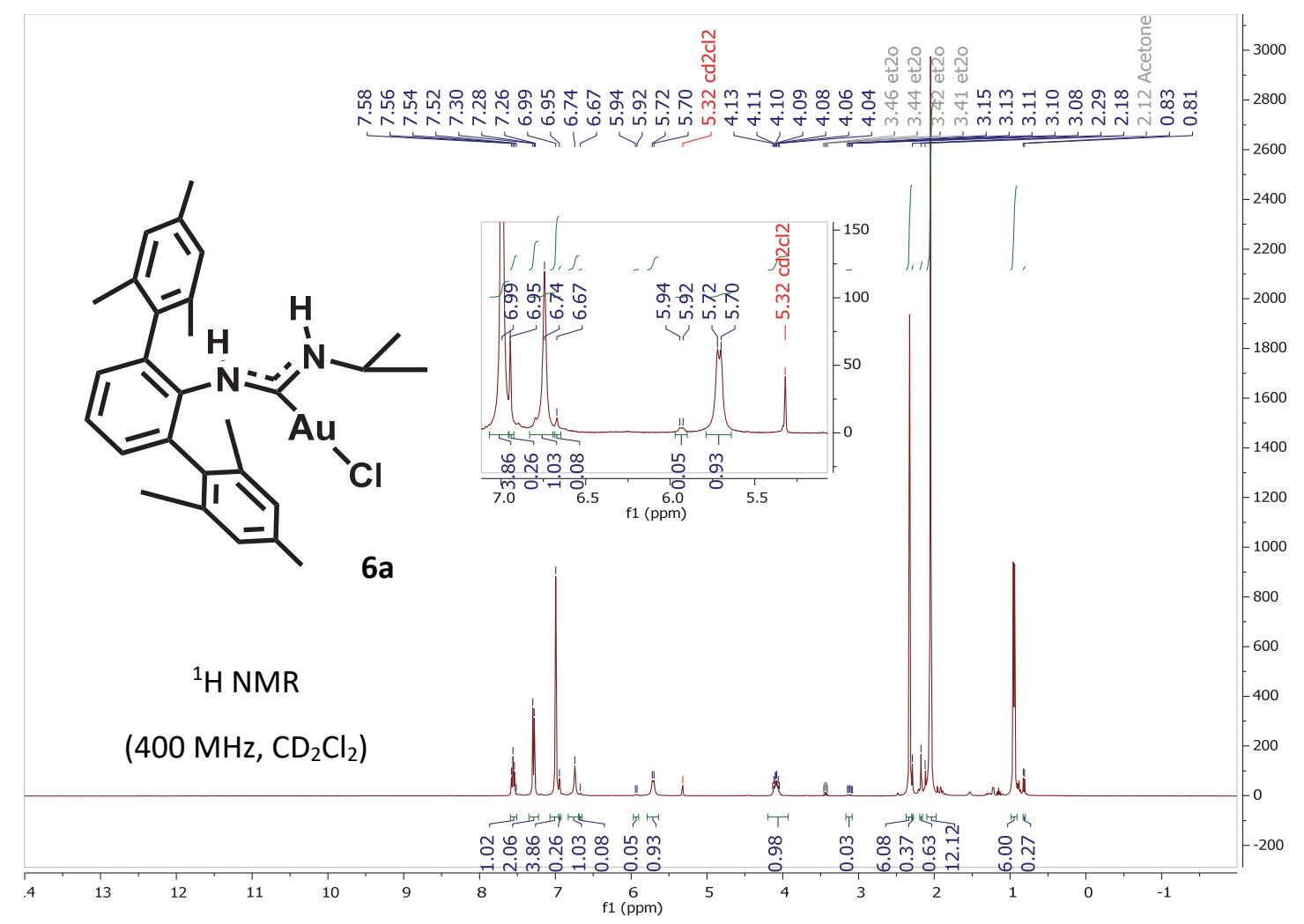

Figure S46. ${ }^{1} \mathrm{H}$ NMR spectrum of dimesityl $\mathrm{Au}(\mathrm{ADC}) \mathrm{Cl}$ complex $6 \mathbf{6}$ in $\mathrm{CD}_{2} \mathrm{Cl}_{2}$ at $400 \mathrm{MHz}$.

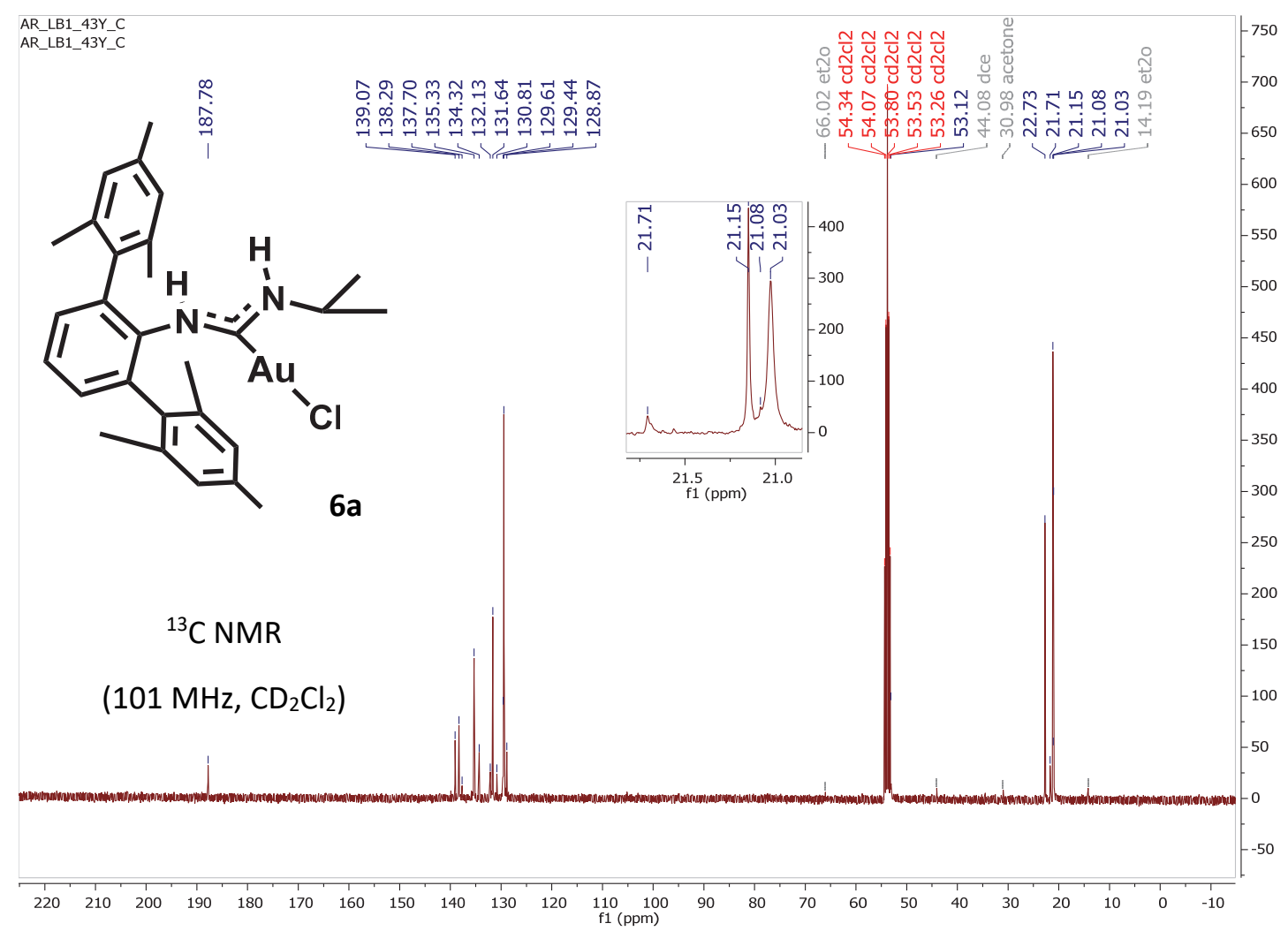

Figure S47. ${ }^{13} \mathrm{C}$ NMR spectrum of dimesityl $\mathrm{Au}(\mathrm{ADC}) \mathrm{Cl}$ complex $6 \mathbf{6}$ in $\mathrm{CD}_{2} \mathrm{Cl}_{2}$ at $101 \mathrm{MHz}$. 


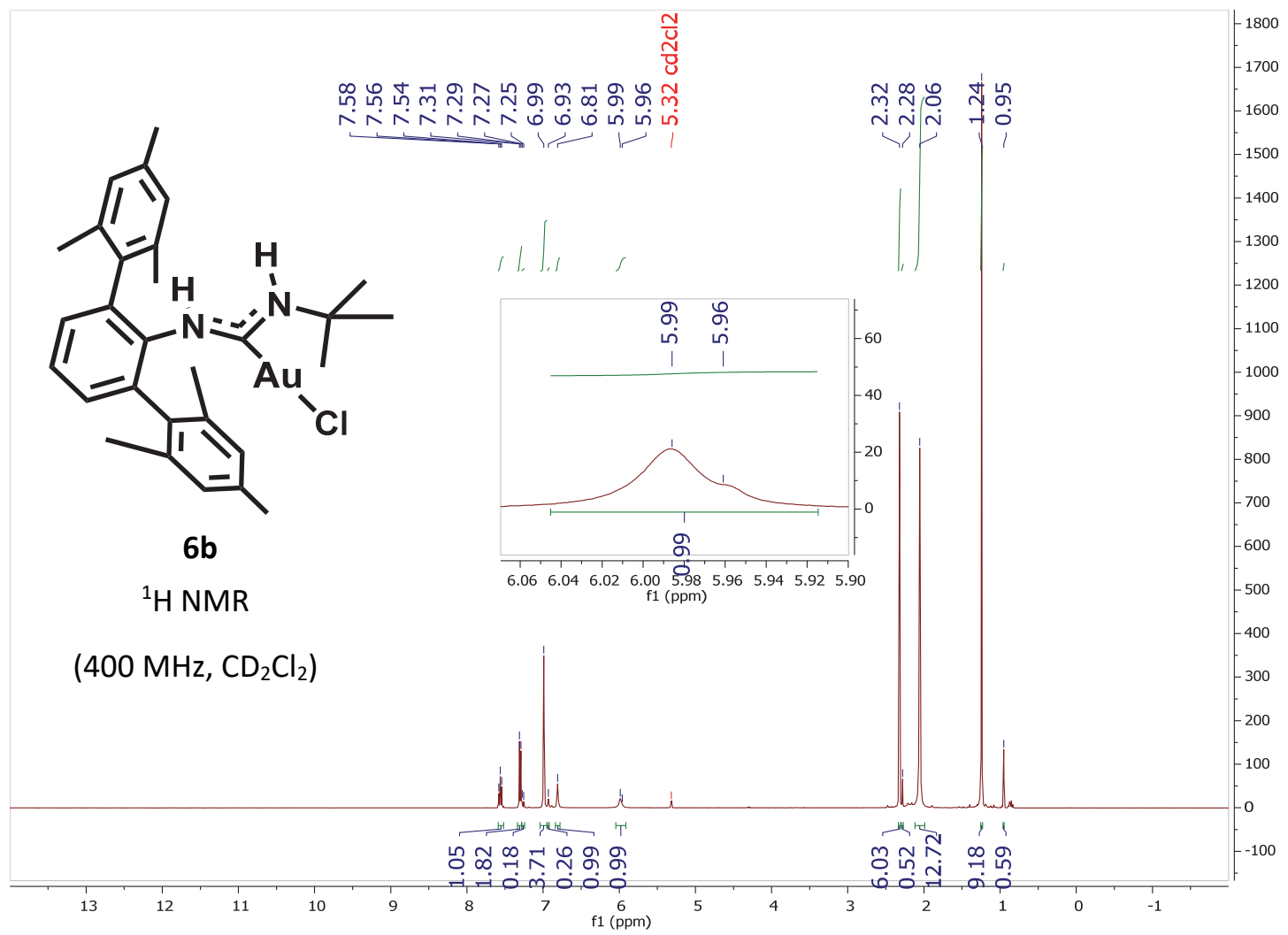

Figure S48. ${ }^{1} \mathrm{H}$ NMR spectrum of dimesityl $\mathrm{Au}(\mathrm{ADC}) \mathrm{Cl}$ complex $\mathbf{6} \mathbf{b}$ in $\mathrm{CD}_{2} \mathrm{Cl}_{2}$ at $400 \mathrm{MHz}$.

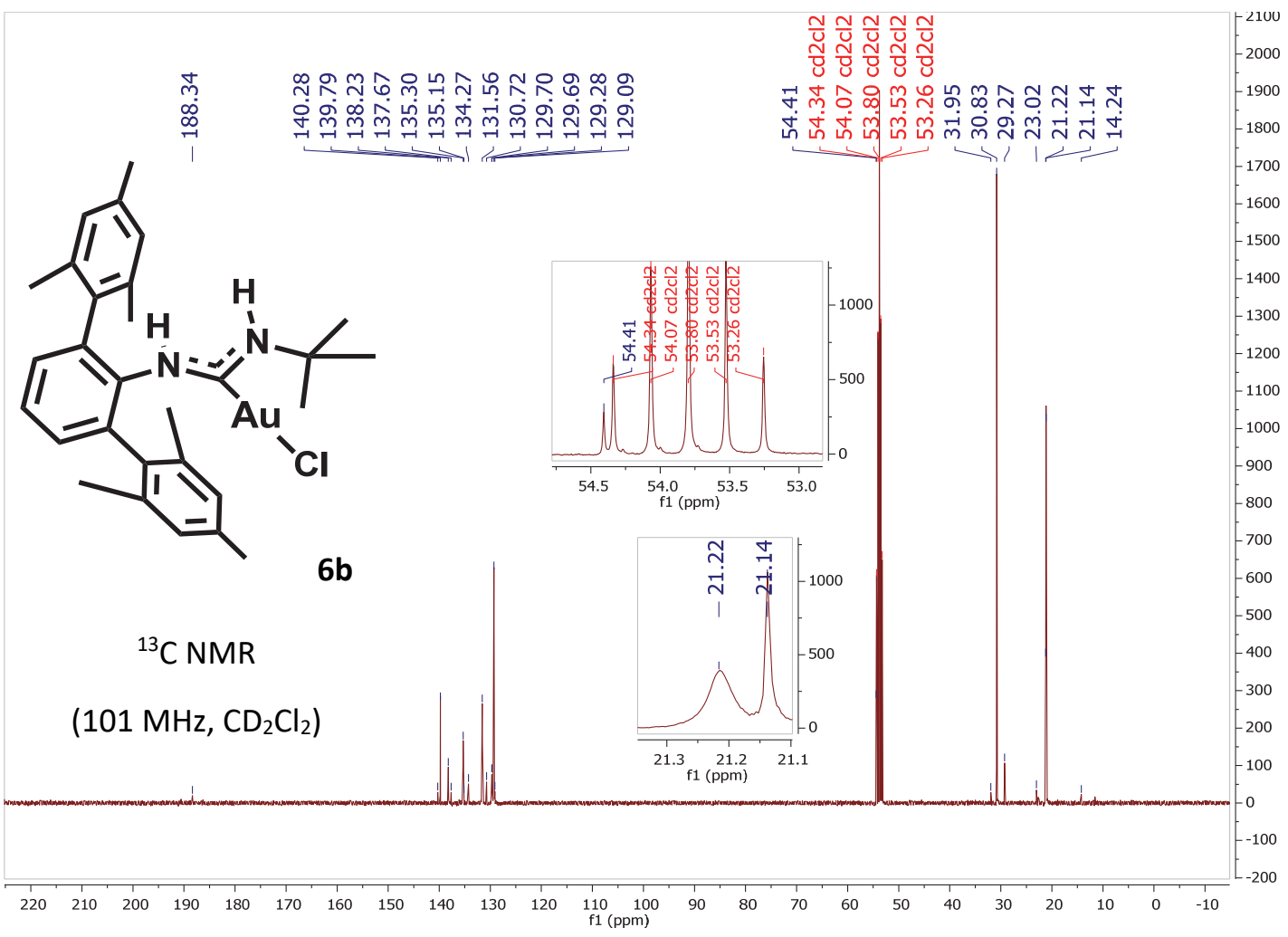

Figure S49. ${ }^{13} \mathrm{C}$ NMR spectrum of dimesityl $\mathrm{Au}(\mathrm{ADC}) \mathrm{Cl}$ complex $\mathbf{6 b}$ in $\mathrm{CD}_{2} \mathrm{Cl}_{2}$ at $101 \mathrm{MHz}$. 


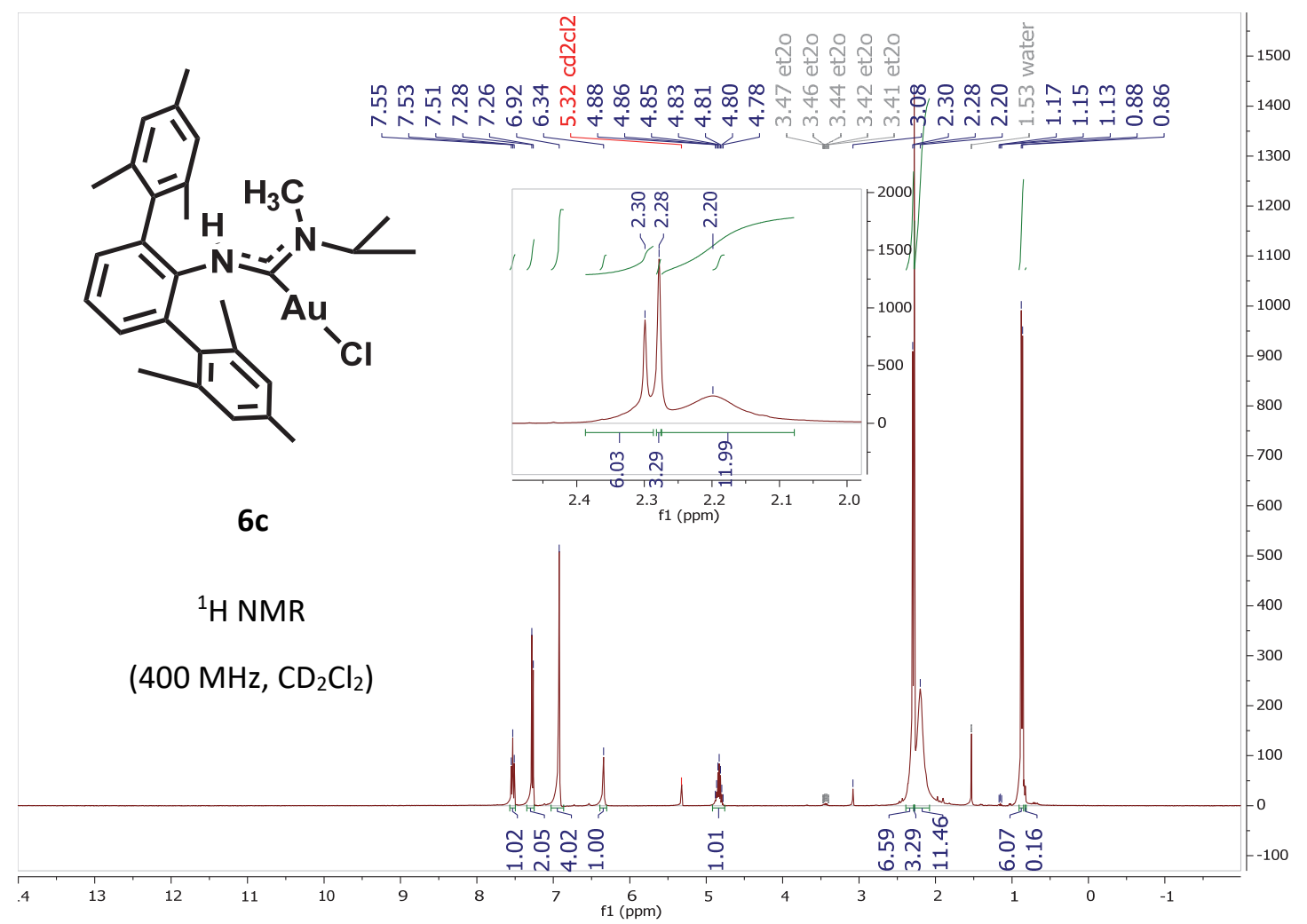

Figure S50. ${ }^{1} \mathrm{H}$ NMR spectrum of dimesityl $\mathrm{Au}(\mathrm{ADC}) \mathrm{Cl}$ complex $\mathbf{6 c}$ in $\mathrm{CD}_{2} \mathrm{Cl}_{2}$ at $400 \mathrm{MHz}$.

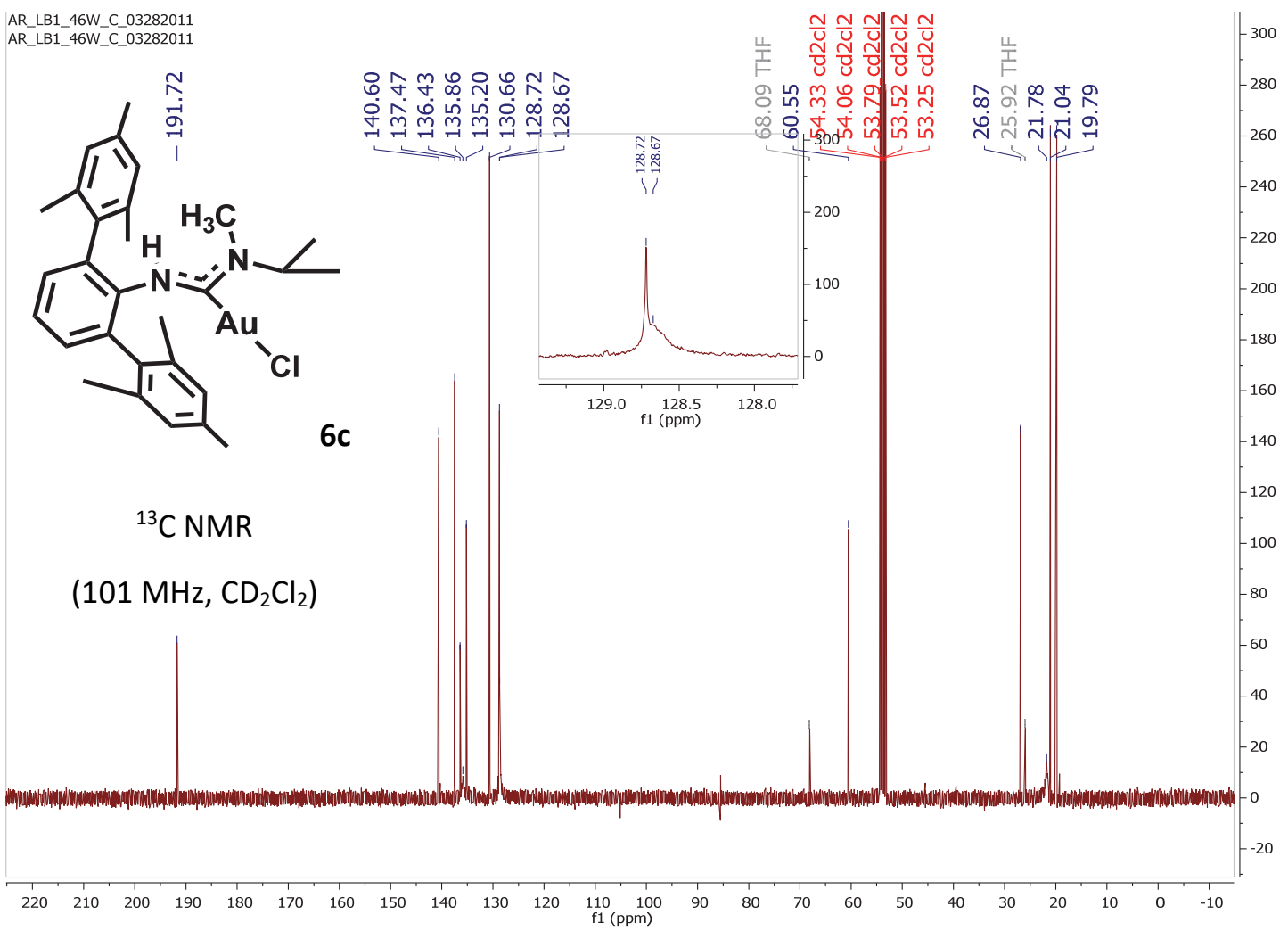

Figure S51. ${ }^{13} \mathrm{C}$ NMR spectrum of dimesityl $\mathrm{Au}(\mathrm{ADC}) \mathrm{Cl}$ complex $\mathbf{6 c}$ in $\mathrm{CD}_{2} \mathrm{Cl}_{2}$ at $101 \mathrm{MHz}$. 


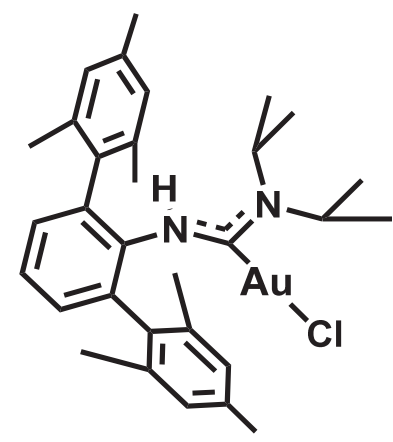

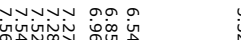
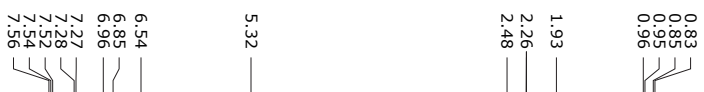

6d

${ }^{1} \mathrm{H} N M R$

(400 MHz, $\mathrm{CD}_{2} \mathrm{Cl}_{2}$ )

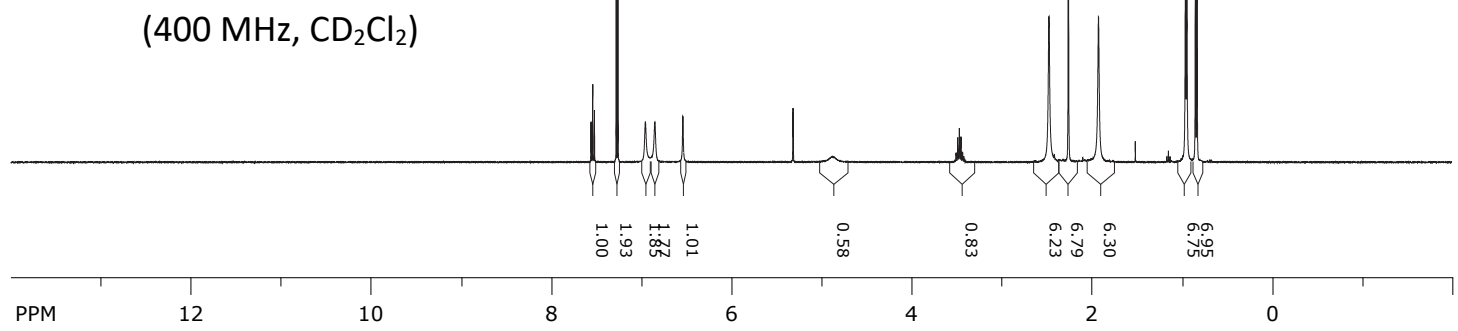

Figure S52. ${ }^{1} \mathrm{H}$ NMR spectrum of dimesityl $\mathrm{Au}(\mathrm{ADC}) \mathrm{Cl}$ complex $\mathbf{6 d}$ in $\mathrm{CD}_{2} \mathrm{Cl}_{2}$ at $400 \mathrm{MHz}$.

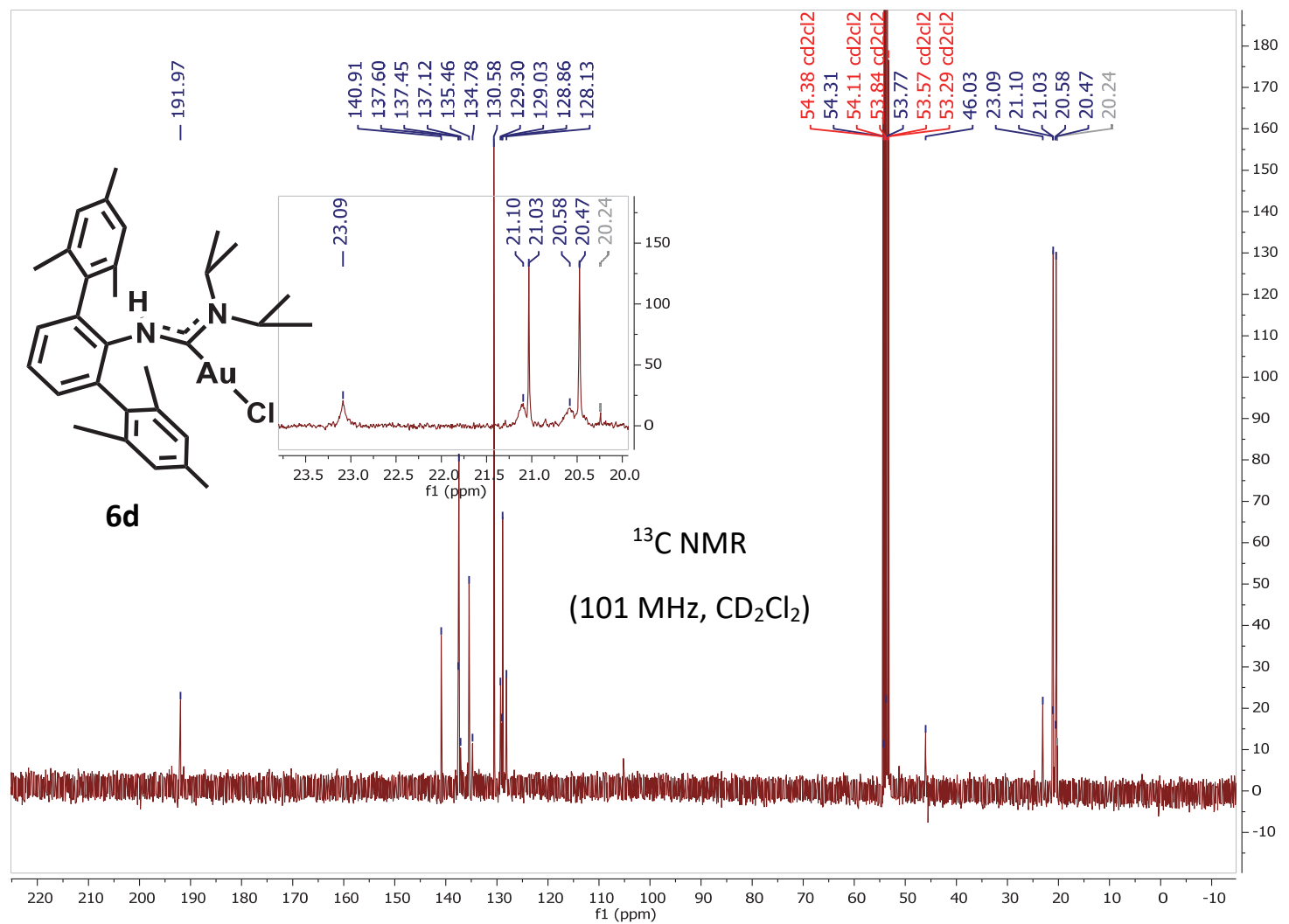

Figure S53. ${ }^{13} \mathrm{C}$ NMR spectrum of dimesityl $\mathrm{Au}(\mathrm{ADC}) \mathrm{Cl}$ complex $\mathbf{6 d}$ in $\mathrm{CD}_{2} \mathrm{Cl}_{2}$ at $101 \mathrm{MHz}$. 


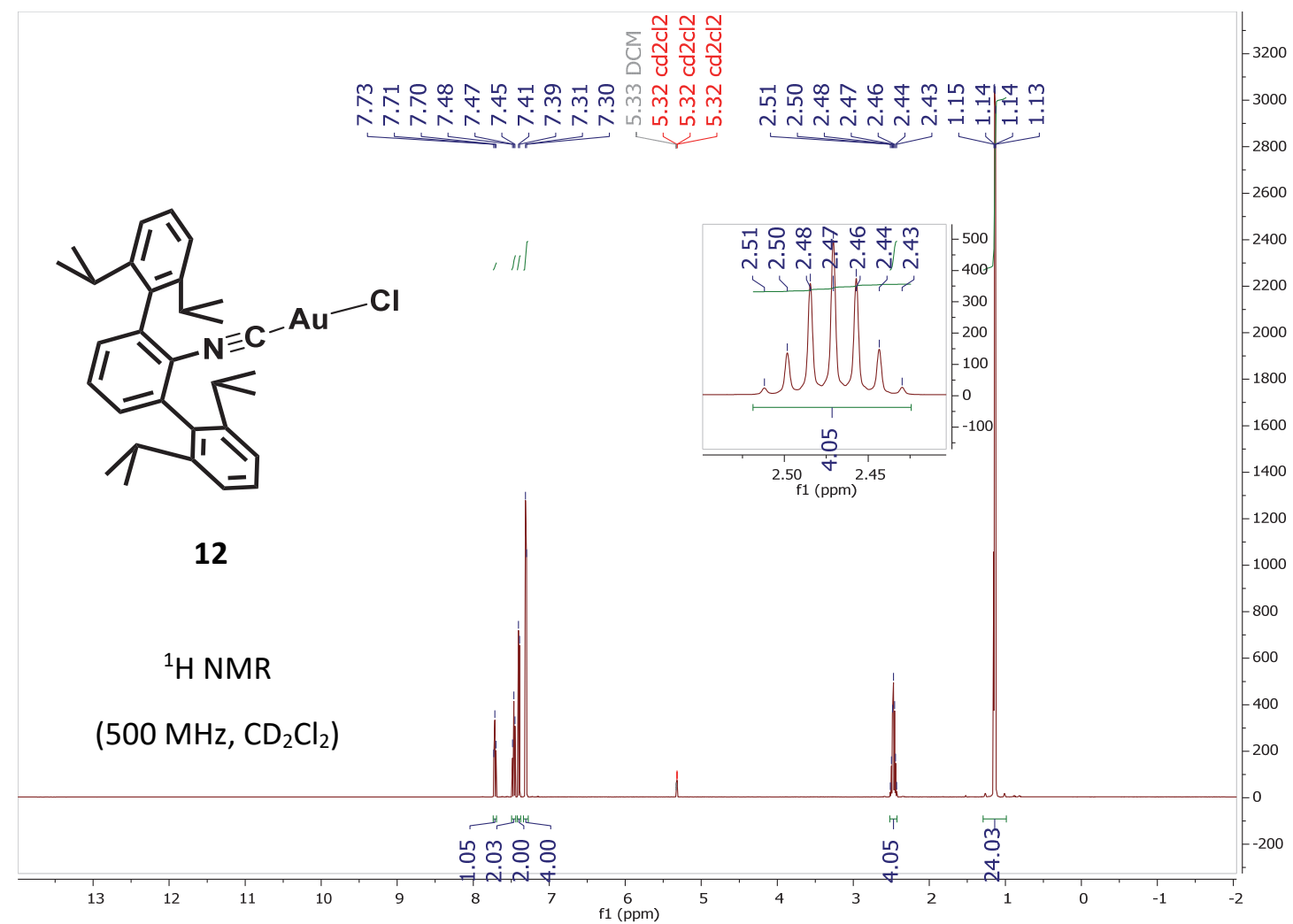

Figure S54. ${ }^{1} \mathrm{H}$ NMR spectrum of Dipp 2 isocyanide gold complex 12 in $\mathrm{CD}_{2} \mathrm{Cl}_{2}$ at $500 \mathrm{MHz}$.

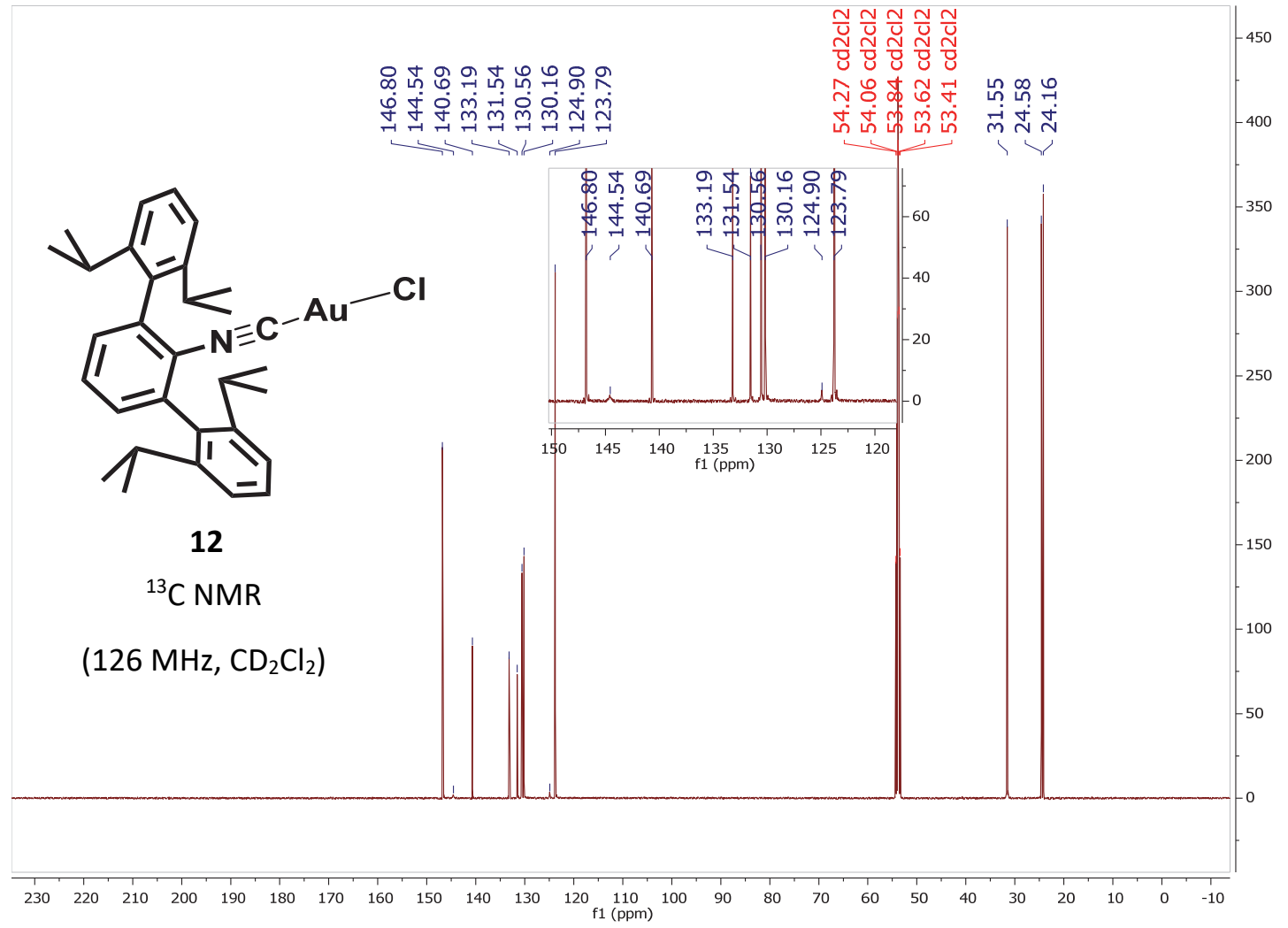

Figure S55. ${ }^{13} \mathrm{C}$ NMR spectrum of Dipp 2 isocyanide gold complex 12 in $\mathrm{CD}_{2} \mathrm{Cl}_{2}$ at $126 \mathrm{MHz}$. 


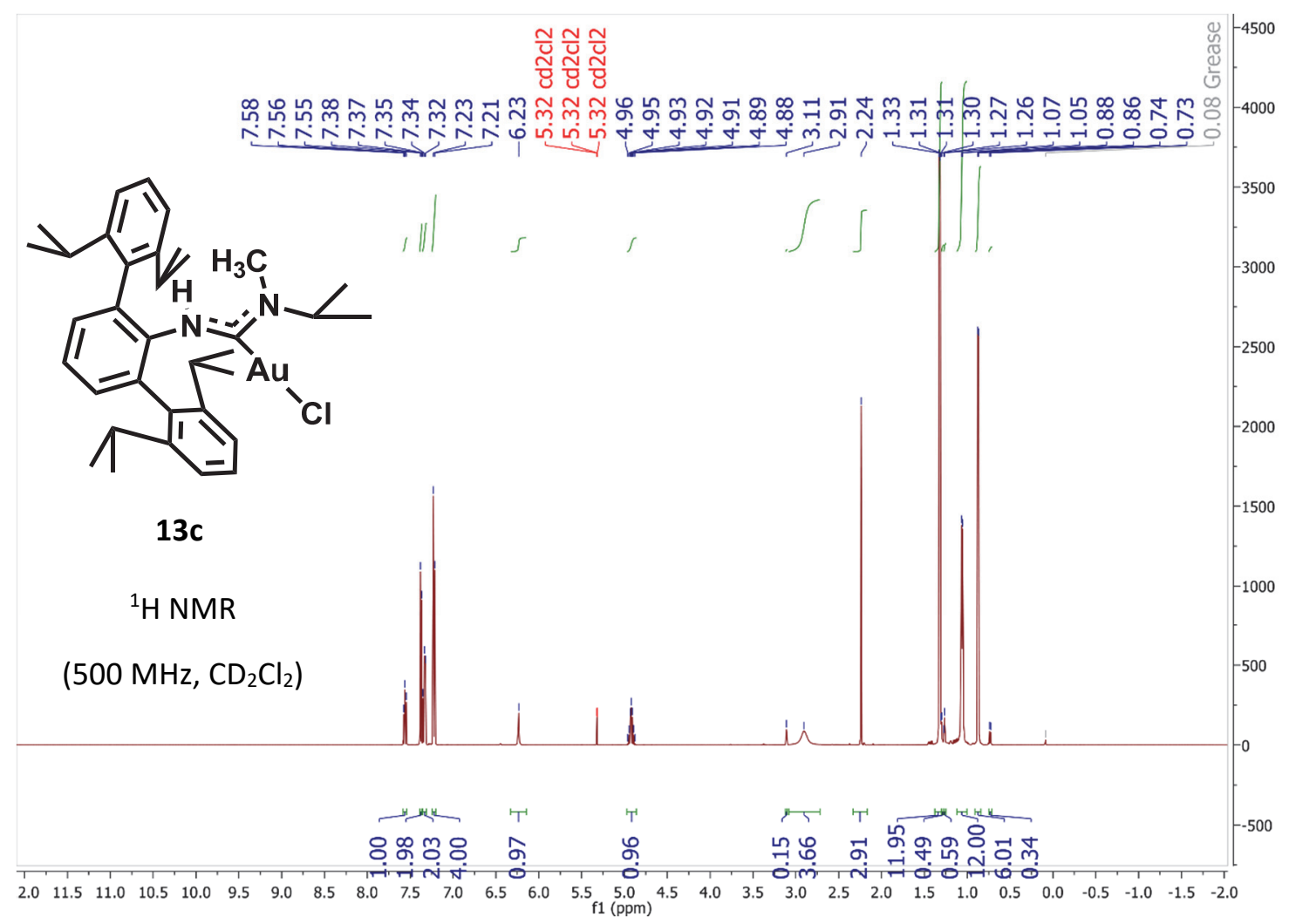

Figure S56. ${ }^{1} \mathrm{H}$ NMR spectrum of Dipp $2 \mathrm{Au}(\mathrm{ADC}) \mathrm{Cl}$ complex $13 \mathrm{c}$ in $\mathrm{CD}_{2} \mathrm{Cl}_{2}$ at $500 \mathrm{MHz}$.

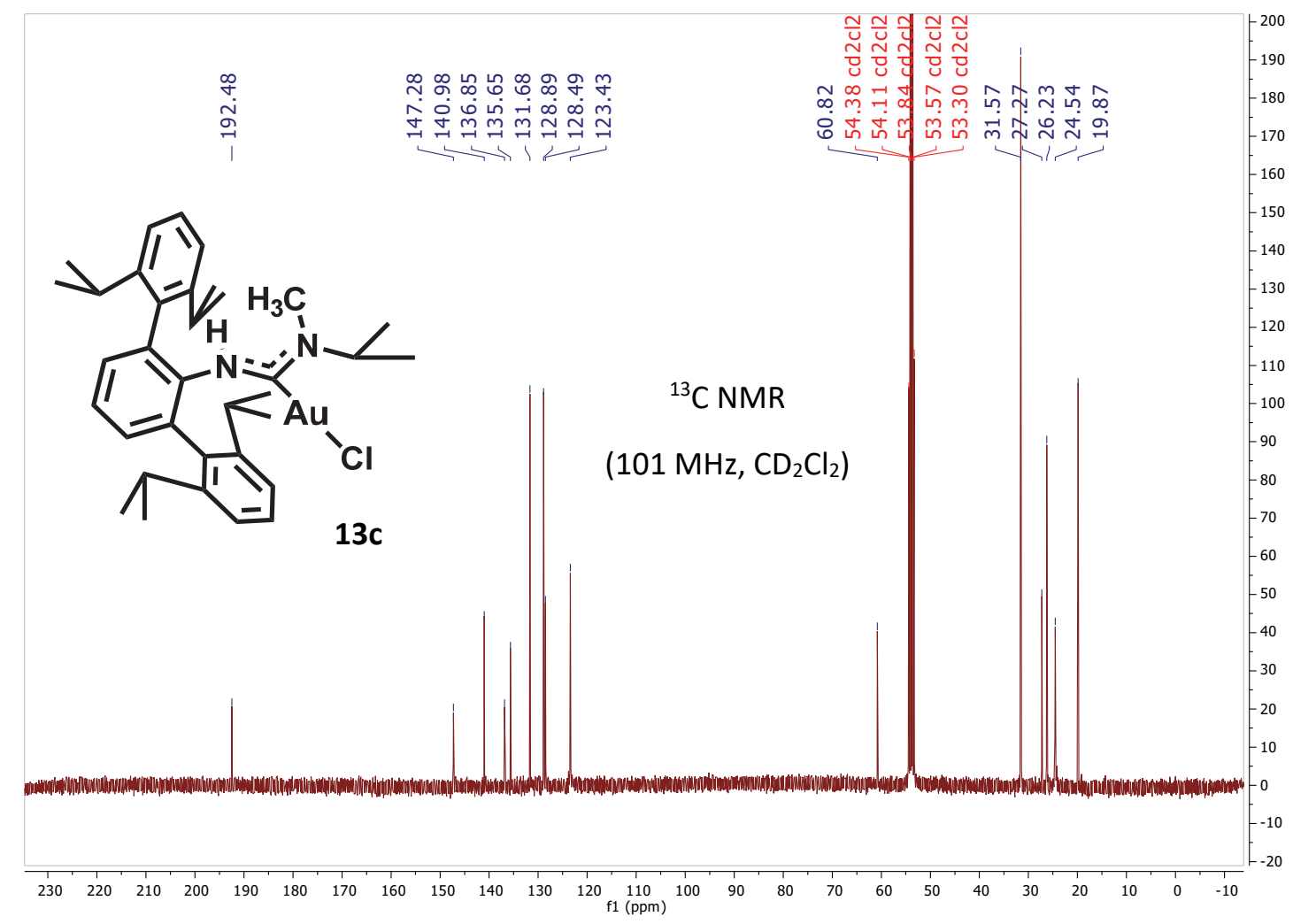

Figure S57. ${ }^{13} \mathrm{C}$ NMR spectrum of Dipp $2 \mathrm{Au}(\mathrm{ADC}) \mathrm{Cl}$ complex $13 \mathrm{c}$ in $\mathrm{CD}_{2} \mathrm{Cl}_{2}$ at $101 \mathrm{MHz}$. 